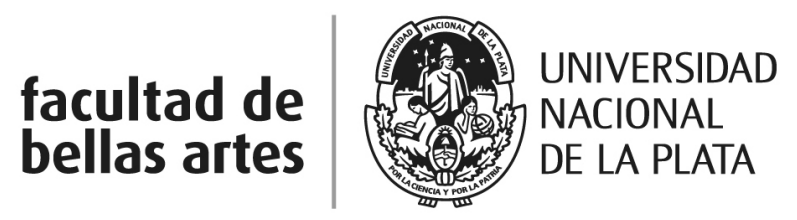

\title{
Gestos en la dirección: Comunicación de significados musicales corporeizados
}

\author{
Javier A. Damesón
}

Directora: Isabel C. Martinez

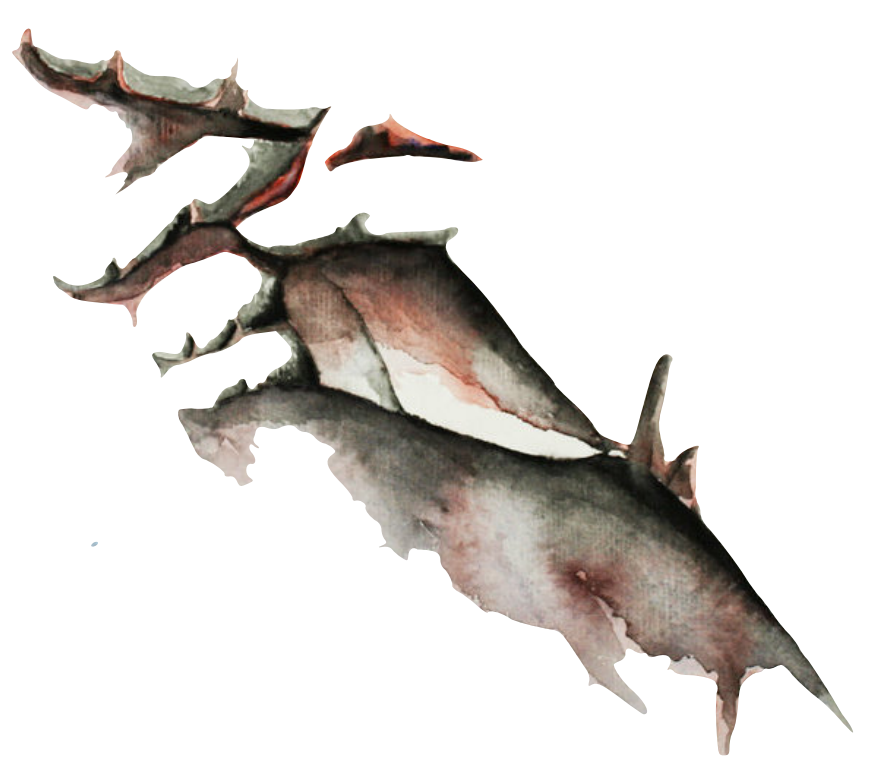

Tesis de Maestría en Psicología de la Música

Facultad de Bellas Artes, Universidad Nacional de la Plata 


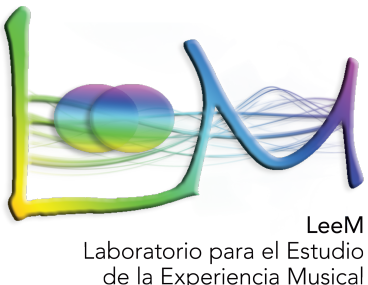

Defensa:

Secretaria de Posgrado:

Dir. María Elena Larregle

Universidad Nacional de La Plata

Facultad de Bellas Artes

Laboratorio para el Estudio de la Experiencia Musical (LeeM)

Diagonal $78 N^{\circ} 680$ | 1900, La Plata, Argentina

Tel.: 54 - 221 - $423-6598$ 
Imagen de portada: Mano abstracta por Kordic 


\section{Reconocimientos}

La realización de esta tesis de posgrado fue posible gracias al auto financiamiento iniciado en el año 2008 y sostenido hasta la actualidad.

A mi directora de tesis la Dra. Isabel Cecilia Martínez, mi sincero y cálido agradecimiento por su dedicación y entusiasmo para con mi formación como investigador. Esto data desde su primer convocatoria en 1998 como ayudante de cátedra para Metodologías de la investigación, su posterior incentivo para presentar un proyecto a la becas de formación, que no fue exitoso pero sin dudas quedó latente. Continuó con el reencuentro en los seminarios de la Maestría en Psicología de la Música, donde renovó su apoyo para que recorra este camino en la investigación con un especial incentivo en relación al dominio de las tecnologías de mediación cuyo uso hoy vemos materializados en esta tesis.

Al grupo académico y colegas del Laboratorio para el Estudio de la Experiencia Musical (LEEM) de la Facultad de Bellas Artes, Universidad Nacional de La Plata y los equipos de investigación B298 La Corporeidad de la Mente Musical. Hacia una definición de su estatura en el estudio de la Ontogénesis, la Percepción y la Performance de la Música y PICT 2013-0368 Musicalidad Comunicativa en las Artes Temporales y la Infancia Temprana ambos dirigidos por la Dra. Isabel Cecilia Martínez, con quienes compartimos trabajos, proyectos, congresos, seminarios, y son parte de esta reflexión y discusión permanentemente para un conocimiento que nunca se detiene.

A Pablo Cánaves por su guía en mi formación en la dirección coral y por generosa predisposición para participar de los estudios

A mi compañera de vida, Romina Herrera, que el curso de esta maestría compartida nos regaló este amor por mucho tiempo anhelado y que hoy resuena cada día junto a la pequeña Luana. 



\section{Contenido}

\section{Introducción}

I.I Perspectiva de la dirección musical ..............................................................................

I.I I Temporalidad y expresión ...........................................................................................................

I.I.2 Mano temporal y mano expresiva .........................................................................................4

I.I.3 Metalenguajes de la dirección .............................................................................................5

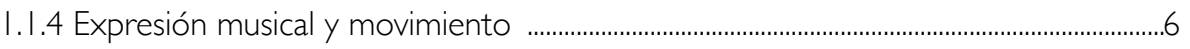

1.2 Objetivos ..........................................................................................................................

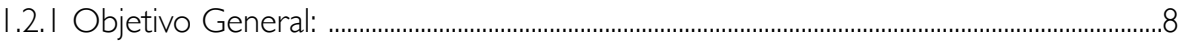

1.2.2 Objetivos Específicos: ..............................................................................................................

1.3 Hipótesis General: .......................................................................................................

\section{Parte I - Marco teórico}

\section{2 . Gesto y significado: una mirada ontológica}

2.I Tensión ontológica: Gesto como experiencia o como mediación semiótica. . 10

2.I.I Gesto y Habla

2.2 Mente, cuerpo y la cognición corporeizada ............................................................. 4

2.2. I Semiótica de la performatividad ...................................................................................... 6

2.3 Gesto y significado musical corporeizado........................................................... 17

2.3. I Gesto, música y los objetivos de las comunidades epistémicas ...................................... 17

2.4 Gesto y la perspectiva de segunda persona .......................................................2 I

2.5 Hacia una integración de las ontologías de gesto musical ..................................22

3. Expresión y Comunicación musical desde la perspectiva de segunda persona $y$ el enactivismo

3.I Expresión Musical. 


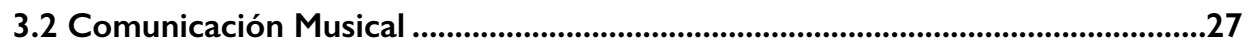

3.2.I Modelo tradicional unidireccional .......................................................................................27

3.2.2 Comunicación desde la ontología de la música como performance ...........................29

3.2.3 Comunicación como Alineamiento Expresivo ....................................................................2

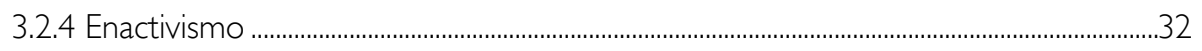

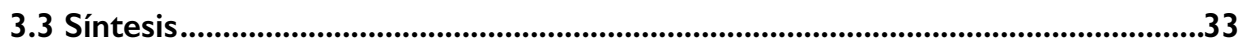

\section{Problemáticas Metodológicas. Categorías y unidades de análisis para patrones de movimiento y de música}

4.I Desafío temporal: sistema discreto, sistema continuo.....................................34

4.2 Espacio-tiempo: Categorías de análisis ............................................................37

4.4 Matriz de referencias conceptuales .....................................................................38

4.4.I Movimiento .............................................................................................................................. 40

4.4.I.I Movimiento bajo-nivel............................................................................................................... 40

4.4.I.2 Movimiento de medio-nivel................................................................................................. 42

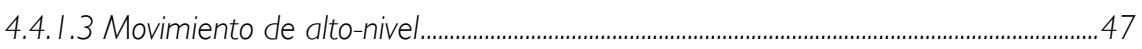

4.4.2 Música. Desde las categorías hacia las unidades de análisis ..........................................47

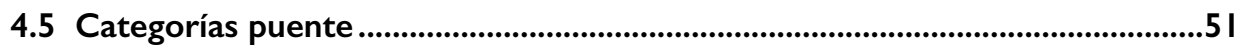

4.6 Matriz de referencias conceptuales movimiento-música .................................5 I

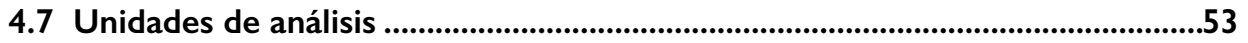

\section{Parte II- Estudios}

\section{Estudio I - Dirección en 3D: la dimensión oculta del significado}

5.I Introducción

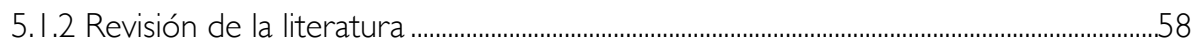

5.I.2.1 Abordaje Pedagógicos ......................................................................................................58

5.1.2.2 Abordaje Científico..........................................................................................................59

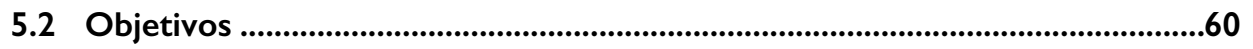

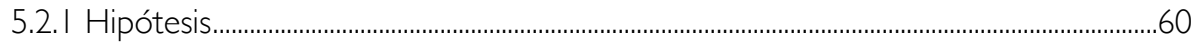

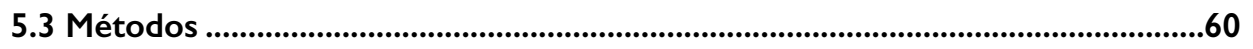

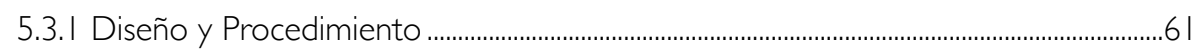




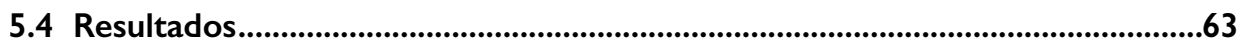

5.4.I Extensión de los movimientos en el espacio tridimensional..........................................63

5.4.2 Comparativa por segmentos ............................................................................................63

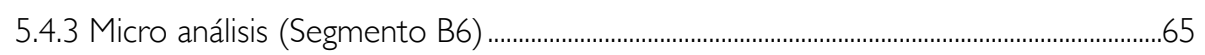

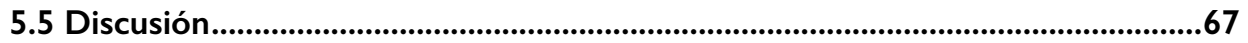

\section{Estudio 2 - Parte I \\ Energía musical expresada: correlación de categorías de música y de movimiento en el contexto de una performance coral.}

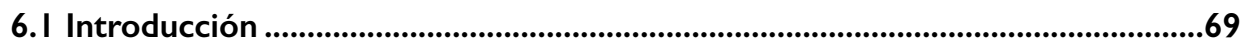

6.2 Hipótesis ...............................................................................................................72

6.3 Objetivos............................................................................................................

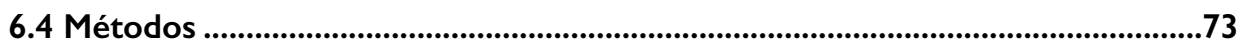

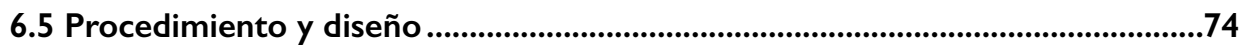

6.5. I Definición de la unidad de análisis ......................................................................................74

6.5.2 Laban: desde los descriptores de movimiento de bajo-nivel ........................................75

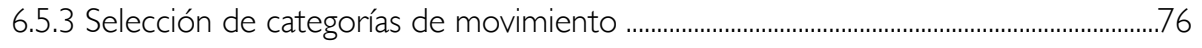

6.5.3.1 Expansividad................................................................................................................................ 77

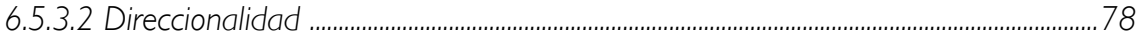

6.5.3.3 Impulsividad ........................................................................................................................... 79

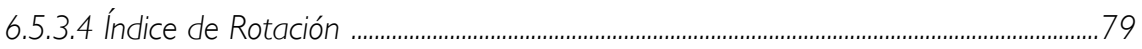

6.5.4 Selección de categorías en Música ....................................................................................80

6.5.4.1 Dinámica (Intensidad).......................................................................................................... 81

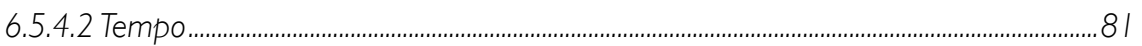

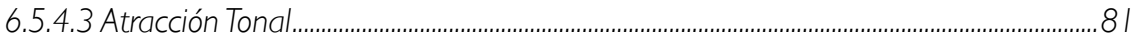

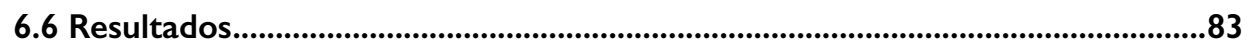

6.6.I Mapa de correlaciones............................................................................................................

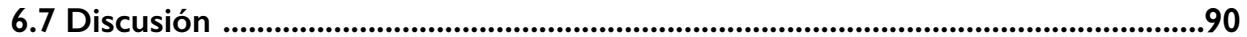

\section{Estudio 2 - Parte 2}

Interacción como comunicación de energía musical expresada

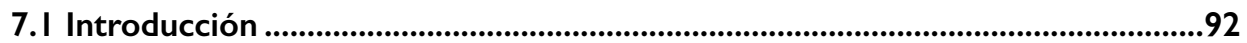

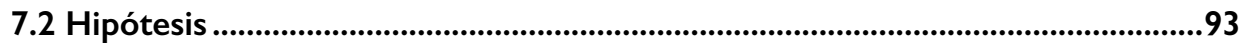




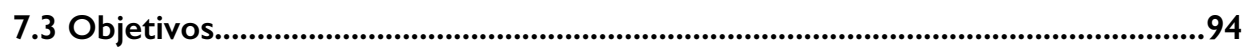

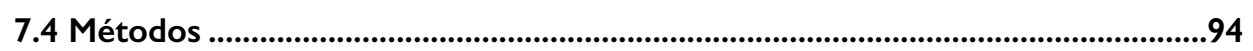

7.4.I Causalidad Granger y Densidad Causal ...................................................................................94

7.4. I. I Serie temporal............................................................................................................95

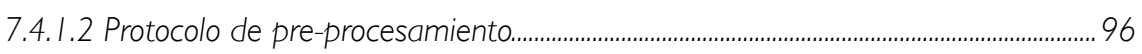

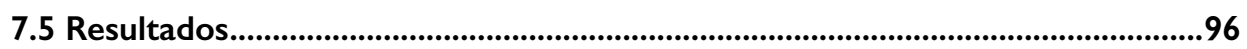

7.5. I Correlaciones Música / Interacción ............................................................................99

7.5.2 Correlaciones Movimiento / Interacción ............................................................................. 100

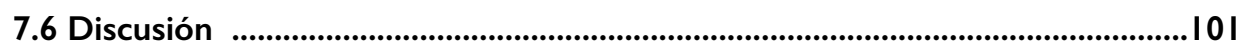

\section{Conclusiones}

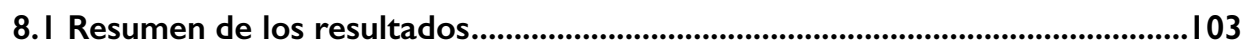

8. I.I Estudio I .............................................................................................................................. 03

8.1.2 Estudio 2 -Parte I .................................................................................................................. 104

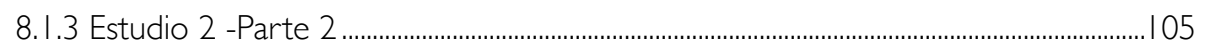

8.2 Recomendaciones para la continuación de los estudios....................................... 06

8.3 Respuesta a las preguntas germinales .............................................................. 106

8.4 Contribuciones y reflexión final .............................................................................109

\section{Referencias}




\section{Lista de Figuras}

Figura 3.1: Modelo de comunicación del alineamiento expresivo......

Figura 5. I: Desviación Estándar de cada dimensión. Comparativa entre tarea A y B. Marcadores de las manos y la cabeza.

Figura 5.2: Porcentaje de incremento entre tarea de la desviación estándar en cada dimensión espacial. Comparativa entre tarea A y B. Marcadores de las manos y la cabeza. .64

Figura 5.3: Desviación Estándar en el eje antero-posterior. Marcadores de las manos y la cabeza. Comparación entre tarea $\mathrm{A}$ y $\mathrm{B}$ x segmentos.

Figura 5.4: Envolvente dinámica de la señal de audio de la tarea A y B. Segmentos señalados A6 y B7. Desviación estándar de la mano izquierda en la tarea B. Vinculación entre segmentos B6 y A6...........66

Figura 5.5: Segmento B6. Caja arriba: Envolvente dinámica de la señal de audio en superposición con la partitura del segmento. Caja central: Desplazamiento de los marcadores mano izquierda, cabeza y mano derecha en el eje antero-posterior. Caja abajo: Distancia entre manos. .67

Figura 6.1:Ave Verum K 618, de W.A. Mozart. Compases 3 a 18. Línea de soprano.....................................73

Figura 6.2: Unidades de análisis (Rojo: Ventana de audio / Azul:Ventana de movimiento)........................75

Figura 6.3: Trayectoria de la mano vs. Indice de expansividad (Frase 4) ...........................................................77

Figura 6.4:Trayectoria de la mano vs. Indice de expansividad (Frase 7)............................................................78

Figura 6.5:Transcripción MIDI de la partitura (caja superior). Magnitud de atracción tonal de cada altura(caja central). Desviación estándar por unidad de análisis (caja inferior).

Figura 6.6: Distribución y varianza de los datos (categoría por unidad de análisis).......................................85

Figura 6.7: Mapa de correlaciones entre música y movimiento (Condición Monológica)... .88

Figura 6.8: Mapa de correlaciones entre música y movimiento (Condición Dialógica)...... .89

Figura 6.9: Frecuencia de correlaciones por mano por condiciones.......................................................................90

Figura 7.1: Esquema de cálculo de Causalidad Granger.......................................................................................95

Figura 7.2: Densidad Causal global por díadas. .97

Figura 7.3: Distribución de la cantidad global de interactividad (densidad causal)... 98

Figura 7.4: Densidad Causal - Distribución de la interactividad por díadas. 99

Figura 7.5: Mapa de Correlación entre categorías de Música y Densidad Causal por díada. 100

Figura 7.6: Mapa de Correlación entre categorías de Movimiento y Densidad Causal por díada...... 101 


\section{Lista de Tablas}

Tabla 2.l: Características de la semiosis de los gestos y la semiosis del lenguaje... 20

Tabla 4. I: Comparación de marcos de referencia conceptual.. 39

Tabla 4.2: Perspectiva de Análisis del Movimiento: Coréutica vs. Eukinética. 43

Tabla 4.3: Continuum de cualidades de los Factores Eukinéticos. 45

Tabla 4.4: Matriz de referencias conceptuales. Lesaffre (2006) .48

Tabla 4.5: Matriz de referencias conceptuales movimiento-música. .52

Tabla 4.6: Resumen categorías de análisis y unidades de análisis utilizados en estudios de performance musical expresiva. 55

Tabla 4.7: Resumen categorías de análisis y unidades de análisis utilizados en estudios de interacción en la performance musical. 56

Tabla 6.1: Congruencias entre modulación del gesto, metáforas y esquema imagen (Garnett,2009)..70

Tabla 6.2: Congruencias entre factores de movimiento Laban y elementos de la expresión musical (Gambetta, 2009).

Tabla 6.3: Resumen de las categorías de análisis implementadas en el estudio 2 .84 



\section{Introducción}

\section{I Perspectiva de la dirección musical}

En este primer capítulo, se describirá el origen de las preguntas germinales en el contexto de la práctica del oficio de dirección. ¿Cómo se dirige expresivamente? ¿Cuáles son las vinculaciones entre el gesto y la expresión? ¿Y entre movimiento y música? ¿Hay comunicación de significados en el movimiento? ¿Y en la música? ¿Que tienen en común?.

\section{I.I.I Temporalidad y expresión}

"El oficio del director compromete los aspectos técnicos y rudimentarios de la configuración gestual. El arte de dirigir le otorga expresión artística a los gestos. Es dificil analizar el oficio y el arte de dirigir por separado. Un director utiliza un vocabulario simple y preestablecido de gestos para la marcación del tiempo, acoplado a este vocabulario básico existe uno más especifico, refinado e idiosincrático, que representa un plano más alto de la expresión musical." (Watson, 2012. p. 24).

Las descripciones de Watson exponen una problemática que separa epistemológicamente el dominio de la dirección de la temporalidad, del dominio de la dirección de la expresión musical; y queda expuesta una 
ontología de rasgos proposicionales, que concibe a los gestos del director como vocabularios.

Se puede seguir esta tensión desde los primeros escritos sobre dirección de mediados del siglo XIX. Wagner (1897) sugiere que el fraseo y la expresión se infieren de una correcta marcación del tempo:

"La tarea del director está totalmente comprometida en la habilidad permanente para indicar el Tempo correcto. Su elección de tempi evidenciará si entiende la pieza o no. Con buenos ejecutantes conjuntamente a un tempo correcto, se inducirá al fraseo y la expresión correcta." (Wagner 1897) p. 20

Por otra parte, Berlioz (1856) considera que un director no puede ser un simple marcador de tiempos, que existe un "don" que le permite transferir sus emociones y energía a quienes dirige. Considera que están involucrados canales de comunicación que van más allá de la marcación rítmica, y que no es posible inferir contenido expresivo de la dimensión temporal per se, sino que existen más dimensiones de comunicación musical que se coarticulan en el devenir temporal.

"El director orquestal debe ver y oír, ser activo y vigoroso, deberá conocer la composición, la naturaleza y alcance de los instrumentos, estar capacitado para leer la partitura, y junto a todo esto, poseer el talento especial, esas cualidades constituyentes que nos estamos esforzando en explicar, el don indefinible sin el cual, no se podrá establecer ese vínculo invisible entre él y aquellos a quien dirige. De cualquier otra manera la facultad para poder transmitir sus emociones le será negada; y la influencia de energía y guía fallará completamente. No será más un director, un conductor, sino un simple marcador de tiempos." (Berlioz, 1856) p. 227

Berlioz y Wagner exponen que dirigir es mucho más que marcar los tiempos, pero ambos consideran la habilidad de marcación temporal como la base sobre la que emergerá la expresión musical. 
En este sentido hay acuerdo con el pensamiento de Bernstein (1959) cuando afirma que la interpretación tiene que estar dentro de la marcación del tiempo. Es decir que dentro de un contexto y encuadre rítmico de referencia, establecido en el esquema de marcación, se debe moldear el contenido y la expresión de la música (Schuller, 1986).

Watson (2012) recopila las ideas de varios pedagogos de la dirección (Faberman, 1997; Jordan,1996; Otranto, 1993) que reconocen que la comunicación de la dimensión expresiva va más allá del nivel básico de la marcación de esquemas temporales; pero que su abordaje constituye una tarea problemática. Lamentablemente no profundizan en la naturaleza y alcances de este problema. Otro referente, Green (1961), expone que el director debe adquirir la habilidad de variar los contornos de los gestos de marcación de compás de manera que puedan describir de la mejor manera los significados musicales.

Sin embargo, como reflexiona Poch (1982), aún no hay una secuencia pedagógica significativa y lógica para el desarrollo de las técnicas y habilidades necesarias para la dirección. Poch adjudica esta persistencia, a que los métodos continúan concentrándose en la reproducción de patrones espaciales y mínimamente en el manejo de dinámicas, articulación y fraseo.

Hasta aquí se describen dos dimensiones implícitas en los de gestos de dirección. La primera, de índole estructural, en un sustrato de base que establece y sostiene los atributos de la temporalidad musical a través del entrenamiento de técnicas de movimiento en relación a esquemas de marcación del compás. Y la segunda, que comprende la modulación o modelado de los movimientos de la primera, en atributos para la expresión musical.

Los parámetros de la dimensión expresiva son más difíciles de analizar y describir, sus categorías son de un acceso menos inmediato que conlleva mayores desafíos en para su transmisión pedagógica. Esta podría ser una razón 
por la que en la literatura específica no se registran análisis y metodologías que desarrollen estas habilidades; las cuales sólo se adquieren, o no, a través de la observación e intuición personal de los directores a lo largo de su ejercicio profesional.

\section{I.I.2 Mano temporal y mano expresiva}

La división entre la dimensión temporal y la expresiva tiene su ejemplo más consistente en la división de los roles de las manos.

La tradición y los libros de pedagogía indican que el rol de marcación del tiempo se debe realizar con el uso de la mano derecha, reservando la mano izquierda para la expresión y la interpretación (McElheran, 1964). Hanna Weir (2013) en su relevamiento de textos de dirección señala que los parámetros dinámica, articulación, fraseo y expresión, son los reservados para ser modelados por la mano izquierda (Malko, 1950; Demaree y Moses, 1995; Green et al, 1997). Concluye que casi la totalidad de los autores no dan pautas técnicas para el entrenamiento de la mano izquierda, por lo tanto esta tarea queda librada a la imaginación e intuición del director. Bartee (1977) especula que esta condición es la consecuencia de un insuficiente sistema de clasificación y vocabularios para la instrucción de los gestos.

Malko (1950), describe las situaciones para el uso de la mano izquierda: i) los cambios de la dinámica y ii) los objetivos expresivos. Por su parte Demaree y Moses (1995) tienen una lista más detallada:

- $\quad$ Finales

- $\quad$ Dinámica

- Crescendos y diminuendos

- Acentos

- Cambios súbitos de todo tipo

- $\quad$ Stress del texto

- Modulación de frase 
Entender los dominios de la temporalidad y la expresión en manos independientes también tiene sus detractores:

"Es simplemente sin sentido, ningún director puede dividirse en dos personas, un marcador de tiempos y un intérprete" (Bernstein, 1968)

De este modo Bernstein sugiere una mirada holística del cuerpo en la comunicación, donde los gestos deben describir la música (Sandene, 1994).

Para finalizar, la mayoría de los autores no mencionan la posibilidad de intercambiar los roles entre las manos (Hanna Weird, 2013), aunque en la práctica real, se observa tanto esta práctica como la de utilizar las manos en espejo.

Pero lo expresivo va más allá de los roles asignados a las manos. Se puede observar a los directores modelar la aparente viscosidad del aire que los rodea con el fin de comunicar efectos expresivos. Dos gestos pueden tener la misma trayectoria y velocidad, pero aparentan fricciones diferentes, lo que aporta impresiones en extremo diferentes (Nakra, 2000). Los movimientos del director corporizan y facilitan organizaciones musicales de alto orden: tempo, dinámica, fraseo, articulación; el esfuerzo de estos movimientos no se relaciona con la ejecución de los sonidos, como en un cantante o instrumentista, sino en la comunicación del modo de producción de los mismos.

\section{I.I.3 Metalenguajes de la dirección}

Otro dominio de reflexión sobre la emergencia de lo expresivo en la configuración de gestos de conducción se encuentra en las categorías y conceptos que organizan el lenguaje; o desde la perspectiva de Nattiez (1987) en el problema de los metalenguajes que se utilizan para referirse al dominio musical. El vocabulario básico para la técnica de dirección es compartido y consensuado; conceptos como tiempo, ictus, levare, subdivisión, legato y staccato son utilizados sin mayor controversia. 
El problema reside en que no hay modelos para describir los gestos expresivos, las categorías expresivas en relación al movimiento de los gestos están significativamente sin teorizar (Garnett, 2009). Una de las razones de superficie que se infiere de la literatura específica, es que "lo expresivo" se considera dentro del ámbito de lo subjetivo y de difícil definición. Epstein (1995) reconoce esta dificultad cuando señala que la esencia de la experiencia del tiempo es el movimiento, y propone construir puentes entre los conceptos de la estructura temporal de la música y los indefinibles del afecto que están íntimamente relacionados a la experiencia del movimiento y resisten su traducción a palabras.

\section{I.I.4 Expresión musical y movimiento}

Un propuesta concreta que establece puentes entre música y movimiento en relación a acordar un metalenguaje del movimiento expresivo, corresponde a la vinculación de las teorías de Rudolf Laban (1879-1958) con los gestos de la dirección musical. El primer escrito que propone este vínculo es la tesis de Neale K. Bartee (1977). En ella expone que las teorías de Laban proveen una taxonomía para poder comunicar verbalmente la efectividad de un movimiento y asegura que las categorías de Eukinética permiten al director describir cómo se sienten los movimientos. Es decir, que el marco de categorías Laban para describir el movimiento corporal se podrían utilizar para comunicar y modelar cualitativamente los gestos de dirección.

Es sumamente significativa la aplicación del Análisis de Movimiento Laban (AML) en la vinculación con disciplinas que no estén relacionadas con la danza, que es su campo disciplinar de origen. Se registran avances tanto en propuestas metodológicas y pedagógicas de la dirección musical (Poch, 1982; Billingham, 2009; Jordan, 1996, Jordan et al, 2011), como en el ámbito de la investigación de la disciplina (Jordan, 1986; Gambetta, 2005; Mathers, 2008; Truong et al, 2016). También se extiende en un corpus de investigación que incluye la inteligencia artificial (Burton et al, 2016), el análisis de movimiento mediado por la tecnología (Chen et al, 2011; Berstein et al, 2015), la 
vinculación de emociones y movimiento (Camurri et al, 2003; Camurri et al, 2009; Glowinski et al, 2011, Samadani et al, 2013), estudios del movimiento en el deporte (Giraud et al, 2016), la infancia temprana y el desarrollo (Español 2007, 2008, 2010).

La destacada variedad de vinculaciones interdisciplinares y la vigencia en proyectos de investigación actuales nos conducen a una ineludible reflexión sobre la probada validez del AML para la observación, descripción, categorización e interpretación del movimiento corporal en relación a la comunicación y la expresión.

La teoría del movimiento de Laban explora el cuerpo humano como un todo que interactúa e impacta en el ambiente donde vive, al considerar la génesis psicológica que impulsa la intención del movimiento corporal. A los fines del presente estudio debemos avanzar en los alcances de cómo la intención y el significado se expresan en el movimiento y en la música; pensando la posibilidad de un origen epistemológicamente compartido. Postulados que emergen de esta idea son los de la instructora del método Dalcroze, Jane Palmquist, quien sostiene que el movimiento emana de la misma fuente/origen que el sonido, o convergentemente los de Laban, que considera que la música tiene el mismo origen kinestésico que el movimiento, o los del director orquestal Charles Gambetta (2005) que en su tesis doctoral sugiere que la idea musical y la idea de movimiento que motoriza los gestos de dirección pueden provenir de una misma fuente.

La intención de esta tesis no es hacer una crítica a las metodologías de entrenamiento a los directores, ni delinear una propuesta innovadora al respecto. El desarrollo de este trabajo se orienta a la delimitación de un marco teórico para reflexionar, describir y analizar los alcances de la comunicación de significados musicales expresados en los gestos de dirección, y los vínculos entre movimiento corporal y expresión musical en el contexto de la dirección musical. 


\section{I.2 Objetivos}

\section{I.2.I Objetivo General:}

Delinear las bases de un modelo para describir la comunicación de significados musicales corporeizados, en el contexto interactivo de la performance coral, con foco en los correlatos de la modulación dinámica de la energía de la música y del movimiento.

\section{I.2.2 Objetivos Específicos:}

Describir una ontología de gesto musical en el marco de las nuevas teorías de la ciencias cognitivas de segunda generación, en adecuación al objetivo general.

Desarrollar metodologías pertinentes y en acuerdo con los paradigmas postulados en el marco teórico, para el estudio de los vínculos entre movimiento, significado y música en el contexto intersubjetivo de un coro.

\section{I.3 Hipótesis General:}

Los significados musicales se configuran con fines expresivos en patrones de movimiento y de música. La energía de estos patrones está modulada con rasgos dinámicos compartidos. La energía expresada en los patrones tiene fines comunicativos en el contexto intersubjetivo de la performance coral. 
Parte I - Marco teórico 
"Los gestos se conectan con la cualidad del sonido, la expresividad de la línea musical y el elemento elusivo y no discursivo de la interpretación musical, se vincula con el interjuego creativo e imaginativo entre los modos simbólicos del gesto y la música”. (Hatten, 2004)

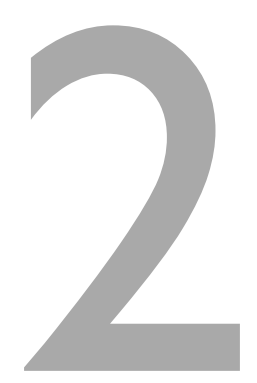

\section{2 . Gesto y significado: una mirada ontológica}

Posicionados en el contexto de la dirección musical, el primer foco de atención son los movimientos que realiza el director para comunicarse con los músicos. A estos movimientos habitualmente se los llama "gestos", o se hace referencia a la géstica de dirección para aludir al corpus de técnicas de movimientos. ¿Que le confiere a estos movimientos la entidad de gesto? ¿Qué es un gesto? ¿Puede haber un gesto que no sea expresivo?

El epígrafe de Hatten enuncia tópicos que todos entendemos están presentes en el hecho que nos abocamos a analizar, pero cada uno encierra nuevos interrogantes cuyas respuestas no son inmediatas. ¿Cómo están conectados los gestos con el sonido?, ¿qué atributos del gesto corresponden a los atributos del sonido?; o ¿cómo se expresa una línea musical? ¿Cuál es el contenido no proposicional de la interpretación? ¿Lo no proposicional se agota en lo simbólico? ¿Cómo se expresa en un gesto?

\section{I Tensión ontológica: Gesto como experiencia o como mediación semiótica.}

La primeras reflexiones en relación al gesto las organizaremos alrededor de las problemáticas que emergen en los estudios de gesto provenientes de distintos 
dominios. Inicialmente profundizaremos en reflexiones de la antropología del teatro y de la danza.

La noción de que el gesto es una forma de experiencia personal, así como un conductor de significados abstractos y predeterminados, ha sido explorada por muchos teóricos de la actuación y la performance. Etnógrafos de la danza han estudiado el contenido afectivo de las sensaciones kinestésicas producidas por la acción del gesto. Como escribe Deidre Sklar (1991, p. 6): "La etnografía de la danza depende del postulado de que el conocimiento cultural es corporeizado en el movimiento y que este conocimiento no es únicamente somático sino también mental y emocional, abarcando la historia cultural, creencias, valores y sentimientos." Para Sklar, la experiencia vivida en la ejecución del gesto es un objeto de estudio tan importante como la dimensión simbólica del mismo. Por otra parte Barba (1994) en su libro sobre antropología del teatro reflexiona que los gestos pueden dar forma a afectos que no tienen significados precisos o codificables, que son energía modelada. La energía de cómo hacer que la presencia física se transforme en presencia escénica y consecuentemente en expresión.

Noland (2008) sugiere que el gesto puede concebirse de múltiples y a veces conflictivas maneras. En Migrations of Gesture presenta dos enfoques fundamentales, el primero se enmarca en la fenomenología y tiene por referentes a Hussertl y a Merleau-Ponty. Desde la perpectiva fenomenológica el gesto es movimiento y está íntima y exclusivamente relacionado con el cuerpo y su expresividad. Para Husserl, los gestos están cercanos a la expresión natural, por tanto son indicadores de la subjetividad y la presencia del individuo. Para Merleau-Ponty, los gestos son el ser a través de un cuerpo; de modo que los gestos no sólo son para la comunicación entre agentes, sino que le dan al agente una experiencia somática privada del propio movimiento corporal. El cuerpo es fuente de experiencia, por lo tanto de conocimiento. Gesticular para Merleau-Ponty es el medio a través del cual las 'formas animadas' navegan entornos y enactuan intenciones. Constituye el vínculo entre un cuerpo/mundo dado y una situación existencial/cultural. No son 
producto exclusivo de la cultura, ni están impuestos inevitablemente por la naturaleza. Los gestos son un modo distintivo de conjugación del conocimiento.

El segundo enfoque proviene del pensamiento postestructuralista y del deconstructivismo, referenciado por autores como Foucault y Derrida. Para ellos gesto es technè, un lenguaje, con su propio régimen semiótico, con signos de significados culturales. Es decir que, a partir de una cultura dada, los gestos inevitablemente devienen, son convencionales y arbitrarios en vez de espontáneos y motivados, y se pueden repetir y desprender del contexto específico de su performance. De este modo los gestos se disocian de la experiencia corporal y se constituyen puramente como mediaciones semióticas. Derrida (1989) argumenta que todos los gestos, en relación a su significado, son iterables y dependen de un orden de representación mas que de presentación, de repetición mas que de la subjetividad pura. Esta concepción disocia completamente el gesto, entendido como signo, del sujeto que lo actúa.

\section{I.I Gesto y Habla}

Un corpus importante de estudios en torno al gesto corresponde a la lingüística cognitiva que investiga el gesto en el contexto del habla. Tradicionalmente se asumía que el gesto pertenecía a un sistema independiente, distinto al del habla. Recién a partir de los trabajos de Adam Kendon (1980) se desafió esta idea encontrando una relación de unidad entre gesto y habla. McNeill (1992, 2005) profundizó este abordaje al avanzar en otro nivel lingüístico, vinculando los gestos con el contenido semántico y pragmático. En sus primeras formulaciones el énfasis se centra en cómo los gestos revelan el pensamiento (McNeill 1992). Con el avance de su trabajo, el eje de investigación se focalizó en cómo los gestos alimentan y estimulan el habla y el pensamiento, concibiendo una dialéctica en donde los gestos impulsan y modelan el habla y el pensamiento en tiempo real en un proceso de mente/cerebro/acción integrado en sus niveles cognitivos y biológicos (McNeill 2005). 
Esta comunidad epistémica también señala el contraste entre los abordajes empíricos de la ciencia cognitiva clásica, afín a la perspectiva de gesto como mediador semiótico, y el enfoque fenomenológico. McNeill et al (2009, pp. 537-538) sintetiza estas dos perspectivas:

“...La concepciones empíricas tienden a focalizarse en el cuerpo como objeto $y$ describen el lenguaje corporeizado en términos de parámetros objetivos. En un proceso discreto, el sistema cognitivo corporeiza un significado pre existente, un pensamiento, a través de una combinación compleja de vehículos materiales (verbal, manual, facial o postural) $y$ de esta manera se 'externaliza' el significado. Así, el rol del cuerpo en el lenguaje funciona como una máquina que puede hablar, una máquina que puede traducir y revelar el pensamiento a través de vehículos materiales convencionalizados. Este tipo de modelo mecanicista de la comunicación describe el evento lingüístico únicamente desde una perspectiva de tercera persona..."

“...En contraste, Merleau-Ponty, desde la tradición fenomenológica, señala la importancia de reconocer la experiencia desde una perspectiva de primera persona, que conciba al cuerpo como sujeto, en cuanto a la cuestión del significado. La sensación que tengo al escuchar a alguien, no es la de un cuerpo mediando entre su pensamiento y mis capacidades cognitivas; sino por el contrario, que a través de su cuerpo, accedo directamente a sus intenciones. El significado entrando en existencia, su corporización y en cierto sentido, la recepción de su significado; son una sola cosa y ocurren en un único y mismo instante. Lo mental (pensamiento o contenido intencional) y lo fisiológico (vehículo material) son co-emergentes..."

Quedan planteadas de este modo dos perspectivas de abordaje: el conocimiento desde la tercera persona, con mayor tradición en los contextos científicos, y el conocimiento desde la primera persona que se centra en la experiencia del sujeto. Notablemente sin darle categoría, se menciona otra perspectiva, la de segunda persona: “...a través de su cuerpo, accedo directamente a sus intenciones...”, esta frase expresa que los estados mentales 
del otro son observables y esta es una de las ideas de base de la perspectiva de segunda persona, que abordaremos con mayor detalle más adelante.

\subsection{Mente, cuerpo y la cognición corporeizada}

La distinción de McNeill nos remite al problema en torno al paradigma de la división entre mente y cuerpo, y la actual revisión del modelo cartesiano acontecido en las ultimas décadas.

El modelo tradicional para el estudio de la mente se basa en la idea de que los procesos mentales tales como la percepción, la atención y el razonamiento, existen en el cerebro. Los procesos mentales serían idénticos a los procesos cerebrales y se realizarían exclusivamente en el cerebro. La ciencia cognitiva es la disciplina que desde la década del 60 ha signado el estudio científico de la mente, siguiendo la premisa de que los procesos mentales son programas abstractos realizados en el "hardware" cerebral; la analogía con el dominio de las computadoras guió fuertemente los inicios de la ciencia cognitiva. El principal objetivo de la CCC (Ciencia Cognitiva Clásica o Cartesiana) es identificar esos programas (psicología cognitiva) y descubrir cómo se implementan en el cerebro (neurociencia cognitiva).

En los últimos años, un nuevo modo de entender la mente se organizó en torno a concebir los procesos mentales con cuatro características: corporeizados, embebidos, enactivos y extendidos. Corporeizado, implica que los procesos mentales están parcialmente constituidos por estructuras y procesos corporales extra neurales. Embebido, considera que los procesos mentales fueron diseñados para funcionar conjuntamente con cierto entorno que se encuentra fuera del cerebro del sujeto. Enactivo, implica que los procesos mentales no están configurados solo para ser procesados neuralmente, sino que también se configuran en las cosas que el organismo hace habitualmente, por el modo en que realiza acciones en el mundo, y de manera recíproca el mundo también influye en el organismo. Finalmente la idea de Extendido, se refiere a que los 
procesos mentales no están exclusivamente dentro del cerebro sino que se extienden de diversas maneras en el entorno.

Las Ciencias Cognitivas de Segunda Generación (CC2G) se abocan a la definición, alcance y verificación empírica de este nuevo paradigma, cuyas cuatro características implican ciertas incompatibilidades (ver Rowland,2010), alcances que no corresponden al desarrollo del presente trabajo. En este nuevo paradigma se desarrollan modelos para describir los procesos mentales corporeizados de comprensión, razonamiento y atribución de significado. Nos focalizaremos en el marco de la teoría de la cognición corporeizada de Mark Johnson (1987).

Desde los enfoques de la cognición corporeizada, la metáfora conceptual (Lakoff y Johnson, 1980, 1999; Gibbs, 2008), ocupa un lugar central. Martínez (2014) señala que dichos enfoques consideran que: i) la actividad corporal, en interacción con el ambiente, estructura nuestra capacidad para organizar las representaciones mentales en unidades coherentes de significación y para crear o generar nuevo orden en los contenidos de nuestra experiencia; y ii) la corporeidad parece desempeñar un rol central en todo lo relativo a los procesos de comprensión, razonamiento y atribución de significado a la experiencia (Lakoff, 1987; Johnson, 1987). En estos procesos de atribución de significado intervienen unas estructuras básicas, los esquemas-imagen, que se configuran en la cognición a partir de la actividad sensorio-motora de nuestros cuerpos en el ambiente. Por medio de las proyecciones metafóricas realizamos correspondencias entre un dominio de experiencia más conocido, por ejemplo el de la experiencia sensorio-motora en el dominio espacial, y otro menos conocido, como el de la experiencia perceptivo-auditiva en el dominio de la cognición musical, con el objetivo de organizarlos (Gibbs, 1994, 2008; Lakoff y Johnson, 1999).

La idea central es que los esquemas imagen son estructuras preconceptuales, no proposicionales, que surgen recurrentemente a partir de nuestra percepción 
y movimiento corporal. Se constituyen en patrones dinámicos que estructuran las acciones que organizan nuestra experiencia de modo comprensible (Johnson, 1987 pp.29-30) Su lógica de estructura dinámica se constituye en un nivel pre-verbal y generalmente no consciente de significado. Facilitan la vinculación de nuestras experiencias sensorio-motoras con la conceptualización y el lenguaje y favorecen la realización de inferencias acerca de la realidad (Martínez, 2014), estableciendo gestalts experienciales (Gibbs, 2006).

\subsection{Semiótica de la performatividad}

La nueva perspectiva que aporta la cognición corporeizada en relación al cuerpo, al movimiento corporal y cómo este se constituye en la base para la configuración del significado, motiva la necesidad de conjugar y profundizar esta perspectiva con la semiótica. López Cano (2014) se anima a proponer lineamientos de lo que define como una post semiótica cognitiva. Su objetivo es modelar un proceso simbólico en donde lo "representado" no significa, sino que es; donde los signos hacen cosas en vez de reenviarnos a otras. En esta línea sugiere trabajar sobre dos conceptos de la semiótica de Pierce para adecuarlos a los nuevos paradigmas de la filosofía de la mente. En primer lugar propone una reinterpretación de la semiosis, considerándola no como una secuencia de signos discretos sino como una red rizomática en continuo que relaciona, vincula e inter-interpreta fenómenos racionales, emocionales y cinéticos, sosteniendo los principios de una cognición corporeizada, embebida, enactiva y extendida. En segunda instancia amplia la noción de inferencia, la cual debería comprender no solo las funciones lógicas tradicionales (deducción, inducción y abducción), sino extenderse e incluir los procesos donde el cuerpo ejerce mayor influencia. Dentro de estás inferencias López Cano incluye, las proyecciones metafóricas de los esquemas imagen (Johnson 1987), la aplicación de las leyes de la Gestalt, las interpretaciones hermenéuticas, las intuitivas y las retóricas. Con este planteo desplaza la semiótica de Pierce de una teoría de la representación, a otra donde el 
conocimiento se gestiona para la cognición, en diálogo con los nuevos paradigmas de la mente.

Con propuestas como la de López Cano, lo que se presentó como dos ontologías antagónicas, la de la experiencia y la del significado, encuentran caminos de conjugación, que se configuran en base a la lógica de los paradigmas de la cognición corporeizada.

\subsection{Gesto y significado musical corporeizado}

Al incluir el dominio de la música en relación al gesto y al significado, se abre una gran red de posibles abordajes para su estudio. Trataremos en primera instancia de ordenar los trabajos más relevantes del corpus de investigación en torno al gesto y la música, en base a sus objetivos epistemológicos. Luego atravesaremos por el análisis ontológico desarrollado hasta ahora para reflexionar sobre posibles líneas de continuidad en la investigación del gesto en vinculación con los significados musicales corporeizados.

\subsection{Gesto, música y los objetivos de las comunidades epistémicas}

Los estudios de análisis del gesto en relación a la música devienen de diversos contextos disciplinares, que implican comunidades epistémicas (Haas, 1992) disímiles: la simulación computacional, el análisis musical semiótico, la musicología antropológica y mas recientemente la cognición musical corporeizada.

La comunidad epistémica con mayor producción en investigación en torno al gesto musical es la que desarrolla sistemas de simulación computacional para la interacción hombre-maquina (HCI), la animación digital y la inteligencia artificial.

Es oportuno tomar en cuenta el tipo de conocimiento sobre gesto que buscan y que de algún modo necesitan definir para dar marco teórico a sus diseños experimentales. Estos estudios en general se orientan a la construcción de 
sistemas para reconocer, analizar y sintetizar gestos/movimientos con el principal propósito del diseño de dispositivos y superficies de control, modelado y animación virtual.

Entre los autores más citados encontramos a Ramstein (1991) que en su tesis sobre el análisis, representación y procesamiento del gesto instrumental, postula que las técnicas informáticas permiten captar, muestrear y memorizar el gesto bajo la forma de un ensamble de signos objetivos. Su meta es programar un editor de gestos para analizarlos, representarlos y procesarlos; un software para la creación musical que no ubique al ordenador como medio de representación del universo sonoro, sino como un medio para abordar la representación y el procesamiento de los gestos musicales y sus causas instrumentales. Para Metois (1996) los gestos musicales son un set de objetos que se encuentran entre las intenciones musicales y una simple onda sonora. Sostiene que estos objetos tienen una naturaleza similar a los formantes, fonemas y la entonación del lenguaje. En esta línea Miranda y Wanderley (2006) sugieren caminos para darle sentido a la variedad de instrumentos musicales digitales (DMI) y avanzar sobre nuevos diseños que no se ajusten a la lógica de los instrumentos acústicos sino que se organicen en torno a las lógicas del movimiento. En este contexto, gesto musical es cualquier acción humana que se use para generar sonidos. Este mismo enfoque es el que abraza Jensenius et al (2010) para encuadrar la categoría de gestos de control. Todos estos autores se focalizan en cómo las variaciones del movimiento corporal se corresponden con variaciones en la onda sonora, y en cómo el gesto constituye cierta codificación de los rasgos de movimiento que impactan directamente en los rasgos de la onda sonora. Un ejemplo empírico de esta concepción es el trabajo de Henbing y Leman (2007) sobre tipologías gestuales en la ejecución del Guqin; allí definen al gesto musical:

"...como una unidad representacional mediadora entre cuerpo y mente, a través de la cual la mente puede controlar parcialmente nuestro cuerpo en términos de acción-orientada al instrumento... nuestro estudio muestra como 
este concepto de gesto permite deconstrucciones en movimientos básicos cuya concatenación se define por una sintaxis particular." pp. 81

Se evidencia aquí una problemática en torno a la concepción del paradigma mente- cuerpo, que señala López Cano con claridad:

"Leman afirma que su investigación sobre el gesto musical supera "la clásica división cartesiana entre mente y materia" pues entiende que el gesto introduce tanto una dimensión material como conceptual, al concebir explícitamente que la conducta motora en situación musical es una piedra angular de la mediación entre mente y entorno físico; pero está claro que deja intacta la dicotomía cartesiana limitándose solo a introducir lo corporal como mero intermediario de esta oposición” (López Cano (2013, p. 15))

Es decir que hay una clara voluntad de integrar en los diseños experimentales el modelo corporeizado, pero la transición entre paradigmas suscita contradicciones relacionadas con la dificultad de desprenderse del paradigma cartesiano.

Otro elemento significativo de los abordajes HCI es que buscan, o necesitan, delinear una dimensión semiótica con rasgos similares a los del lenguaje. Tomando en cuenta las conclusiones de McNeill (2012) en relación a la evolución de su larga investigación sobre gesto y habla, este autor distingue una oposición entre las características de la semiosis de los gestos y la semiosis del lenguaje (Tabla 2.1). Él describe con precisión que los gestos tienen una naturaleza gestáltica, de síntesis y globalidad. Una sintaxis gestual en relación al sonido, es decir una relación de unidades de correspondencia gesto-sonido estaría en conflicto epistemológico con la naturaleza misma del gesto.

Otra comunidad epistémica que ha desarrollado reflexiones teóricas en relación al gesto musical, hizo foco en las relaciones entre movimiento corporal y semiótica musical. Por un lado encontramos el pensamiento de 
Delalande (2013) quien entiende que los gestos productores de sonido, es decir las acciones para ejecutar el instrumento, se cargan de un poder evocativo, es decir simbólico. Él señala dos niveles simbólicos: uno que se corresponde con proyecciones culturales y otro mas fundamental en relación al movimiento, “...mover el arco no solo es producir sonido, sino también dar al sonido ligereza o vigor..." (Delalande (2013), p. 53); así define una ambivalencia entre el movimiento real del brazo productor de sonido y el movimiento imaginario evocado; entendida no como dos dimensiones independientes, la senso-motora y la simbólica, sino como una simbolización de la acción.

\begin{tabular}{|c|c|}
\hline \multicolumn{1}{|c|}{ Semiosis del Gesto } & Semiosis del Lenguaje \\
\hline Global: Ios significados dependen del todo & $\begin{array}{c}\text { Composicional: el significado depende de las } \\
\text { partes }\end{array}$ \\
\hline $\begin{array}{r}\text { Sintético: los significados son distinguibles en una } \\
\text { sola imagen }\end{array}$ & $\begin{array}{c}\text { Analítico: los significados son distinguibles en } \\
\text { formas lingǘsticas independientes }\end{array}$ \\
\hline $\begin{array}{r}\text { Idiosincrático: Ias formas son creadas en tiempo } \\
\text { real }\end{array}$ & $\begin{array}{c}\text { Convencional: las formas son reguladas por } \\
\text { estándares }\end{array}$ \\
\hline $\begin{array}{c}\text { Aditivo: cuando las imágenes se combinan, no } \\
\text { hay un nuevo valor sintagmático }\end{array}$ & $\begin{array}{c}\text { Combinatorio: cuando las partes se combinan hay } \\
\text { un nuevo valor sintagmáticos }\end{array}$ \\
\hline
\end{tabular}

Tabla 2.I: Características de la semiosis de los gestos y la semiosis del lenguaje

Por otra parte Hatten (2006) define gesto como un modelado de energía a través del tiempo que puede ser interpretado con significado; ese significado implica una información con respecto al afecto, la modalidad o la comunicación. El gesto humano incluiría características que pueden ser asociadas a componentes musicales tales como: variaciones de ritmo, timing, contorno melódico e intensidad. Hatten, al igual que Delalande, incluye dos niveles simbólicos: uno de base, motivado por asociaciones dinámicas (categoría indexical) y asociaciones de forma [imagistic en el original] (categoría icónica) y un nivel superior en relación al estilo musical y sus proyecciones culturales (categoría simbólica).Encontramos una coincidencia 
entre estos autores en delinear correspondencias al organizar las categorías en dos dimensiones simbólicas: una cinética y otra cultural. El problema mentecuerpo no genera tensión en estos abordajes porque la discusión no está atravesada por la cognición corporeizada; simplemente se asume que el gesto evoca o se asocia a un significado. Esta perspectiva tampoco entra en conflicto con la semiosis gestual de McNeill, porque la unidad sonora no es el sonido en sí mismo, una altura determinada con una duración determinada, sino el modelado de la energía sonora en una frase musical.

\subsection{Gesto y la perspectiva de segunda persona}

El avance del estado del arte da cuenta de cómo evoluciona la concepción de los paradigmas de pensamiento y cómo crece la red de conocimiento e implicancias que tiene el estudio de un fenómeno. En este sentido devienen los abordajes desde una nueva perspectiva, la de segunda persona (Shifres, 2009; Gomila, 2010; Gallagher, 2005; Thompson, 2001).

La perspectiva de primera persona muestra qué es lo que un gesto significa para el sujeto que lo realiza desde dos posibles abordajes: uno basado en la acción-orientada y otro basado en la experiencia Leman (2010). El primero significa que puedo imaginar una acción como si se desplegara en el tiempo, y que tengo la capacidad de ejecutar esta acción. En el segundo el foco se encuentra en relación con la experiencia y la sensibilidad personal del sujeto.

La perspectiva de tercera persona se concentra en la observación distal, en técnicas de medición objetiva, extracción de rasgos, y búsqueda de patrones. Considera que las características de movimiento corporal pueden ser estudiadas como contenedor de información de significado.

En la perspectiva de segunda persona, el gesto es considerado como la expresión de un acto comunicativo. La comprensión de la expresión corporal comunicativa se puede rastrear en la literatura hasta el libro sobre expresión de las emociones de Charles Darwin (1872) pero se ha incorporado recientemente 
a los diseños metodológicos. Esta perspectiva sostiene el supuesto de que los estados mentales como la atención, las intenciones y las emociones, son observables directamente en nuestra expresión y conducta. La expresión del otro es percibida directamente de modo significativo (Gomila, 2010). Las neurociencias aportan evidencias al respecto: las neuronas espejo demuestran que las regiones cerebrales de la percepción de la acción y de la ejecución de la acción están superpuestas, de modo que la percepción de la acción del otro se espeja en un enactivamiento de esa acción en mi persona. Los movimientos del otro se convierten en portadores de significado que nosotros enactuamos basados en nuestra propia ontología de acción-orientada.

Las perspectivas de primera y tercera persona suponen un escenario donde la percepción es propioceptiva (primera persona) o distal (tercera persona), es decir dos vías diferenciadas. Esto conlleva el problema de cómo hacer puentes entres ambas perspectivas, es decir cómo la información propioceptiva de primera persona permite entender la información perceptiva distal del otro.

Por el contrario el abordaje de segunda persona asume que la percepción del otro siempre incluye propiocepción. De este modo la idea de un hiato entre mentes desaparece y se reemplaza por una unión perceptiva de activa reciprocidad (Español, 2014).

\subsection{Hacia una integración de las ontologías de gesto musical}

Gesto, movimiento, significado, son palabras clave para abordar el estudio del oficio de la dirección musical. Hasta este punto nos hemos posicionado en el paradigma de la cognición corporeizada, y en el rol preponderante del cuerpo en la configuración de procesos mentales corporizados, no proposicionales como los esquemas imagen. $\mathrm{Y}$ en cómo esos patrones dinámicos (esquemas imagen) constituyen procesos de inferencia de significado a través de las proyecciones metafóricas y cómo la semiótica cognitiva da cuenta de estos significantes cinéticos. Y por último, cómo los objetivos epistémicos modelan los diseños y procedimientos de investigación. 
Asumir una ontología de gesto como comunicador de significados no proposicionales vinculados a la música y al movimiento, en el contexto de dirección musical, nos orienta a delimitar el alcance de los conceptos de expresión y comunicación musical desde la perspectiva de segunda persona. Este será el eje de siguiente capítulo. 


\section{3}

\section{Expresión y Comunicación musical desde la perspectiva de segunda persona y el enactivismo}

\section{I Expresión Musical}

El contenido expresivo ha sido visto como la base del valor estético del arte, por ende la calificación de expresivo para las performances en general y musicales en particular, está en el centro de las atribuciones de valor (Shifres, 2014). Como se discutió en el capítulo 1, desde los primeros escritos de dirección musical emerge la valoración expresiva: un director tiene que lograr ser más que un marcador de tiempos, debe alcanzar el oficio de expresar ideas e intenciones musicales con su cuerpo. De modo que el gesto del director es considerado como un acto comunicativo expresivo; desde esta perspectiva, el gesto no es un mediador de significados, sino un impulso que activa nuestra propia experiencia corporal (Shifres, 2007).

La Expresión, para la psicología cognitiva y la filosofía de la mente, se puede abordar desde dos sentidos. Para uno de ellos expresar significa manifestar un estado mental; para el otro, expresar es un tipo de acción mediante la cual no solamente se revela un estado mental, sino que también se dirige la atención 
hacia él ostensivamente (Gomila, 2010). Este sentido es el que nos permite calificar a un gesto como más o menos expresivo. Valoramos su eficacia para la expresión del estado mental. Este es el sentido en el que usamos expresión en relación a la música y a la expresión estética en general. Expresar es una forma de indicación, de comunicación intencional. En tanto se reconozca la intención en la acción, la expresión será exitosa y habrá una comunicación efectiva. Desde un abordaje musical la expresión es un aspecto intrínseco a la experiencia musical, es decir que no podemos separar la experiencia expresiva de la percepción de los sonidos. Es intrínseca en el mismo sentido que al escuchar hablar no podemos separar el sonido de la palabra de su significado. La expresión musical se percibe no por inferencia a posteriori de la percepción, sino que es la percepción directa de la expresividad musical, es decir que se constituye en una percepción significativa. No se basa en proyecciones simuladas de mis experiencias de primera persona, como sugiere la teoría de la simulación, sino que se articula a partir de consideraciones fenoménicas y de nivel subpersonal. Expresar es una forma de comunicación intencional y su éxito depende del reconocimiento de la intención en la acción.

La propuesta de Gomila es cercana a la de Robinson (2005), quien considera que podemos percibir una obra musical como la articulación de una subjetividad implícita en la propia música; esto consiste en entender los estados expresivos en la música como la expresión de un punto de vista, de un sujeto mínimo, implícito en la obra, y de atribuirle a tal sujeto los estados expresivos, esto es, considerarlos como estados de ese sujeto. Percibimos la música como triste en la medida en que la imaginamos como la expresión de un sujeto triste. Hay trabajos empíricos, guiados por otros marcos teóricos pero con resultados convergentes a los que estamos discutiendo, que demuestran que al escuchar música, en ella se identifican cualidades como si fueran las de una persona; los resultados de estos estudios indican que este tipo de cualidades se identifican más rápido que otras, y que de algún modo a la música se la escucha como si fuera una persona virtual (Watt y Ash, 1998). 
Esta postura de Gomila tiene implicancias de base: i) considerar que la música sí tiene contenido expresivo; ii) que la comprensión estética de la música implica captar ese contenido expresivo; y iii) que tal contenido expresivo depende en primera instancia de la producción intencional del compositor, asumiendo que éste debe situarse tanto en los roles de creador, de intérprete y de espectador para asegurar la efectividad de su composición. Por lo tanto conseguimos percibir expresión en la música si adoptamos una actitud de interacción intencional con ella. Si bien para Robinson como para Gomila la percepción de la expresión se da en el contexto de la interacción intersubjetiva, ambos autores se diferencian. Para Robinson la expresión tiene lugar por la proyección imaginativa hacia un sujeto implícito en la música; esto es, que la remite a un mecanismo psicológico de alto nivel. Por el contrario, para Gomila la expresión musical consiste en un mecanismo de bajo nivel, perceptivo, que tiene lugar de manera directa, espontánea, implícita y reactiva, sin pretensiones explicativas o predictivas. Un mecanismo donde la atribución se da de manera implícita en la propia experiencia perceptiva, no mediada por una inferencia a partir de los gestos o expresiones faciales; es el reconocimiento perceptivo de una instancia de un estado psicológico y nuestra reacción a esa situación depende de la atribución que hayamos hecho. Percepción significativa, por lo tanto, es ver en la conducta del otro, de manera on line, la intención que lo guía o la emoción que expresa.

Expresar, desde este abordaje, es hacer perceptible de manera manifiesta la dimensión expresiva de un estado mental (emoción, intención) y percibir cómo se experimenta corporalmente. La dimensión expresiva muestra la naturaleza de la experiencia en cuestión, objetiva la subjetividad en términos de referencia corporeizada y no se limita a indicar la presencia del estado mental, sino que manifiesta cómo se experimenta. En el caso de la expresión musical la referencia corporeizada se manifiesta en patrones dinámicos reconocibles y vinculados a dicha experiencia.

Experiencia que se construye desde la temprana infancia, a partir de las acciones compartidas entre adultos y bebés, dando lugar a fenómenos de 
comunalidad (Martínez, 2014) a los que se ha denominado musicalidad comunicativa (Malloch y Trevarthen, 2008), caracterizados por el modo en que experimentamos estar juntos compartiendo el tiempo. En estos encuentros ocurren performances multimodales que se organizan en formas expresivas (visual-sonoro-kinético-táctiles) y contienen un alto grado de redundancia en la simultaneidad de las modalidades expresivas involucradas (Shifres, 2008; Martínez y Español, 2009; Español, 2007, 2008, 2010, 2014; Español y Shifres, 2015). Esta característica de los contextos de intersubjetividad temprana ofrece las condiciones para la emergencia de las estructuras imagenesquemáticas en la cognición musical, en la expresión y la comunicación. Se trata de experimentar un ámbito de la experiencia en relación a otro con el que establecemos una analogía estructural gracias a la congruencia psicofisiológica experimentada. Esto nos provee una estrategia para entender de qué modo experimentamos la música en términos expresivos: en la medida en que reconocemos en ella propiedades expresivas con rasgos intermodales coincidentes.

\subsection{Comunicación Musical}

Si expresar es un tipo de acción, cuya finalidad es revelar un estado mental (emoción, intención) de manera clara y contundente de modo que si tal estado mental se reconoce habrá comunicación efectiva, entonces es importante revisar los modelos de comunicación musical que emergen de los estudios empíricos de expresión musical y performance.

\subsection{Modelo tradicional unidireccional}

Moran (2014) encara la revisión de 86 estudios sobre performance musical buscando los modelos de comunicación implícitos. Ella concluye que en la gran mayoría de estos trabajos hay un modelo de transmisión lineal de la información musical, que describe en cuatro eslabones de flujo de información de una única vía resumidos en: 


$$
\text { intención } \Rightarrow \text { notación } \Rightarrow \text { interpretación } \Rightarrow \text { recepción. }
$$

Esta cadena incluye i) las intenciones del compositor; ii) la transcripción de esas intenciones, o parte de ellas, en la notación musical; iii) la interpretación del director y/o los performers; y iv) la audiencia. El performer evoca la obra del compositor y se la envía al oyente. La concepción de obra es la de una entidad cerrada, que contiene las intenciones del compositor; el performer está al servicio de la obra. Como referencia de este modelo se propone la influyente publicación de Palmer (1997)

"Los compositores codifican ideas musicales en la notación de la partitura, los intérpretes-ejecutantes las recodifican desde la partitura a señales acústicas, y los oyentes las recodifican desde las señales acústicas nuevamente a ideas. Cada intérprete-ejecutante tiene la intención de transmitir. La comunicación de ideas contenidas en la performance musical, incluye la interpretación conceptual de la composición musical que realiza el intérprete-ejecutante" (Palmer, 1997, pp. 118-119).

En este modelo de comunicación musical emerge una noción de composición musical, performance musical y escucha musical fundamentalmente individualistas.

La creciente adhesión al paradigma de la cognición corporizada impulsa la reformulación de este modelo, incorporando los aspectos emergentes de la interacción y la intersubjetividad. La importancia de la interacción en el estudio de la música es de reciente incorporación en proyectos científicos en relación a la música: EmcoMetecca (Leman, 2008-2011), SIEMPRE (Camurri y Piana, 2010-2013) y en el que se enmarca el presente trabajo "La Corporeidad de la Mente Musical. Hacia una definición de su estatus en el estudio de la Ontogénesis, la Percepción y la Performance de la Música" (Martínez, 2014-2017). 


\subsubsection{Comunicación desde la ontología de la música como performance}

Moran sugiere ubicar el evento performativo como organizador central de la comunicación. Performers, ideas y audiencias son requisitos para que la performance musical suceda, es decir que si no hay performance no hay objeto de análisis. El evento musical, en tanto objeto de análisis, se genera en el proceso de la performance musical. El principal giro de esta propuesta es que se centra en una ontología de música como performance en contraste al tradicional enfoque ontológico de la música como texto (Cook, 2003; Shifres, 2014). En el capítulo 4 discutiremos cómo estas ontologías organizan los diseños metodológicos para el estudio de los parámetros expresivos de la música, en su mayoría bajo la concepción ontológica de la música como texto. Esto deviene en prácticas metodológicas que se organizan principalmente en la desviación expresiva entendida como desviaciones canónicas, es decir de la norma establecida en el texto-partitura.

\subsubsection{Comunicación como Alineamiento Expresivo}

Por otro lado, se encuentra la propuesta de Leman (2016) quien propone un modelo de comunicación impulsado por el eje de la expresión, considerado como un elemento constructivo de la habilidad de comunicarse y como un elemento clave para establecer interacciones.

Las diferencias del modelo de comunicación propuesto por Leman en comparación con los abordajes tradicionales se vinculan a los rasgos que denomina como Enacción y Flujo dinámico.

Enacción en este modelo se define como el aspecto enactivo, consistente en la habilidad para transformar patrones complejos en unidades que puedan ser tratadas en términos de acciones. Es decir, que se trata de un proceso de codificación (i.e. generar patrones musicales en una performance) o decodificación/alineamiento (i.e. percibir patrones musicales en la escucha) (Leman 2016, p. 26). El proceso de enactuar sería el proceso que reduce la 
complejidad de los patrones musicales a unidades de acción, enfatizando las metas de acción orientada implícitas en estos patrones. De manera que la enacción es el alineamiento entre acción y patrón musical, esto permite transferir las metas de la acción a los patrones musicales, y por consiguiente podemos asociar éstos con las intenciones. Se asume que el mecanismo subyacente de la enacción es la predicción sensoriomotora. El proceso de enacción nos habilitaría a evaluar patrones musicales en términos de significados relacionados a acciones: metas, sentimientos, intenciones, effort, emociones.

El proceso enactivo se basa en un flujo dinámico dado por la codificación y el alineamiento. Este flujo se inicia con la transformación de una idea musical (intención, emoción) a un patrón musical. Cuando se escucha este patrón musical, el oyente se alinea expresivamente con el patrón, transformando nuevamente el patrón musical en intenciones, emociones, sentimientos de empatía).

El alineamiento expresivo es un modo de enacción, con un flujo de doble vía: puede transformar estados intencionales en articulaciones corpóreas y/o viceversa (Figura 3.1).

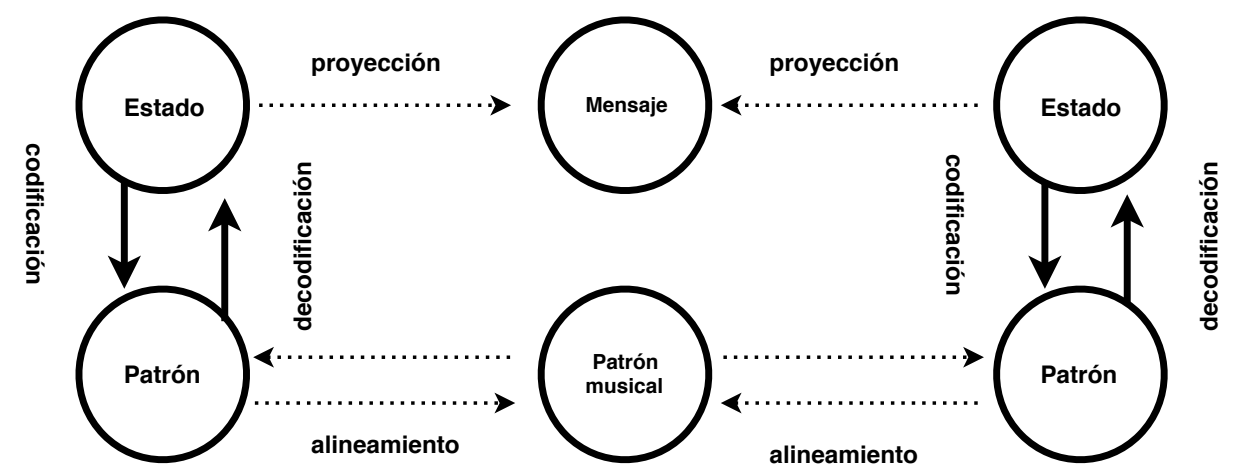

Figura 3.I: Modelo de comunicación del alineamiento expresivo 
Es importante señalar que este modelo no requiere un significado proposicional, un mensaje. El proceso de predecir intenciones, metas, o emociones, es una actividad significativa en sí misma, focalizada en la interacción y la expresión.

Una descripción final de cómo se organiza el modelo, reside en la distinción entre estrato de patrones y estrato de intenciones. El primero asume que los patrones de movimiento pueden originarse por metas de acción intencional, basados en los procesos de predicción sensoriomotora que asocian intenciones con movimientos, acciones y comandos motores. El estrato de intenciones, por otro lado, asume los estados intencionales como fuente principal de los patrones. Dada su asociación con la acción, la activación del patrón musical funciona como una expectativa del emergente de acción. Si bien los estados intencionales son invisibles e inaccesibles, este abordaje asume que se puede acceder a ellos a través de los patrones de actividad cerebral o a través de los patrones de movimiento, y que ambos patrones permiten su medida $\mathrm{y}$ observación.

El abordaje científico se puede realizar desde una perspectiva objetiva, en la cual describimos movimientos corporales en correspondencia con formas sónicas en movimiento (Leman, 2008) o desde un punto de vista subjetivo, donde describimos acciones que se alinean expresivamente con la música.

No hay que perder de vista los objetivos epistémicos de los autores de ambos modelos. Por un lado, Moran tiene como objetivo el giro de los estudios musicológicos desde el individualismo hacia una perspectiva social. Por otro lado en la línea de Leman, si bien también está presente la revisión del escenario musical con la incorporación del factor intersubjetivo, lo más relevante es la emergencia constante de la necesidad de diseñar metodologías válidas y objetivas para el estudio de las vinculaciones entre música y movimiento para el desarrollo de tecnologías de mediación. 


\subsubsection{Enactivismo}

El alineamiento expresivo que propone Marc Leman se basa fundamentalmente en los principios de la enacción (Schiavio et al, 2017; Di Paolo, 2015). El enactivismo es una perspectiva multidisciplinaria sobre la cognición humana que integra ideas de campos tales como la fenomenología, la filosofía de la mente, la neurociencia cognitiva, la psicología social y del desarrollo (Stewart et al., 2010; Thompson, 2007; Varela et al., 1992). En vez de entender la cognición sólo en término de estructuras (representaciones, activaciones neurales, computaciones), el abordaje enactivo los considera como una actividad constituida por interacciones circulares que ocurren entre un organismo y su entorno. Estas interacciones están motivadas las normas de adaptabilidad del organismo estableciendo un acoplamiento sensoriomotor con el mundo (Maiese, 2011). A través de estos bucles sensoriomotores continuos (definidos por ciclos continuos de acción-percepción en tiempo real), el organismo enactúa (produce, acciona, “da a luz”) su propio dominio de significados (Colombetti y Thompson, 2008; Thompson, 2007), sin una separación real existente entre los estados cognitivos del organismo, su psicología, y el entorno en el cual está embebido. La cognición, desde este punto de vista, genera un interjuego entre el organismo y el entorno que se desarrolla como un sistema dinámico (Hurley, 1998).

Di Paolo (2015, p.2) lo resume así:

“... El enactivismo considera a la cognición como una actividad continua moldeada por procesos auto-organizados de participación activa en el mundo y por la experiencia y auto-afección del cuerpo animado. El cuerpo vivo crea un mundo de significados en su ser y su accionar (enact) y no recibe pasivamente información neutra de un entorno a la cual luego tiene que "sumarle" un significado...Conocer es participar, esta es la idea que motiva al enactivismo, una nueva forma de plantear el estudio de la vida, la mente y lo social...." 


\subsection{Síntesis}

Nuestro punto de partida, en el capítulo 1, fue reconocer la problemática en relación a qué es la expresividad de un director musical, continuando en el capítulo 2 con una revisión del estado del arte sobre las ontologías de gesto, y cómo la teoría de la cognición corporeizada da marco a entender el origen de las vinculaciones conceptuales entre música y movimiento. Esto nos motivó a profundizar el marco teórico en relación a los conceptos de expresión y comunicación aportándonos el siguiente enfoque:

Que en situaciones intersubjetivas entendemos las intenciones del otro porque se expresan en sus acciones (Gallagher, 2005).

Que la expresión, desde la perspectiva de segunda persona, es una acción cuya finalidad es revelar un estado mental (por ejemplo intención o emoción) en búsqueda de su reconocimiento efectivo, y que por lo tanto constituye un acto de comunicación.

Que la música tiene características constitutivas, vinculadas al movimiento, que nos permiten adoptar una actitud de interacción intencional con ella.

Por lo expuesto, y considerando el contexto interactivo y comunicacional de la performance coral, encontramos que el marco del alineamiento expresivo (Leman, 2016) resulta adecuado para describir los modos en que la expresión musical se modela en los procesos enactivos de alineamiento entre los patrones de movimiento corporal y los patrones musicales.

En el capítulo siguiente desarrollaremos problemáticas metodológicas sobre las categorías de análisis de los patrones de música y de movimiento. 


\section{4}

\section{Problemáticas Metodológicas. Categorías y unidades de análisis para patrones de movimiento y de música}

Referimos al movimiento musical y analizarlo supone el desafío de entender las vinculaciones inter dominio música-movimiento en términos de un modelo dinámico de relaciones espacio-temporales compartidas (Sievers et al., 2013). Describiremos problemáticas de este abordaje desde el punto de vista de las descripciones de la señal física, también denominadas descripciones de bajonivel. Las vinculaciones de bajo-nivel describen las variaciones del dominio del movimiento, configuradas por el espacio-tiempo en el cual sucede nuestra existencia y las variaciones musicales que suceden el espacio-sonorotemporal. Tanto movimiento como música comparten el hecho de transcurrir en una temporalidad. Esta correlación es la más directa a los fines de establecer vinculaciones.

\section{I Desafío temporal: sistema discreto, sistema continuo.}

Desde la física, un evento o suceso es un punto en el espacio-tiempo que se caracteriza por cuatro coordenadas; en otros términos, es un hecho que puede ser identificado o señalado por el momento y el lugar en el que ese hecho ocurre. 
Pensemos la dimensión temporal, focalizándose únicamente el rasgo temporal del evento, es decir, en la descripción de las características de ocurrencia del evento. En esto reside la principal dificultad, ya que la entelequia de desacoplar el tiempo del espacio, resulta abstracta y desvinculada de la experiencia.

Si sólo intentamos describir modificaciones de la temporalidad en el dominio del movimiento, las categorías de análisis deben referirse a cuánto tiempo un punto permanece en una posición espacial determinada. Pero esta descripción ya encierra una problemática: el movimiento no es una serie de eventos discretos; un punto no puede estar en una posición, para luego desaparecer y aparecer en otra posición. No puedo hacer desaparecer mi mano de un lugar para que aparezca en otro; tengo que recorrer todas las infinitas posiciones intermedias entre el punto de partida y el de llegada. Nuestra realidad existe en el espacio. No hay posibilidad de un 'silencio' espacial; esto sería el equivalente a un 'silencio existencial'. Por el contrario, el sonido puede sonar o no sonar (silencio), puede existir en el plano físico (vibración del aire), o no existir. Es decir que el espacio-sonoro está discretizado por la presenciaausencia de sonido; se trata de eventos con una duración determinada. Una vinculación inmediata podría correlacionar: i) un sonido de altura y timbre constante y de intensidad variable, donde el cambio en la intensidad corresponde al cambio de posición; ii) un sonido de intensidad y timbre constante y de altura variable no discreta, es decir que no utilice escalas para organizar el parámetro de frecuencia, pero de este modo quedaría excluida toda la música tonal; o iii) un sonido de altura e intensidad variable, pero de timbre variable. Considerar cualquiera de estas tres posibilidades más inmediatas, nos enfrenta al hecho de que no constituyen ejemplos de vinculaciones habituales y preferidas entre música y movimiento, son de mayor presencia en el estado-del-arte los vínculos entre cambio-de-altura/ movimiento por ejemplo (Palmer et al., 2009). Esto nos vuelve a posicionar en el problema en torno a la discretización del espacio. 
¿Cómo se supera esta diferencia ontológica en un abordaje metodológico? La estrategia consiste en realizar procesos de discretización de las series temporales de movimiento, a un nivel que esté por debajo del umbral de percepción visual. Consideremos el balanceo de un brazo, desde el punto de inicio del movimiento hasta el punto en que se detiene. El procedimiento consiste en la discretización finita de posiciones intermedias, por ejemplo, en fotogramas por segundo como utiliza el cine (24-30 fps), o en la frecuencia muestreo de los sistema de captura de movimiento (Motion Capture, MoCap), que capturan 60,100 , o 200 muestras por segundo.

Pero este proceso no nos habilita una correlación directa entre las medidas de temporalidad de la música (intervalo entre ataques) y las del movimiento (muestras por segundo). No es válido considerar cada muestra del movimiento como un evento para medir su intervalo entre ataques. Los límites de una unidad de movimiento están dados por el inicio y la detención del movimiento (Kendon, 1980; McNeill, 1992). Esta unidad incluye todas las muestras intermedias entre el inicio y el final de dicho movimiento. Teniendo esto en cuenta, desde la perspectiva de la temporalidad, la correspondencia más válida, aunque no la más inmediata (Kohn y Eitan, 2009), es la correlación con unidades de agrupamiento musical (motivos, semifrases, frases, periodos). La nota, como unidad musical temporal mínima, desde este punto de vista, será considerada como el evento que discretiza el 'recorrido' entre el inicio y el final de la unidad de agrupamiento musical.

Tanto la unidad de movimiento, como la unidad de agrupamiento musical, son una serie de variables con una estructura identificable, lo cual nos permite definirlas como patrón. Por lo tanto, son los patrones de movimiento y los patrones musicales los que se constituyen en unidades de análisis válidas, que habilitan el diseño de comparaciones y correlaciones; tal como se propuso en el capítulo 3 en relación a los modelos de expresión y comunicación musical (Leman, 2016). 
Molde, diseño, modelo, pautas, sistema, condiciones, costumbres, formato, son palabras comprometidas en la constitución de una idea más amplia del concepto patrón. El rasgo o idea común es la repetición. Larson (2012) describe tres tipos de ideas en relación a los patrones: i) Diseño o forma que puede constituirse en modelo, potencialmente repetible, ii) Cuando algo tiene una simetría o lógica interna (i.e. mandala), iii) Cuando algo se repite o tiene un comportamiento reiterado (puede estar incluso constituido por otros patrones). Larson sugiere que es la organización en patrones lo que conecta y facilita la constitución de significados, incluso llega al punto de considerar que nuestro pensamiento crea significado a partir de la posibilidad de establecer relaciones configuradas en patrones, “...nuestra mente tiene una fuerza conductora (fortalecida por la evolución, o resultado de la misma) para crear significado a través de agrupar perceptos en relaciones sistemáticas (patrones). Cuando escuchamos eventos musicales que reflejan los patrones de nuestro intelecto, emoción, imaginación o movimiento, consideramos que ese significado musical es un significado expresivo..." (Larson,2012, pp. 35-36)

El tema de los patrones nos confronta con la definición de las unidades de análisis, tema que abordaremos más adelante.

\subsection{Espacio-tiempo: Categorías de análisis}

Al estudiar el movimiento o la música desde la perspectiva espacio-temporal, se nos presenta la dificultad que implica intentar describir rasgos espaciales y temporales por separado. Esto en sí mismo es una abstracción contra intuitiva que contradice la experiencia espacio-temporal en la que estamos embebidos como seres humanos.

Si también consideramos la problemática de la representación de la información musical y de movimiento, surgen más decisiones y otros desafíos. Naveda (2011) puntualiza elementos problemáticos al momento de representar el movimiento: 
a) El movimiento generalmente se aborda desde un punto de vista espacial o temporal por separado, pero la dirección coral u orquestal, como también la danza, necesita de un link dinámico e intermodal entre los dominios del movimiento, de la música y de las descripciones lingüísticas.

b) Se concentra el foco en los descriptores de bajo nivel, es decir, se define principalmente la forma del movimiento en relación a claves de posición, velocidad y aceleración; o la música en términos de notas y posiciones temporales discretas (beats).

En acuerdo con las problemáticas señaladas, nos proponemos establecer un marco de referencia conceptual que conecte por un lado lo espacial y lo temporal, y por otro que organice el rango de descriptores desde los de bajonivel hasta los de alto-nivel, es decir, desde las descripciones de la señal física, hasta las conceptualizaciones expresivas e intencionales. En este sentido, haremos una revisión de marcos de referencia conceptual en el dominio de la música y del movimiento, para luego presentar una propuesta de conexión que dé marco a esta tesis.

\subsection{Matriz de referencias conceptuales}

Los estudios de música y movimiento que administran gran cantidad de información y variables de distintos tipos y modalidades, necesitan de un marco de referencia para organizar la interrelación de inferencias y conceptos.

La figura 4.1 reúne y compara la organización de los estratos entre los marcos de referencia conceptual de Camurri et al. (2003), diseñados a partir de objetivos de inferencia de emociones básicas en la danza; Lesaffre (2006), que estudia el desarrollo de sistemas de recopilación de información musical para conformación de bases de datos musicales; Leman (2008), cuyo objetivo epistémico es el procesamiento de la expresividad en el contexto de multimodalidad de música-movimiento; y Maes et al. (2014), que estudia la acción-percepción para la conformación de los significados musicales. 


\begin{tabular}{|c|c|c|c|}
\hline Camurii et al., 2003 & Lesaffre, 2006 & Leman, 2008 & Maes et al., 2014 \\
\hline $\begin{array}{l}\text { Conceptos y Estructuras } \\
\text { clasificación en términos de } \\
\text { emociones básicas, } \\
\text { intenciones } \\
\text { Ej. Miedo }\end{array}$ & $\begin{array}{c}\text { Alto-nivel II } \\
\text { Rasgos Expresivos } \\
\text { Ej: Afecto, experiencia }\end{array}$ & $\begin{array}{l}\text { Descripciones } \\
\text { basadas en los } \\
\text { significados }\end{array}$ & $\begin{array}{l}\text { Descripciones } \\
\text { linguisticas bipolares } \\
\text { Ej. (duro/blando } \\
\text { pesado/liviano } \\
\text { vigoroso/frágil } \\
\text { rudo/delicado) }\end{array}$ \\
\hline $\begin{array}{l}\text { Nivel-Medio - Mapas } \\
\text { Segmentación en frases y/o } \\
\text { en espacios de } \\
\text { significación } \\
\text { Ej. Cantidad de energía } \\
\text { Contorno melódico } \\
\text { Rugosidad tímbrica }\end{array}$ & $\begin{array}{c}\text { Alto-nivel I } \\
\text { Rasgos estructurales } \\
\text { Ej.Melodía } \\
\text { Medio-nivel } \\
\text { Rasgos perceptuales } \\
\text { Ej. Patrón de alturas }\end{array}$ & $\begin{array}{l}\text { Descripciones } \\
\text { basadas en la } \\
\text { trayectorias en el } \\
\text { espacio }\end{array}$ & $\begin{array}{l}\text { Categorias effort/ } \\
\text { shape Laban } \\
\text { Ej: Peso-weight } \\
\text { (liviano/pesado) }\end{array}$ \\
\hline $\begin{array}{l}\text { Bajo-nivel } \\
\text { Datos de la señal } \\
\text { procesada } \\
\text { Ej. Aceleración }\end{array}$ & $\begin{array}{c}\text { Bajo-nivel II } \\
\text { Rasgos sensoriales } \\
\text { Ej: Altura }\end{array}$ & \multirow[t]{2}{*}{$\begin{array}{c}\text { Descripciones } \\
\text { basadas en la señal } \\
\text { física }\end{array}$} & \multirow{2}{*}{$\begin{array}{l}\text { Rasgos del } \\
\text { Movimiento } \\
\text { Ej: Aceleración } \\
\text { (Alta/baja) }\end{array}$} \\
\hline $\begin{array}{c}\text { Señal física } \\
\text { Datos sin procesar } \\
\text { Ej. Posición }\end{array}$ & $\begin{array}{c}\text { Bajo-nivel I } \\
\text { Rasgos Acústicos } \\
\text { Ej: Frecuencia }\end{array}$ & & \\
\hline
\end{tabular}

Tabla 4.I: Comparación de marcos de referencia conceptual

El rasgo principal de todos estos modelos consiste en su organización por estratos o niveles, lo que habilita abordajes metodológicos abajo-arriba (bottom-up) y arriba-abajo (top-down), a través de la conexión entre descriptores acústicos, perceptuales, estructurales y expresivos. Ninguno detalla o es riguroso al momento de dar cuenta de las conexiones músicamovimiento, ni tampoco abordan el movimiento con el mismo detalle con los que, por ejemplo, Lesaffre describe los niveles y las categorías de la música. 


\subsection{Movimiento}

\subsection{I Movimiento bajo-nivel}

Describiremos ahora con más detalle y precisión los rasgos del movimiento que los de la música, dado que como la música es nuestro campo disciplinar principal, nos hemos enfrentado a la necesidad de "alfabetizarnos" en el movimiento, es decir, al modo de entender, pensar y describir este dominio.

Los primeros rasgos del movimiento, que hemos consignado en la matriz de referencia conceptual, son los de bajo nivel, que se describen por los cambios de posición que ocurren en el espacio tridimensional.

Un patrón de movimiento se describe: i) por los modos en que cambia la posición en cada una de las tres dimensiones por separado (arriba-abajo, adelante-atrás, izquierda-derecha), o ii) en simultáneo, es decir en una medida que integre las variaciones ocurridas en las tres dimensiones al mismo tiempo. La categoría de la geometría para describir esta simultaneidad de cambio es el espacio euclidiano. El estado-del-arte en la elección de la independencia o la integración de las dimensiones espaciales para el estudio del movimiento en vinculación con la música, revela una progresión desde la independencia (Wanderley, 2001; Davidson y Malloc, 2008; Palmer et al., 2009; Luck et al., 2010; Castellano et al, 2008; Demos, 2013; Walton, 2015) a la integración (Thompson y Luck, 2012; D’Ausilio et al., 2012; Glowinski et al., 2013). El acceso y el avance de la tecnología han promovido este cambio. El uso de videos, o las representaciones en papel, limitan los análisis al plano bidimensional (Damesón y Martínez, 2015, incluido en el capítulo 5 de esta tesis). La progresiva incorporación de sistemas de captura de movimiento en los estudios científicos permitió abordar las tres dimensiones en simultáneo; aunque aún se evidencia el formato de perspectiva bi-dimensional videocéntrica en los diseños metodológicos (ej: Walton, 2015). Es importante 
subrayar que el uso de videograbaciones preserva un aspecto positivo: la observación cuasi directa, que da acceso a análisis holísticos multimodales del movimiento, que proveen claves para la identificación de significados corporizados.

Derivado de los cambios de posición en el tiempo, podemos obtener otras descripciones del movimiento de bajo nivel (Camurri et al., 2003):

a) la distancia acumulada en el recorrido entre el inicio y el fin del movimiento;

b) la razón de cambio de la posición, esto es la velocidad instantánea, que se obtiene a partir de la discretización del muestreo. Es la razón de cambio de la posición momento a momento, siendo la medida de muestreo la que se configure o provea la tecnología de medición (en video en general es de 30 cuadros por segundo (fps); actualmente ya hay acceso a tasas de 60 o $100 \mathrm{fps}$, y en MoCap es posible obtener 100, 200, y hasta 1000 fps). Es importante aclarar la diferencia con la idea de sentido común que tenemos de la velocidad, ya que el idioma español no la distingue. Cuando nos referimos a la velocidad de un auto, por ejemplo, estamos describiendo la velocidad promedio entre el momento de inicio y de finalización del recorrido, es una única magnitud, el promedio de todas las velocidades momento a momento. Para estudiar el patrón de movimiento se utiliza la velocidad instantánea, que nos provee una serie temporal de magnitudes que describen el flujo y comportamiento en el tiempo de la razón de cambio de la posición. El idioma inglés tiene dos vocablos distintos para estas descripciones: velocity, para la velocidad instantánea, y speed, para la velocidad promedio;

c) la segunda medida derivada de los cambios de posición es la razón de cambio de la velocidad, que es lo que se denomina aceleración. Al igual que con b) se puede medir la aceleración instantánea y la aceleración promedio.

d) La tercer derivada es la sobreaceleración, sacudida o jerk; a partir de esta medida se pueden realizar cálculos para inferir la fluidez del movimiento. 
El movimiento también se puede describir en términos de relaciones entre parámetros de bajo-nivel, que no se relacionan directamente con los cambios de posición, a saber: i) Energía, o esfuerzo; ii) Flujo; y iii) Direccionalidad. Otras perspectivas son las morfokineticas (forma del movimiento) y las topo kinéticas (ubicación del movimiento).

Es importante considerar que estas descripciones del movimiento, de bajonivel, son variaciones de una magnitud en un vector de tiempo, del cambio de posición de un punto en el espacio; pero las más directas y cercanas a nuestro sentido común de estar en el espacio, son las categorías de medio y alto nivel. En este sentido las categorías propuestas por Laban y Lawrence (1947) resultan válidas y consistentes para las descripciones de medio nivel y permiten conectar las propiedades físicas, cuantitativas y medibles del movimiento, con las clasificaciones cualitativas en el espacio "virtual" de las intenciones (Maletic, 2005 ; Moore, 2009)

\subsubsection{Movimiento de medio-nivel}

"La experiencia de interdependencia entre las secuencias de movimiento analizadas en la dinamosfera y en la kinesfera nos demuestra que la idea convencional de que el espacio es un fenómeno que podemos separar del tiempo, de la fuerza y de la expresión, es completamente errónea” ( Laban, 1974, p67.)

El sistema de análisis de movimiento Laban (Laban y Ullmann, 1971; Laban 1974; Laban y Lawrence, 1947) ofrece un modelo riguroso para la describir funciones y expresiones del movimiento discriminado en cuatro componentes: Cuerpo, Espacio, Forma y Energía.

El componente Cuerpo se refiere las partes del cuerpo que son usadas en el movimiento. El componente Espacio da cuenta de cómo se usa el cuerpo en el espacio. El componente Forma describe los cambios constantes en la configuración formal-postural del cuerpo en el espacio, utilizando los pares lógicos elevarse-hundirse, extenderse-encogerse, avanzar y retroceder. El componente Energía se refiere a la cualidad del movimiento y cómo se administra el flujo de la energía en término de acción intencional. 
Carol-Lynne Moore (2009) llevó adelante la tarea de revisar todo el material editado y no editado de Laban, lo que le permitió describir el desarrollo de sus teorías, en su concepción y sus proyecciones. Allí describe los dos dominios paralelos que Laban define en su taxonomía de movimientos: la Coréutica y la Eukinética. La Coréutica describe las formas del movimiento en el dominio “exterior” del espacio, la morfología y la topología del movimiento, esta involucra los componentes: Cuerpo, Espacio y Forma. La Eukinética atiende a los elementos kinéticos en el dominio "interior" de las intenciones psicológicas, cómo es el movimiento en cuanto al flujo de energía; la eukinética se corresponde al componente Energía. Moore (2009) destaca el trabajo de Laban en reducir al máximo el número de categorías, dando como resultado un marco de referencia de cierta abstracción, pero que permite a su vez un enfoque descriptivo del movimiento en general y no restringido únicamente a la danza, que fue su campo disciplinar principal. La tabla 4.2 compara la perspectiva de análisis del movimiento de la coréutica y de la eukinética.

\begin{tabular}{|c|c|}
\hline \multicolumn{2}{|c|}{ Dominio de Movimiento } \\
\hline Coréutica & Eukinética \\
\hline Estudio de "lugar a lugar" & Estudio de "estado a estado" \\
\hline Donde & Dynomososfera \\
\hline Kinesfera & Psicológico \\
\hline Físico & Cuatro Factores de movimiento \\
\hline Tres dimensiones & Cualidades Bipolares \\
\hline Direcciones opuestas &
\end{tabular}

Tabla 4.2: Perspectiva de Análisis del Movimiento: Coréutica vs. Eukinética

A los fines de esta tesis, pondremos foco en el componente Energía o eukinética, que formaliza las cualidades energéticas del movimiento, aporta 
descripciones sobre cómo se despliega, y permite observar y describir actitudes corporales que revelan las intenciones de quien se mueve en respuesta a su entorno (Laban and Lawrence, 1947; Francoise, 2015; Truong et al., 2016).

Las categorías de la eukinética reflejan actitudes, intenciones, estados mentales a partir de la energía cinética de la persona en movimiento. Laban diseño dos modelos gráficos para organizar los análisis, uno para el espacio "interior" de los estados mentales, la dínamosfera; otro para el espacio “exterior", referido al espacio físico tridimensional del mundo donde nos movemos, la kinesfera. Si bien cuando Laban escribió su teoría las revisiones y críticas al paradigma cartesiano de mente-cuerpo no tenían el desarrollo actual, es importante subrayar que él no concebía la separación entre espacio interno y externo. En la kinesfera se despliega la forma del movimiento; mientras que en la dínamosfera se analizan los patrones fluctuación de la energía esos movimientos, pero esta división es artificial y se pensó únicamente a los fines prácticos del análisis. Los movimientos de "lugar a lugar" y los movimientos de "estado intencional a estado intencional" constituyen un ámbito fenomenológicamente unificado de la experiencia humana (Moore, 2009).

La eukinética se basa en la concepción de estados mentales de movimiento. Se organiza en cuatro categorías denominadas factores de movimiento: espacio, tiempo, peso y flujo. En las acciones voluntarias se discierne una fuerza dinámica que nos permite elegir entre dos actitudes polarizadas definidas por i) resistir, restringir, retener, rechazar, confrontar, y otra por ii) aceptar, permitir, flexibilizar, permanecer. Los cuatro factores de movimiento oscilan entre estas cualidades opuestas en lo que se denomina el continuum de Factores Eukinéticos. Para dar una mejor idea de las posibilidad de combinaciones entre los extremos del continuum (Tabla 4.3) se propuso descripciones utilizando gerundios (Lamb, 1965, 1978; Davies, 2001) 


\begin{tabular}{|c|c|c|c|}
\hline \multirow{2}{*}{ Factor de movimiento } & \multicolumn{2}{|c|}{ Continuum de cualidades de los Factores Eukinéticos } \\
\cline { 2 - 4 } & $\begin{array}{c}\text { Polo de actitud } \\
\text { de rechazo }\end{array}$ & $\begin{array}{c}\text { Estado de } \\
\text { balance relativo }\end{array}$ & $\begin{array}{c}\text { Polo de actitud } \\
\text { de aceptación }\end{array}$ \\
\hline Espacio & Direccionando & Foco & Desviando \\
\hline Tiempo & Acelerando & Ditmo del Paso & Decrementando \\
\hline Peso & Incrementando & El flujo es transversal a \\
los tres factores & Liberado \\
\hline
\end{tabular}

Tabla 4.3: Continuum de cualidades de los Factores Eukinéticos

Factor Espacio: Se percibe en término de la plasticidad del movimiento, son las variaciones desde la cualidad recto-dirigido y curvo-flexible, la actitud y modo de abordaje de una trayectoria.

- Rechazo: directo, trayectoria recta, sensación de estrechez. Es la atención al entorno, focalizada en un solo elemento.

- Aceptación:flexible, trayectoria ondulada, sensación de inmensidad. Es la atención a la totalidad del entorno.

Factor Tiempo: Se visibiliza en los procesos de aceleración/desaceleración, en el grado o urgencia de los mismos.

- Rechazo: súbito, rapidez, lapsos cortos, sensación de momentaneidad. Actitud interna expresada por la aceleración.

- Aceptación: sostenido, lentitud, lapsos largos, sensación de infinitud, de permanencia. Actitud interna expresada por la desaceleración.

Factor Peso: Se manifiesta y percibe en la intensidad de la fuerza-energíapresión del movimiento. 
- Rechazo: firmeza, sensación de pesadez, fuerte resistencia a la gravedad incrementando la presión usando la tensión muscular.

- Aceptación: suavidad, sensación de liviandad, baja resistencia a la gravedad disminuyendo la tensión muscular.

Factor Flujo: Se manifiesta en el movimiento como la cualidad del control muscular, en un rango que va desde movimiento controlado-obligado, confinado, a movimiento libre.

- Rechazo. confinado/limitado, sensación de interrupción/ obstaculización. Experiencia y expresión del movimiento que determina cómo es controlado en su continuidad.

- Aceptación: libre, sensación de fluidez.

A partir de los cuatro factores de movimiento, Laban construye un red de interrelaciones entre factores, describiendo combinaciones de a dos, tres y cuatro, con las cuales describe la constitución de un conjunto de acciones básicas de la eukinética (BEA). No avanzaremos en la descripción de las mismas, dado nuestro estudio utilizará como categorías los factores de movimiento.

Encontramos antecedentes del uso de los factores de movimiento en diseños metodológicos en (Gambetta, 2005; Mathers, 2008; Truong et al., 2016; Truong y Zaharia, 2017; Burton et al., 2016, Chen et al., 2011; Berstein et al., 2015, Camurri et al., 2003; Camurri et al., 2009; Glowinski et al., 2011, Samadani et al., 2013, Giraud et al., 2016; Chang et al., 2017); estos son estudios que: i) buscan caracterizar gestos en términos de las cualidades Laban y requieren el uso de técnicas de machine learning para inferir configuraciones expresivas a partir de atributos de bajo y medio-nivel; o ii) utilizan los conceptos Laban para delimitar descriptores de movimiento, a partir de las descripciones de medio-nivel con el objetivo de determinar rasgos 
y atributos de las categorías de alto-nivel, tales como emociones y estados mentales.

También hay otro grupo de estudios, con abordajes principalmente cualitativos, que utilizan las categorías de las acciones básicas de la eukinética; estos son estudios sobre el desarrollo de la infancia temprana (Español, 2008; Español y Shifres, 2015), y de aplicaciones pedagógicas del análisis de movimiento Laban para mejorar el uso de los gestos en la dirección coral (Poch, 1982; Billingham, 2009; Jordan,1986, 1996; Jordan et al., 2011).

\subsubsection{Movimiento de alto-nivel}

Se podría continuar analizando la utilización del marco teórico que aporta Laban para realizar vinculaciones con las categorías de alto-nivel en el marco de referencia conceptual. El propio Laban ensayó vincular los factores de movimiento con las funciones de la consciencia de Jung (Moore, 2005, pp. 156); los estudios del grupo SIEMPRE (Camurri y Piana, 2010-2013) elaboraron un importante corpus de estudios que vinculan los factores de movimiento con las emociones (Camurri et al., 2003; Piana et al., 2013b). En la pedagogía de la dirección musical los factores de movimiento han sido relacionados con las categorías expresivas de la música (Jordan et al., 2011; Gambetta, 2005). Asimismo los factores de movimiento se correlacionaron con conceptos y metáforas lingüísticas sobre la expresión (Maes et al., 2014).

\subsubsection{Música. Desde las categorías hacia las unidades de análisis}

En $\underline{4.4 .1}$ desarrollamos las ideas relacionadas con las categorías de análisis desde la perspectiva del movimiento con un especial detalle porque no es nuestro campo disciplinar principal, y ello implicó nuestra alfabetización en el dominio del movimiento. Ahora abordaremos las categorías de análisis desde la perspectiva musical.

Dado que la temporalidad de la música es de base discreta, las categorías de bajo-nivel son objetivables, se refieren a características acústicas y sensoriales 
del sonido, son descriptores locales no-contextuales (Lesaffre, 2006) y sus parámetros son de cuantificación directa. Las categorías de medio-nivel y altonivel referidas a características perceptuales, estructurales y/o expresivas de la música, son descriptores globales y contextuales (Lesaffre, 2006) e involucran varios parámetros, en consecuencia su cuantificación no es inmediata o directa. La tabla 4.4 detalla cómo se interrelacionan las categorías en el marco conceptual propuesto por Lesaffre.

\begin{tabular}{|c|c|c|c|c|c|c|c|c|}
\hline \multicolumn{2}{|c|}{ Estructura } & \multicolumn{2}{|c|}{ Nivel Conceptual } & \multicolumn{5}{|c|}{ Categorias Musicales } \\
\hline \multirow{6}{*}{ 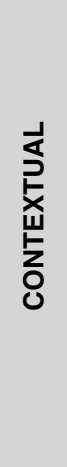 } & \multirow{6}{*}{ 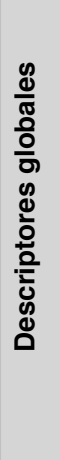 } & \multirow{2}{*}{ Alto II } & \multirow{2}{*}{ expresivo } & \multicolumn{5}{|c|}{ expresión } \\
\hline & & & & \multicolumn{5}{|c|}{ afectos / experiencia } \\
\hline & & \multirow[b]{2}{*}{ Alto I } & \multirow[b]{2}{*}{ estructural } & melodía & armonía & ritmo & fuente & dinámica \\
\hline & & & & tonalidad & $\begin{array}{c}\text { cadencia } \\
\text { tonal }\end{array}$ & $\begin{array}{l}\text { patrones } \\
\text { rítmicos }\end{array}$ & instrumento & $\begin{array}{l}\text { trayectoria } \\
\text { articulación }\end{array}$ \\
\hline & & \multirow[b]{2}{*}{ Medio } & \multirow[b]{2}{*}{ perceptual } & $x$ & $x$ & $x$ & $x$ & $x$ \\
\hline & & & & $\begin{array}{c}\text { patrones } \\
\text { interválicos }\end{array}$ & $\begin{array}{l}\text { patrones } \\
\text { armónicos }\end{array}$ & $\begin{array}{l}\text { intervalo } \\
\text { entre } \\
\text { ataques }\end{array}$ & $\begin{array}{l}\text { envolvente } \\
\text { espectral }\end{array}$ & $\begin{array}{l}\text { rango } \\
\text { dinámico }\end{array}$ \\
\hline \multirow{4}{*}{ 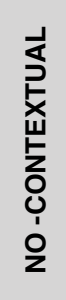 } & \multirow{4}{*}{ 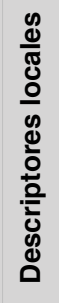 } & \multirow{2}{*}{ Bajo II } & \multirow{2}{*}{ sensorial } & \multicolumn{2}{|c|}{ altura } & tiempo & timbre & sonoridad \\
\hline & & & & \multirow{2}{*}{\multicolumn{2}{|c|}{$\begin{array}{l}\text { desviaciones de altura } \\
\text { frecuencia fundamental }\end{array}$}} & \multirow{2}{*}{$\begin{array}{l}\text { duración de } \\
\text { la nota } \\
\text { ataques }\end{array}$} & \multirow{2}{*}{$\begin{array}{l}\text { rugosidad } \\
\quad \text { flux } \\
\text { espectral } \\
\text { centroide } \\
\text { espectral }\end{array}$} & \multirow[b]{2}{*}{ energía } \\
\hline & & \multirow[t]{2}{*}{ Bajo I } & \multirow[t]{2}{*}{ acústico } & & & & & \\
\hline & & & & frec & cia & duración & espectro & intensidad \\
\hline
\end{tabular}

Tabla 4.4: Matriz de referencias conceptuales. Lesaffre (2006)

Señalamos nuevamente que nuestro el objetivo es encontrar categorías puente entre música y movimiento para diseñar análisis desde abordajes cuantitativos utilizando tecnologías de mediación.

Con el marco de referencia conceptual hemos precisado la atención en las categorías del medio-nivel. En el dominio del movimiento, encontramos que 
los factores de movimiento Laban permiten conectar las descripciones de bajo-nivel con las de medio-nivel. En el dominio de la música no hay categorías específicas para el medio-nivel; nótese la ausencia de ellas en el nivel perceptual de la tabla 4.4, para ello se hace referencia a patrones interválicos, patrones rítmicos; y podríamos agregar, perfiles de flujo de la dinámica, o perfiles de variación de timing. Las categorías elegidas para el nivel estructural tampoco aportan una taxonomía de los patrones musicales, sino que describen de manera general la perspectiva de caracterización de patrones (melodía, armonía, ritmo, dinámica).

Asumimos que la ausencia de una taxonomía específica para los patrones musicales, motiva el uso del concepto de gesto musical para describirlos. La idea de gesto musical canaliza, la necesidad de describir los aspectos expresivos y estructurales de la música, de difícil verbalización, utilizando descripciones del movimiento.

En el capítulo 2, se presentaron ontologías en relación a la definición de gesto en general. Ahora revisaremos los estudios de gesto musical con el objetivo de encontrar categorías gestuales que puedan utilizarse como puente conceptual de medio-nivel entre el dominio de la música y el del movimiento. En la revisión sobre gestos musicales de Jensenius et al.(2010), el principal organizador de categorías que emerge es la función gestual; principalmente desde la perspectiva del ejecutante de un instrumento musical y, en algunos casos, desde el bailarín. Las funciones de los gestos musicales recopiladas son: i) gestos de producción de sonido (Delalande, 1988; Cadoz y Wanderley, 2000); ii) gestos facilitadores de la producción del sonido (Cadoz y Wanderley, 2000); iii) gestos de acompañamiento del sonido, auxiliares (Delalande, 1988; Cadoz y Wanderley, 2000); y iv) gestos comunicativos (Kendon, 1980; Mc Neill, 1992, 2005). Cabe aclarar que en esta revisión, la función comunicativa se restringe a los gestos que acompañan el habla, sin presentar referencia a cómo interpretarlos en el contexto de una performance musical. Por último se presentan los gestos metafóricos, donde se incluyen: i) gestos expresivos (Camurri et al., 2001) que transfieren información sobre las 
emociones; ii) gestos figurativos (Delalande, 1988) que comunican una "imagen" mental (nosotros interpretamos: estado mental o intención); y iii) gesto musical (Hatten, 2004, 2006) que se refiere al modelado energético del sonido en el tiempo para ser significativamente interpretado.

Es evidente la ausencia de categorías para la configuración estructural o perceptual de los gestos musicales, del mismo modo que advertimos al analizar la taxonomía de Lesaffre. La perspectiva de Hatten es la que más se sintoniza con nuestra búsqueda. Al profundizar en sus escritos, encontramos categorizaciones funcionales de los gestos: dialógicos, retóricos y tropológicos. El autor señala cuatro aspectos fundamentales para constituir un gesto, que encontramos muy adecuados para la perspectiva de esta tesis: i) Identidad Gestáltica; la interpretamos como la coherencia necesaria para configurar un segmento de movimiento, como unidad de análisis. Es decir que pensar un gesto implica su discretización dentro del continuo del movimiento. ii) Continuidad: este aspecto subraya la posibilidad que provee el pensar en gestos musicales para poder “...establecer un puente entre la discretitud de eventos acústicos aislados, con la coherencia, los matices y la consistencia necesarias para describir en simultaneidad parámetros potencialmente muy variables..." (Hatten, 2004, pp. 233). iii) Carácter cualitativo: corresponde a cómo está modulada la energía del gesto; y iv) Agencia: la energía modulada de (iii) comparte los rasgos de configuración del movimiento humano, que expresa estados mentales, intenciones, emociones; y es esto lo que nos conduce a otorgar agencialidad a los gestos musicales.

En referencia a las búsqueda de esta tesis; nos interesa el aspecto cualitativo (iii) de Hatten para contextualizar metodológicamente en el marco del alineamiento expresivo (Leman, 2016) en su segunda modalidad. En 3.1.2 se presentó el alineamiento expresivo, pero no detallamos sus dos perspectivas metodológicas: i) el Alineamiento con marcadores temporales discretos (i.e.. Beats) con la teoría del entrainment como marco de referencia; que da cuenta de cómo se organiza la sincronización, caracterizada por puntos temporales discretos; y ii) el Alineamiento con el flujo del ritmo propiamente dicho (lo 
que pasa entre los beats o entre las marcas discretas elegidas para el análisis); donde se establecen unas correspondencias continuas entre el alineamiento de la fluidez del movimiento del cuerpo y el del discurso musical. El foco de esta segunda modalidad reside en las correspondencias de los patrones que ocurren entre los puntos temporales discretos y se rige por procesos energéticos, afectivos e intencionales.

\subsection{Categorías puente}

Como ya señalamos, Hatten tampoco propuso categorías para el aspecto cualitativo del gesto musical (iii). Consideramos que es en este intento de describir el modo en que se configura la energía desplegada en el tiempo, cuando aparece la necesidad de establecer puentes categoriales interdominios (movimiento-música). En general los conceptos utilizados en estos puentes son categorías de alto-nivel, por ejemplo: amable/vigoroso; nervioso/ tranquilo; lírico/heroico (Maes et al., 2014); hay trabajos que las vinculan con las categorías de la formas de la vitalidad de Stern (2010) (Ej. Precipitado, Vacilante, Inestable, Calmo) (Martínez y Pereira Ghiena, 2015; Martinez, Damesón et al., 2015); y trabajos que adoptan las categorías de las acciones básicas de la eukinética (Español, 2008; Español y Shifres, 2015; Poch, 1982; Billingham, 2009; Jordan 1986,1996; Jordan et al., 2011; Camurri et al, 2003, Piana et al., 2013).

La perspectiva expresiva del gesto musical o del alineamiento expresivo de patrones musicales, aborda preferentemente la descripción de cómo se desenvuelve la energía en el tiempo. En el marco de la teoría de análisis de movimiento Laban, se corresponde a las descripciones de "estado a estado", es decir a las cualidades "internas" del flujo del movimiento, organizadas en las categorías de la eukinética.

\subsection{Matriz de referencias conceptuales movimiento-música}




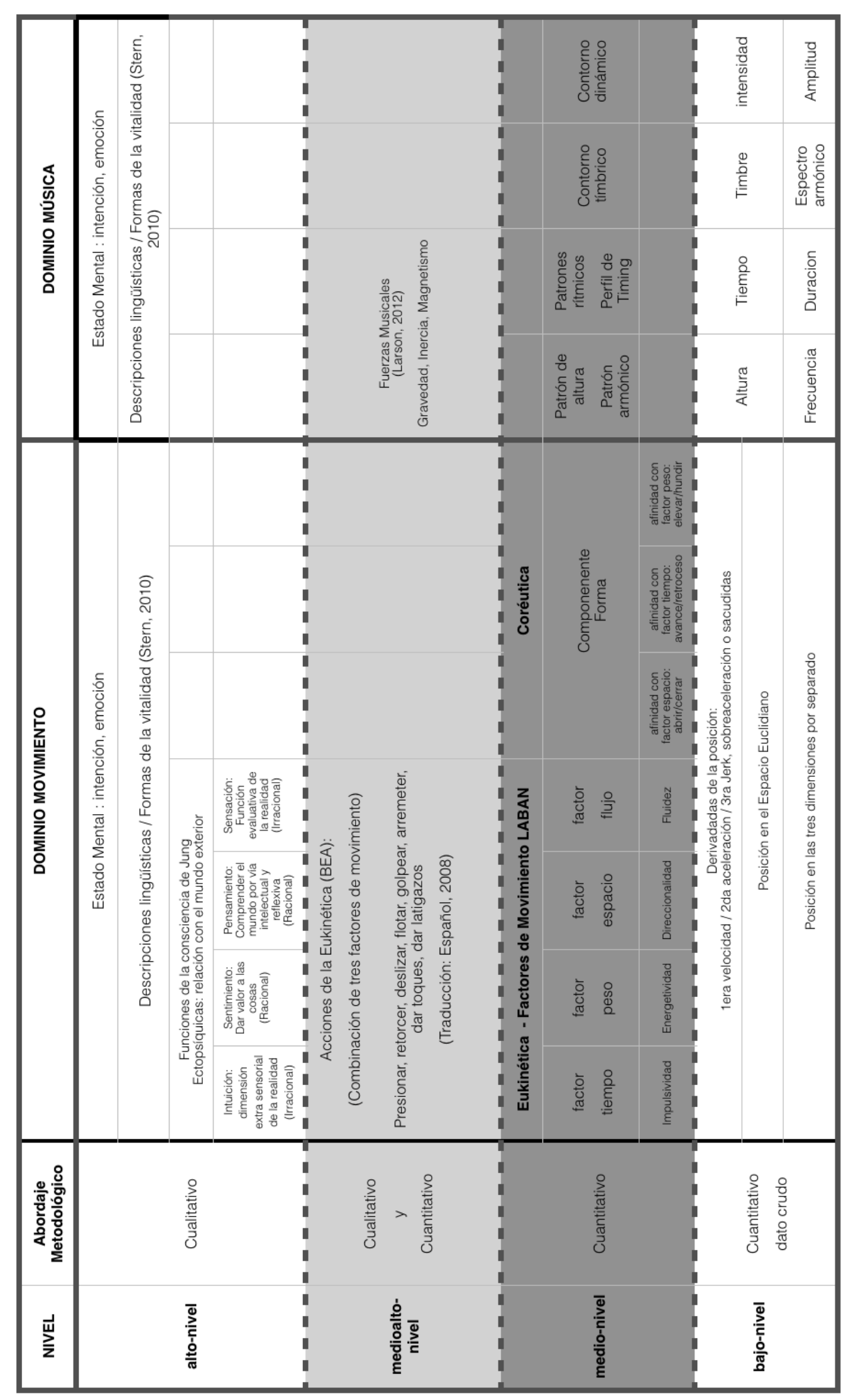

Tabla 4.5: Matriz de referencias conceptuales movimiento-música 
En la tabla 4.5 presentamos una propuesta de vinculación entre las categorías de música y movimiento descritas.

La organización de las categorías en la matriz de referencias propone una lectura de abajo hacia arriba. Cuanto más alto es el nivel al que corresponde la categoría, mas baja es la posibilidad de objetivarla o generalizarla, dado que esta empieza a conjugarse con componentes y variables culturales. Esto se refleja en la elección entre abordajes metodológicos cuantitativos y cualitativos.

Los marcos teóricos de las categorías de medio-alto y alto-nivel, no son objeto de análisis de esta tesis, se incluyen en la tabla para ponderar el alcance de esta matriz de referencias en vista a posibles vinculaciones entre descriptores bajo-nivel y significados musicales.

Los estudios propuestos en este trabajo se encuadran en el medio-nivel, entendemos que utilizar categorías del mismo nivel de referencia, le otorga solidez epistemológica a los análisis.

\subsection{Unidades de análisis}

El encuadre en el medio-nivel nos confronta a delimitar el alcance de patrón musical como unidad de análisis. Estar en un entorno sonoro nos embebe en una temporalidad definida por la música, por lo tanto será coherente realizar la segmentación temporal en base a los criterios musicológicos tradicionales: estructura métrica, frases, periodos, motivos melódicos, beat u otros; la "nota" como unidad, queda fuera de las opciones, ya que en sí misma no constituye un patrón. Se considera un mínimo de dos notas para que una unidad se configure como patrón (Larson, 2012; Hatten, 2004).

A partir de la revisión de categorías y unidades de análisis en estudios de música y movimiento e interacción esquematizada en las tablas 4.6 y 4.7, inferimos: i) Que la elección de la variable de movimiento es de bajo-nivel en la totalidad de los estudios revisados; ii) Que el abordaje de la interacción en 
los estudios intersubjetivos se propone desde un solo dominio: o bien desde el del movimiento (D’Ausilio, 2012; Glowinski et al., 2013; Walton, 2015; Chang et al., 2017) o bien desde el de la música (Aucouturier, 2017).

No encontramos trabajos que correlacionan variables de música y movimiento de bajo-nivel en contextos de interacción. En Martínez, Dameson et al. (2017) proponemos una alternativa metodológica para analizar en simultáneo la confluencia música-movimiento; iii) Que la unidad de análisis en los estudios de interacción tiende a ser la más abarcativa: la obra entera o las unidades de frase más largas. En el último trabajo citado se buscó una alternativa que permita evaluar el flujo continuo de intercambio de información en términos de liderazgo, a partir de una derivación del estudio de la Causalidad Granger; iv) Que en contrapartida, la unidad de análisis de los trabajos que estudian un sujeto a la vez, tiende a ser la más pequeña: la nota musical, el beat o el compás. Entendemos que esta diferencia radica en que el patrón como unidad de análisis, tiene una organización temporal por estratos (motivos, semifrase, frase). La interacción emerge en los patrones expresivos, y en el devenir interactivo el alineamiento expresivo se puede enactuar en una sucesión de distintas unidades temporales. Metodológicamente es más consistente/fácil optar por los estratos más inclusivos, es decir, por la obra entera.

En base a las problemáticas analizadas en este capítulo aspiramos a diseñar estudios empíricos que realicen aportes en relación a: i) La integración de los tres ejes, en particular, la incidencia del eje sagital, para estudiar el despliegue de movimientos expresivos en el contexto de la performance coral. ii) La utilización de categorías de movimiento de medio-nivel -los factores de movimiento Laban-, para correlacionar con patrones musicales y describirlos en término de energía expresada; iii) vincular la energía musical expresada con la actividad de intercambios intersubjetivos que se pueden inferir de una variable de movimiento, en búsqueda de evidencia empírica en relación al estudio la expresión musical desde la perspectiva de segunda persona. 


\begin{tabular}{|c|c|c|c|c|}
\hline Autores & Instrumento & $\begin{array}{c}\text { Categorías de análisis } \\
\text { Movimiento }\end{array}$ & $\begin{array}{l}\text { Categorías de } \\
\text { análisis música }\end{array}$ & $\begin{array}{l}\text { Unidad de } \\
\text { análisis } \\
\text { musica }\end{array}$ \\
\hline \multicolumn{5}{|c|}{ Intrasubjetivos } \\
\hline $\begin{array}{c}\text { Palmer } \\
\text { Wanderley } \\
\text { et al. } 2009\end{array}$ & Clarinete & $\begin{array}{l}\text { Media de elevación } \\
\text { (grado de rotación entre } \\
\text { el marcador de la } \\
\text { campana y el de la } \\
\text { embocadura) }\end{array}$ & $\begin{array}{l}\text { - Media de } \\
\text { desvío timing } \\
\text { - Intensidad }\end{array}$ & $\begin{array}{c}\text { Onset de cada } \\
\text { nota }\end{array}$ \\
\hline $\begin{array}{l}\text { Wanderley } \\
2001\end{array}$ & Clarinete & $\begin{array}{c}\text { Posición de la campana } \\
\text { en milímetros } \\
3 \text { ejes } \times \text { separado } \\
\text { (arriba /abajo el principal) }\end{array}$ & $\begin{array}{l}\text { - Nota } \\
\text { musical }\end{array}$ & $\begin{array}{c}\text { Onset de nota } \\
+ \\
+ \\
\text { Time Warping }\end{array}$ \\
\hline $\begin{array}{l}\text { Thompson } \\
\text { y Luck } 2012\end{array}$ & Piano & $\begin{array}{c}\text { Cantidad de } \\
\text { desplazamiento = } \\
\text { Distancia total } \\
\text { velocidad total y } \\
\text { aceleración total }\end{array}$ & $\begin{array}{l}\text { Duración del } \\
\text { compás }\end{array}$ & $\begin{array}{c}\text { Compás } \\
\text { con time- } \\
\text { warping } \\
\text { no lineal }\end{array}$ \\
\hline $\begin{array}{l}\text { Castellano et } \\
\text { al } 2008\end{array}$ & Piano & $\begin{array}{c}\text { Velocidad de la cabeza } \\
\text { en dos ejes } \\
\text { QoM - Cantidad de } \\
\text { Movimiento }\end{array}$ & $\begin{array}{l}\text { Condiciones } \\
\text { expresivas }\end{array}$ & $\begin{array}{l}\text { segmentacion } \\
\text { de "gestos" } \\
\text { evaluados } x \\
\text { músico } \\
\text { experto }\end{array}$ \\
\hline Demos 2013 & Trombón & $\begin{array}{l}\text { balanceos } \\
\text { izquierda-derecha y } \\
\text { adelante-atrás }\end{array}$ & $\begin{array}{l}\text { - Timing } \\
\text { - Claves de } \\
\text { Intensidad }\end{array}$ & Beat \\
\hline
\end{tabular}

Tabla 4.6: Resumen categorías de análisis y unidades de análisis utilizados en estudios de performance musical expresiva 


\begin{tabular}{|c|c|c|c|c|c|}
\hline Autores & Instrumento & $\begin{array}{l}\text { Categoría de } \\
\text { análisis } \\
\text { Movimiento }\end{array}$ & $\begin{array}{l}\text { Categoría } \\
\text { de análisis } \\
\text { música }\end{array}$ & $\begin{array}{l}\text { Unidad de } \\
\text { análisis } \\
\text { musica }\end{array}$ & $\begin{array}{c}\text { Categoría } \\
\text { interacción }\end{array}$ \\
\hline \multicolumn{6}{|c|}{ Intersubjetivos } \\
\hline $\begin{array}{l}\text { Davidson } \\
\text { y Malloc } \\
2008\end{array}$ & $\begin{array}{c}\text { Clarinete y } \\
\text { Flauta }\end{array}$ & $\begin{array}{l}\text { Posición en } \\
\text { eje vertical }\end{array}$ & & $\begin{array}{l}\text { Segmentos } \\
\text { de frase }\end{array}$ & No usan \\
\hline $\begin{array}{l}\text { D Ausilio } \\
\text { et al. } 2012\end{array}$ & $\begin{array}{l}\text { Director } \\
\text { y Octeto de } \\
\text { violines }\end{array}$ & Aceleración & & Toda la obra & $\begin{array}{c}\text { Causalidad } \\
\text { Granger }\end{array}$ \\
\hline $\begin{array}{l}\text { Glowinski } \\
\text { et al. } 2013\end{array}$ & $\begin{array}{l}\text { Cuarteto de } \\
\text { cuerdas }\end{array}$ & $\begin{array}{l}\text { Vector entre } \\
\text { cabezas } \\
\text { Centro del } \\
\text { polígono }\end{array}$ & & Toda la obra & Entropía \\
\hline $\begin{array}{l}\text { Glowinski } \\
\text { et al. } \\
2013 b\end{array}$ & $\begin{array}{l}\text { Cuarteto de } \\
\text { cuerdas }\end{array}$ & $\begin{array}{l}\text { Distancia en el } \\
\text { espacio } \\
\text { euclidiano } \\
\text { de la cabeza al } \\
\text { centro del } \\
\text { Cuarteto }\end{array}$ & & $\begin{array}{l}\text { Segmento } \\
\text { de frase }\end{array}$ & Entropía \\
\hline $\begin{array}{l}\text { Walton } \\
2015\end{array}$ & Dúo pianistas & $\begin{array}{l}\text { cabeza y } \\
\text { eje vertical } \\
\text { mano derecha } \\
\text { eje lateral. }\end{array}$ & & $\begin{array}{c}\text { toda la } \\
\text { improvisación }\end{array}$ & $\begin{array}{l}\text { recurrencia } \\
\text { de las } \\
\text { mismas } \\
\text { alturas }\end{array}$ \\
\hline $\begin{array}{c}\text { Aucoturier, } \\
2017\end{array}$ & Dúos varios & & $\begin{array}{l}\text { Intensidad } \\
\quad \text { (RMS) }\end{array}$ & Toda la obra & $\begin{array}{c}\text { Causalidad } \\
\text { Granger }\end{array}$ \\
\hline $\begin{array}{l}\text { Chang et } \\
\text { al. } 2017\end{array}$ & $\begin{array}{l}\text { Cuarteto } \\
\text { Cuerdas }\end{array}$ & $\begin{array}{c}\text { Posición cabeza } \\
\text { en dos } \\
\text { dimensiones } \\
\text { adelante/atrás, } \\
\text { izq./der. }\end{array}$ & & Toda la obra & $\begin{array}{c}\text { Causalidad } \\
\text { Granger }\end{array}$ \\
\hline $\begin{array}{l}\text { Martínez } \\
\text { Damesón } \\
\text { et al. } \\
2017\end{array}$ & $\begin{array}{l}\text { Dúo de } \\
\text { Saxos + } \\
\text { Pianista }\end{array}$ & $\begin{array}{c}\text { Desplazamiento } \\
\text { en el espacio } \\
\text { euclidiano }\end{array}$ & $\begin{array}{l}\text { Intensidad } \\
\quad \text { (RMS) } \\
\text { Perfil de } \\
\text { variación } \\
\text { continua de } \\
\text { frecuencia }\end{array}$ & $\begin{array}{l}\text { Segmento de } \\
\text { frase ( } 8 \\
\text { compases) }\end{array}$ & $\begin{array}{l}\text { Sense } \\
\text { Granger } \\
\text { Flujo de } \\
\text { Causalidad } \\
\text { Granger }\end{array}$ \\
\hline
\end{tabular}

Tabla 4.7: Resumen categorías de análisis y unidades de análisis utilizados en estudios de interacción en la performance musical. 


\section{Parte II- Estudios}




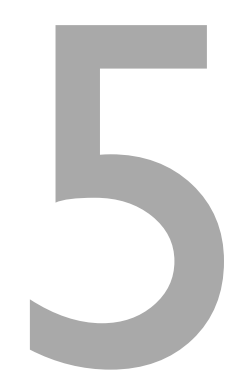

\section{Estudio I - Dirección en 3D: la dimensión oculta del significado}

Publicado en actas del XII Encuentro de Ciencias Cognitivas de la Música (Buenos Aires, 2015)

\section{I Introducción}

El estudio del movimiento y el significado en el marco de las ciencias cognitivas de segunda generación revela múltiples ontologías del gesto a saber: i) la unidad experiencial gesto-habla (McNeill, 2012); ii) el gesto como mediador entre cuerpo y significado (Leman, 2008); iii) el gesto como signo interpretante cinético (López Cano, 2014); y iv) el gesto como significado metafórico de base imagen-esquemática (Martínez, 2014; Larson, 2012). En este trabajo se realiza un experimento para estudiar la significación emergente del entonamiento (Malloch y Trevarthen, 2008) entre el movimiento corporal que organiza la géstica de dirección y la música, desde una perspectiva ontológica multidimensional del gesto.

\subsubsection{Revisión de la literatura}

\subsubsection{Abordaje Pedagógicos}

El problema de la definición de los componentes expresivos de los gestos del director es reconocido (Berlioz,1882; Garnett, 2009; Watson, 2012; Hanna Weir, 2013). Aunque no existen desarrollos técnicos y/o metodológicos para describirlos. 
La tradición y los libros de pedagogía sobre dirección indican que el rol de marcación del tiempo se debe realizar con el uso de la mano derecha, mientras que la mano izquierda tiene eventuales participaciones en vinculación a la expresión. A diferencia de las pautas detalladas para la marcación temporal, los autores no definen estrategias y técnicas para el entrenamiento de la modulación expresiva, quedando esta tarea librada al plano de la intuición del director. La comunicación de la dimensión expresiva va más allá del nivel básico de la marcación de esquemas temporales y su análisis emerge como una tarea problemática.

Asimismo, las representaciones gráficas que se encuentran en los libros para la comunicación y enseñanza de estos esquemas de dirección, despliegan la representación de los movimientos únicamente en las orientaciones arribaabajo e izquierda-derecha, es decir en dos dimensiones; quedando de esta manera invisibilizada la orientación adelante-atrás. Pero es conocimiento aceptado e informado en la práctica de dirección, que los movimientos corporales en el plano transversal, es decir en el eje antero-posterior (Drake, R. et al. (2015) se utilizan organizan el despliegue de significados expresivos.

\subsubsection{Abordaje Científico}

Del mismo modo en los abordajes científicos que estudian el movimiento en relación a la expresión en la dirección, encontramos un desprecio por los análisis de la profundidad del movimiento, es decir aquellos realizados en el eje antero-posterior.

En Luck et al. (2010) encontramos uno de los principales antecedentes para el abordaje del estudio de la expresión de los gestos de director utilizando técnicas de captura de movimiento. El objetivo principal de este trabajo fue investigar las relaciones entre las características cinemáticas de los gestos de director y la expresión percibida. En ninguna de las once categorías de análisis cinemáticas extraídas de los datos del movimiento de los directores se 
consideraron los movimientos en el eje antero-posterior como variable de análisis. La justificación para ello fue el hecho que los participantes realizaron juicios a partir de la observación de animaciones digitales de los vectores entre los marcadores colocados a los directores para las capturas MoCap, proyectadas en una pantalla.

Esta decisión condujo a excluir el eje $z$ (profundidad) de los cálculos de velocidad y aceleración. Estos cálculos no se realizaron a partir de las tres dimensiones del espacio euclidiano, sino considerando únicamente los ejes $x \mathrm{e}$ $y$. Esta decisión implica un importante supuesto: la energía y los movimientos desplegados en el eje antero-posterior, no son relevantes en relación a la modulación expresiva del movimiento.

\subsection{Objetivos}

Este trabajo pretende: i. Detectar, describir y aislar desviaciones/modulaciones desplegadas en el eje antero-posterior, de los movimientos comprendidos en la realización de los esquemas de dirección. ii. Buscar vinculaciones entre el modelado del movimiento del esquema de dirección y los componentes dinámico-expresivos del estímulo musical. iii. Afirmar la necesidad de incluir las tres dimensiones en el estudio de la expresión de los gestos de dirección.

\subsection{Hipótesis}

A partir del análisis de la trayectoria de los movimientos del director se observarán desplazamientos en el eje antero-posterior, en particular en aquellos momentos en los que se busque comunicar un énfasis en el discurso musical.

\subsection{Métodos}

Participante: Hombre, 55 años, director de coro en actividad, con formación académica en dirección orquestal en la Universidad de La Plata, docente de Dirección Coral. 
Estímulo: Ave Verum K618, de W.A. Mozart, selección de fragmento para el análisis entre los compases 3 a 18. Se utilizó únicamente la línea de soprano para simplificar los análisis de la señal de audio.

Aparatos: El movimiento fue grabado usando un sistema de captura de movimiento, Optitrack, compuesto por 12 cámaras infrarrojas modelo flex $3, \mathrm{y}$ el software Motive como sistema de control desde una computadora con entorno windows. Asimismo se realizaron capturas de audio en mono a $44.1 \mathrm{khz}$ y de video a $60 \mathrm{fps}$.

\subsubsection{Diseño y Procedimiento}

El participante llevó adelante dos tareas: una tarea de control consistente en cantar el estímulo y auto dirigirse (A); y otra tarea de dirección a dos cantantes (B) organizada en dos fases, i) Ensayo (15 min.) y ii) Performance (1 min.).

La primer estrategia de análisis fue de tipo global. El objetivo fue visualizar la relevancia de cada dimensión en las configuraciones morfológicas del esquema de dirección. Para esto se utilizó el cálculo de la desviación estándar de las posiciones de los marcadores en cada eje $(x, y, z)$ por separado. Los marcadores considerados fueron: mano izquierda, cabeza, y mano derecha. La medida estadística utilizada para los análisis fue la desviación estándar: la misma provee información sobre la extensión del área cubierta por el movimiento a partir de las series de datos temporales (Burger et al., 2013). Los cálculos se realizaron con ayuda de los algoritmos programados en el MoCap Toolbox para entorno MatLab (Burger $y$ Toiviainen, 2013).

Para decidir el tamaño de las unidades de análisis, en una instancia previa a la toma de datos, se le pidió al participante que consignara el criterio de segmentación formal que adoptaría. Segundo, en el marco de los modelos de las fuerzas musicales (Larson, 2012) y acentos estructurales (Lerdahl y Jackendoff, 1983), se buscaron los momentos de gravitación hacia zonas melódico-armónicas dentro de las unidades de análisis, para predecir 
momentos de énfasis en el discurso musical y buscar vinculaciones con la extensión de los movimientos en el eje antero-posterior. En base a esta información, se decidió la segmentación del estímulo musical en unidades de análisis de dos compases.

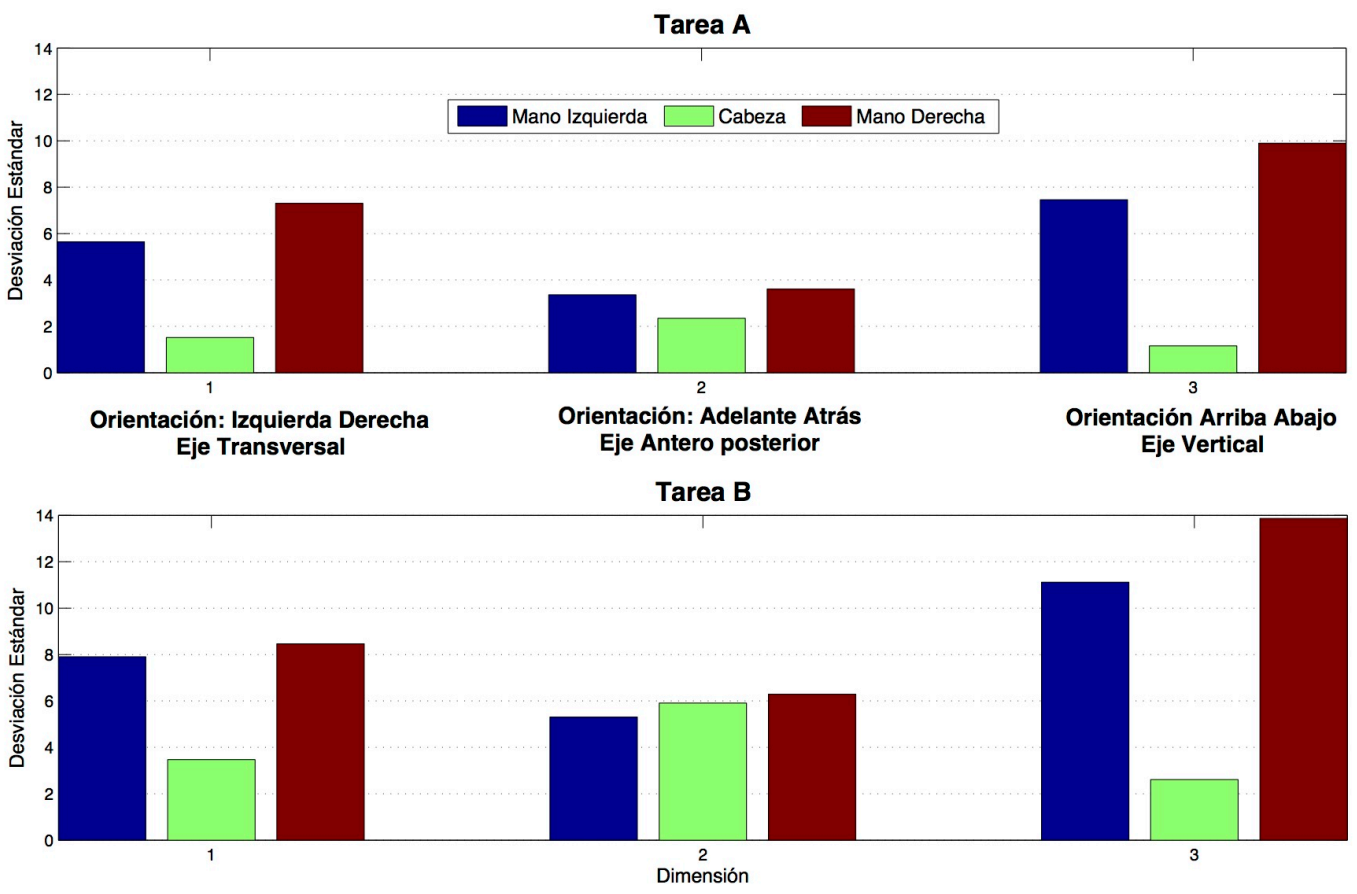

Figura 5. I: Desviación Estándar de cada dimensión. Comparativa entre tarea A y B. Marcadores de las manos y la cabeza.

La segunda estrategia comprendió el análisis de correlatos entre: $i$. La desviación estándar de los marcadores antes señalados en el eje anteroposterior; ii. El índice de contracción/expansión entre las manos, a partir de la función mcmarkerdist del MoCap toolbox; y iii. La envolvente dinámica de la performance del estímulo, utilizando la función mirenvelope del mir toolbox (Lartillot et al., 2008) filtrada para simplificar la visualización. 
Esta segunda estrategia tuvo dos instancias, una de análisis y visualización de los datos en su totalidad, y otra de abordaje de las unidades de segmentación en detalle.

\subsection{Resultados}

\subsection{Extensión de los movimientos en el espacio tridimensional}

La lectura de los datos en la figura 5.1 evidencia una mayor extensión del área cubierta por el movimiento en la tarea intersubjetiva (B), contrastando con la tarea de auto-dirección (A).

La dimensión con valores más altos en ambas tareas es la que organiza los movimientos en el eje vertical. Esto probablemente corresponde a la morfología del esquema de dirección, que plantea recorridos mayores hacia arriba en cada levare. Pero si comparamos los porcentajes de variación entre las tareas (figura 2), la dimensión con mayor índice de variación es la del eje antero-posterior. Esto podría sugerir que los movimientos involucrados en la tarea de comunicación intersubjetiva (B), y en especial la comunicación de componentes dinámico expresivos, se despliegan en esta dimensión.

Del mismo modo si nos guiamos por los métodos tradicionales de la pedagogía en dirección, donde se propone como principal eje de variación para la mano izquierda el eje vertical, encontramos nuevamente que el eje que presenta mayor variabilidad entre la tarea A y B es el antero-posterior; siempre bajo el supuesto que una de las principales diferencias entre las tareas propuestas es la comunicación de componentes expresivos del discurso musical. Un dato inesperado es la variación del marcador de cabeza, que es el que mayor incremento tuvo en todas las dimensiones.

\subsubsection{Comparativa por segmentos}

En búsqueda de un mayor detalle acerca del modo en que se administró el uso de la modulación de los movimientos del esquema de dirección a lo largo del 
estímulo, se presenta el gráfico de la figura 5.3. En ella podemos observar los datos del uso del eje antero-posterior para cada uno de los ocho segmentos de análisis, agrupados por cada marcador (mano izquierda, cabeza y mano derecha). A partir del análisis del énfasis musical descrito en el apartado diseño y procedimiento, se predijo una mayor actividad en el segmento 7, correspondiente al texto "in cruce...". En la tarea A se observa coincidencia para este incremento, principalmente en las manos. Sin embargo, dos casos sugieren correlatos con otros componentes, la mano izquierda en el segmento B6, y la cabeza en el segmento B3.

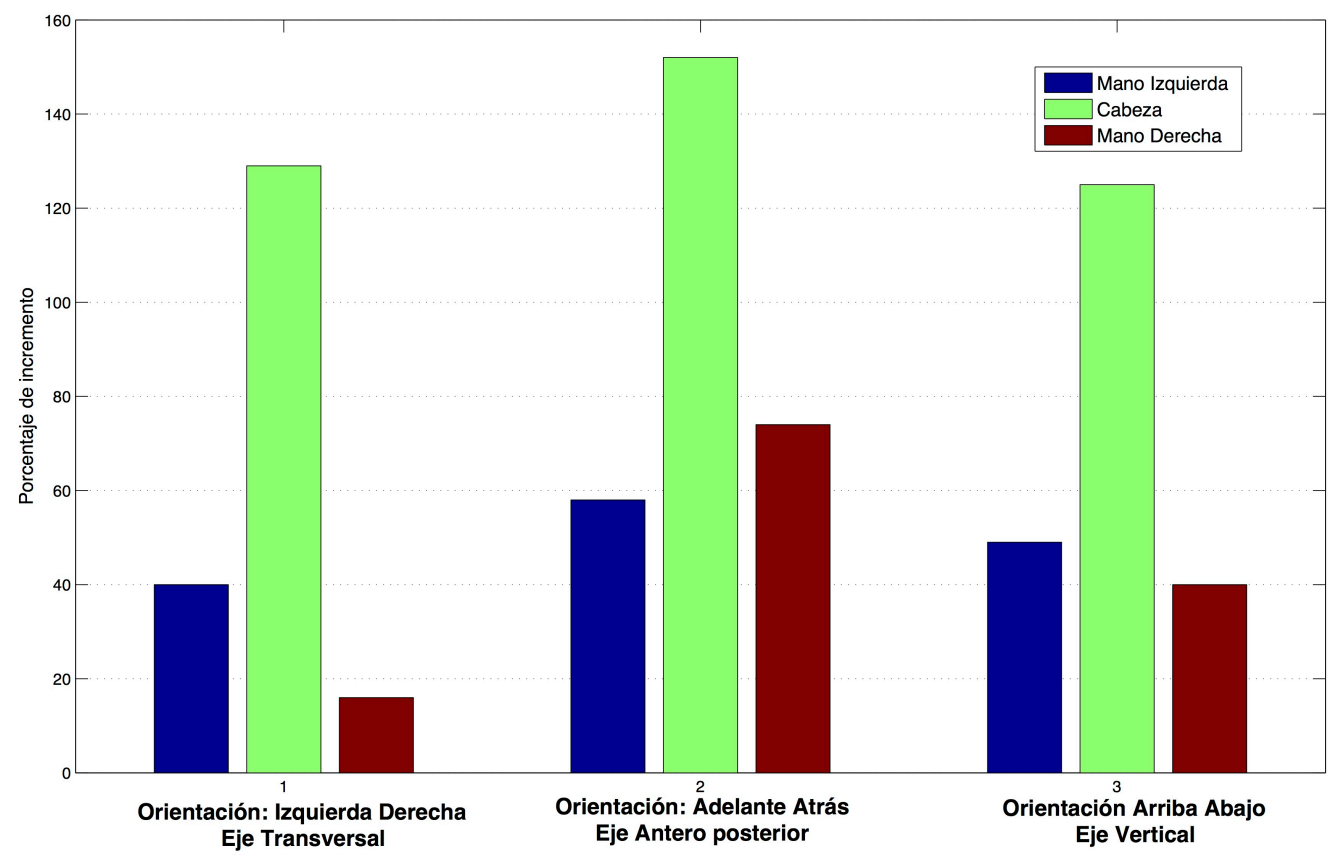

Figura 5.2: Porcentaje de incremento entre tarea de la desviación estándar en cada dimensión espacial. Comparativa entre tarea A y B. Marcadores de las manos y la cabeza.

Se incorporó el análisis de la envolvente dinámica de la señal de audio para establecer nuevos correlatos. En la figura 5.4 vemos los perfiles de la envolvente comparando la tarea A y B. Y señalamos en particular en la tarea A, cuando canta el director, un mayor énfasis dinámico en el segmento 6. Sin 
embargo en la tarea B, a cargo de los cantantes, los mayores valores dinámicos están presentes en el segmento 7. Esto nos sugiere una posible respuesta a los valores más altos en la mano izquierda, señalados en el gráfico anterior

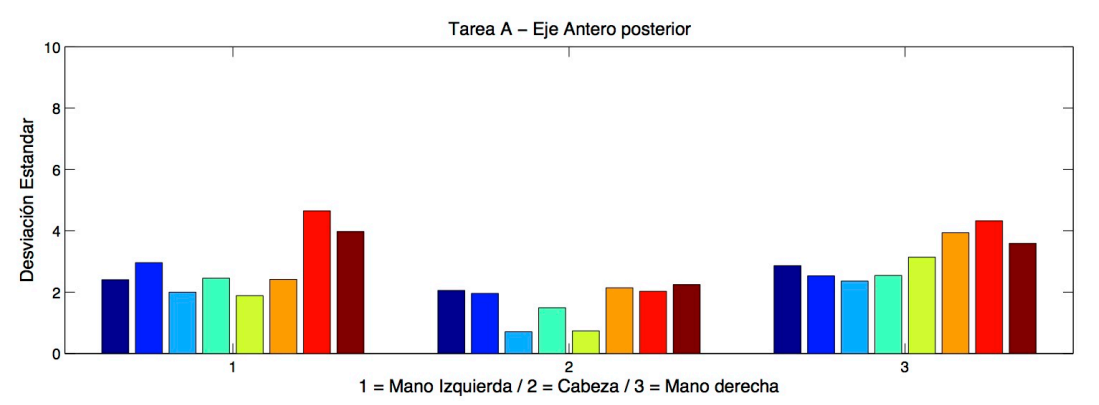

Segmentos

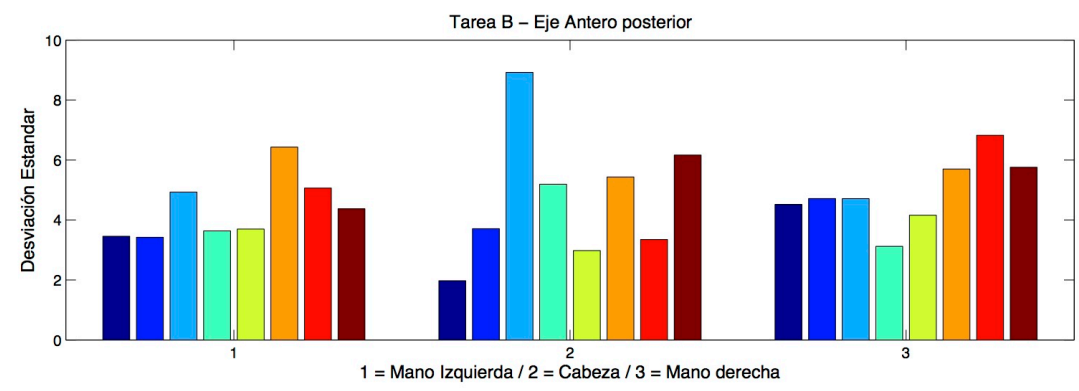

1 Ave, Ave

2 verum Corpus

3 Natum de Maria

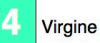

Virgine

5 Vere Passum

6 Inmolatum

7 In cruce

8 Pro Homine

Figura 5.3: Desviación Estándar en el eje antero-posterior. Marcadores de las manos y la cabeza. Comparación entre tarea $A$ y $B \times$ segmentos

(Figura 5.3, segmento B6). La tarea de auto-dirección evidencia una intención interpretativa de mayor énfasis para el segmento 6 que, al no ser entonada por los cantantes, provoca un mayor despliegue de movimientos en la mano izquierda del director; y este énfasis es interpretado por los cantantes en el segmento siguiente (B7) como se aprecia en el perfil de la envolvente dinámica.

\subsubsection{Micro análisis (Segmento B6)}

En este segmento encontramos dos ejemplos del despliegue de movimientos en el eje antero-posterior con una clara intención de énfasis dinámico. 
El primero sucede en relación al Sol\# (silaba "in" del texto). En el gráfico de la figura 5 podemos observar el recorrido hacia adelante que fue realizado con la mano izquierda, conduciendo un crescendo sobre el desarrollo del Sol\#.

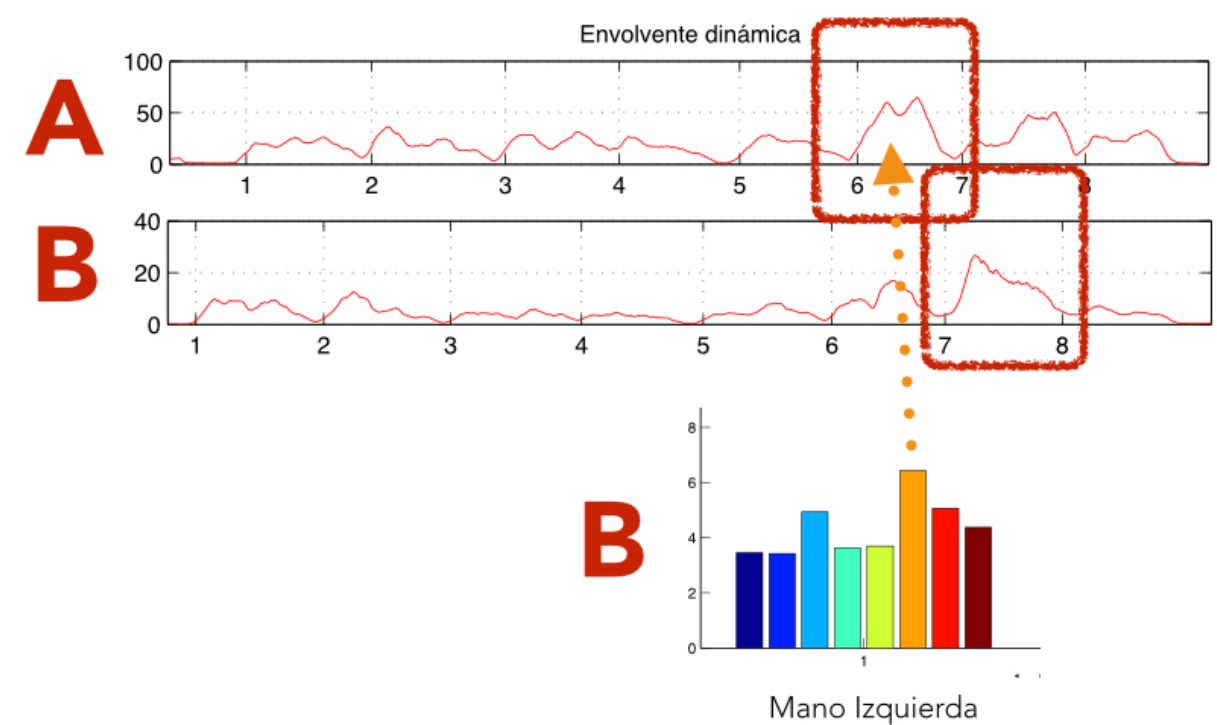

Figura 5.4: Envolvente dinámica de la señal de audio de la tarea A y B. Segmentos señalados A6 y B7. Desviación estándar de la mano izquierda en la tarea B. Vinculación entre segmentos B6 y A6.

El segundo ejemplo se configura en relación al segundo $\mathrm{Si}$ (sílaba "la" del texto); que desde una perspectiva armónica está funcionando como apoyatura de la nota $L a$. En este caso se aprecia un doble énfasis hacia adelante de ambas manos en sincronía, reforzado por el avance de la cabeza. Este segundo ejemplo nos sugiere un compromiso global del cuerpo en búsqueda del énfasis musical. La figura 5.5 incluye los datos de un indicador tradicional (Luck et al., 2010) del modelado dinámico: la distancia entre las manos. En este ejemplo podemos comprobar el incremento de la expansión entre la manos en acuerdo con los movimientos hacia adelante en el eje antero-posterior, reforzando la comunicación de énfasis. 

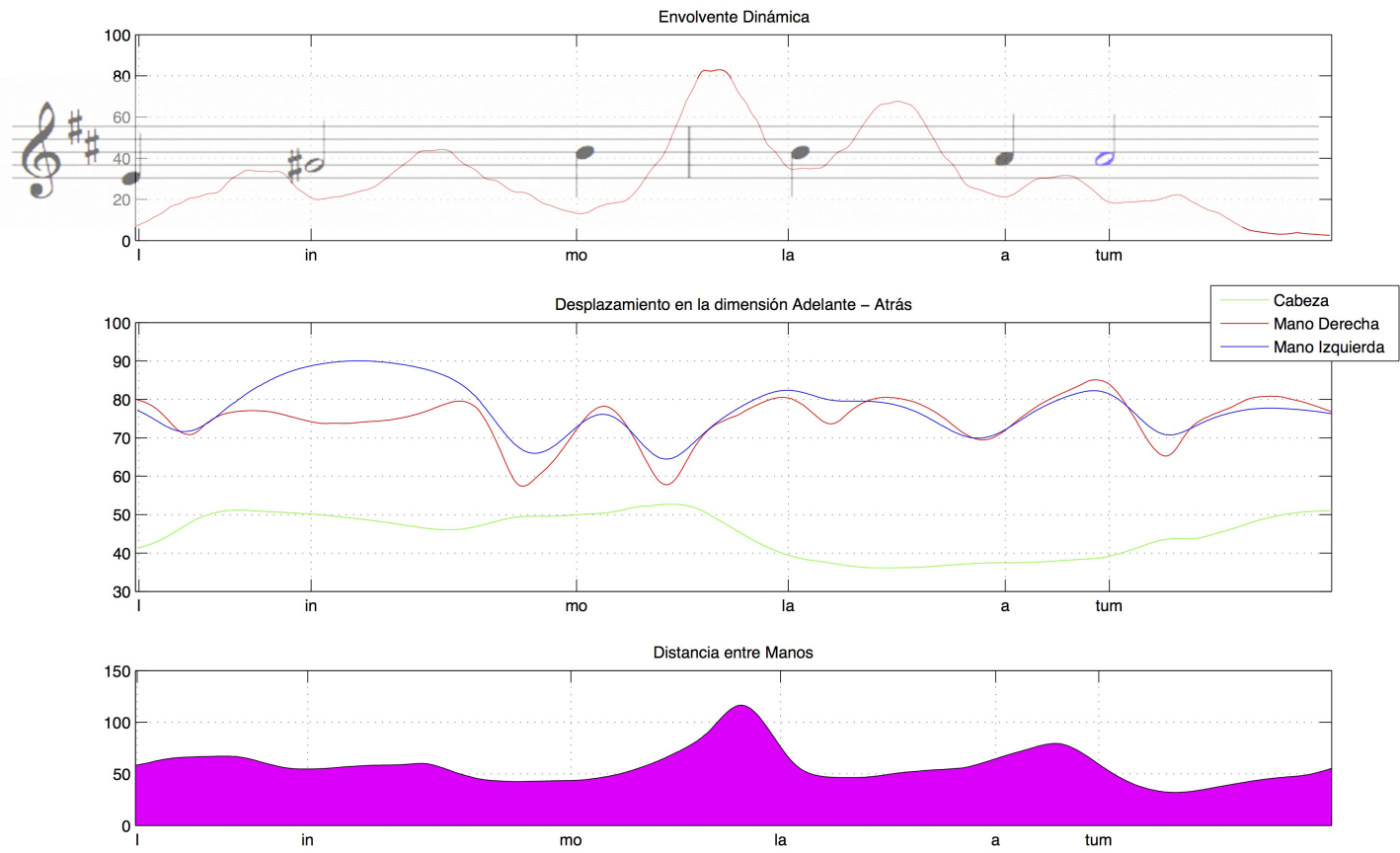

Figura 5.5: Segmento B6. Caja arriba: Envolvente dinámica de la señal de audio en superposición con la partitura del segmento. Caja central: Desplazamiento de los marcadores mano izquierda, cabeza y mano derecha en el eje antero-posterior. Caja abajo: Distancia entre manos.

\subsection{Discusión}

El presente trabajo pretende realizar aportes para la elección de categorías de análisis para el estudio de la vinculación entre el movimiento corporal que organiza la géstica de dirección y los componentes expresivos de la música(en particular el modelado dinámico del discurso musical); haciendo foco en cómo puede abordarse el estudio de significados no proposicional emergentes del entonamiento (Malloch y Trevarthen, 2008) entre el movimiento y la música.

Los resultados alientan a indicar que hay incluir el estudio de los movimientos que el director despliega en el eje antero-posterior, es decir hacia adelante y atrás, en los abordajes pedagógicos y científicos del estudio de la dirección.; y 
que las series temporales de movimiento para el estudio de la gestualidad del director deberían integrar las tres dimensiones espaciales.

Este trabajo sugiere evidencia en relación al incremento de movimientos organizados en el eje antero-posterior en relación a las intenciones comunicativas; profundizar esta vinculación brindaría aportes para estudios desde una perspectiva intersubjetiva. 


\section{6}

\section{Estudio 2 - Parte I Energía musical expresada: correlación de categorías de música y de movimiento en el contexto de una performance coral.}

El estudio 2 consiste en un micro análisis que se organiza en dos partes, cada una con métodos diferentes. A los fines de una mejor lectura comunicaremos cada parte en capítulos separados.

\section{I Introducción}

Se cree que el movimiento corporal del director de coro tiene un efecto directo en cómo canta el coro; a la vez que se reconoce que las categorías expresivas en relación al movimiento de los gestos de dirección están significativamente sin teorizar (Garnett, 2009). Encontramos dos antecedentes cuyo objetivo fue establecer puentes categoriales entre la modulación de la dinámica musical y la modulación de los movimientos de las manos:

(a) Garnett (2009) compara i) las categorías establecidas en el lenguaje de señas (Mudler, 1996) para modular el significado expresivamente; ii) las congruencias con los gestos de dirección en referencia a la pedagogía de la dirección; iii) las metáforas; y iv) los esquemas imagen (Tabla 6.1). 


\begin{tabular}{|c|c|c|c|c|}
\hline $\begin{array}{l}\text { Parámetros } \\
\text { Mudler, } 1996\end{array}$ & $\begin{array}{l}\text { Gestos de } \\
\text { dirección }\end{array}$ & Metáfora & $\begin{array}{l}\text { Esquema } \\
\text { Imagen }\end{array}$ & $\begin{array}{l}\text { Referencia } \\
\text { pedagogía } \\
\text { en dirección } \\
\text { musical }\end{array}$ \\
\hline \multirow{3}{*}{$\begin{array}{c}\text { Tamaño del Espacio } \\
\text { Gestual }\end{array}$} & $\begin{array}{c}\text { Distancia de los gestos } \\
\text { desde el centro del } \\
\text { cuerpo }\end{array}$ & $\begin{array}{l}\text { Sonidos más } \\
\text { fuertes } \\
\text { se escuchan de } \\
\text { más lejos }\end{array}$ & $\begin{array}{l}\text { CENTRO- } \\
\text { PERISFERIA }\end{array}$ & $\begin{array}{r}\text { Rudolph, 1995, p.85 } \\
\text { Decker y Kirk 1988, p. } \\
11 \\
\text { Reynolds } 1972, \text { p.26 }\end{array}$ \\
\hline & Tamaño del esquema & $\begin{array}{l}\text { Más grande es } \\
\text { más fuerte }\end{array}$ & TAMAÑO & $\begin{array}{c}\text { Rudolph, 1995,p. } 71 \\
\text { Roe 1970, p.235 } \\
\text { Garretson 1970,p. } 73 \\
\text { Woodgate, 1944, p.27 } \\
\text { Holst 1973, p.21 } \\
\text { Kahn 1975, p.86 }\end{array}$ \\
\hline & $\begin{array}{l}\text { Articulación conductora } \\
\text { del gesto } \\
\text { (hombro, codo, muñeca, } \\
\text { nudillo) }\end{array}$ & $\begin{array}{l}\text { Delicado utiliza } \\
\text { dedos. } \\
\text { Pesado usa los } \\
\text { brazos }\end{array}$ & $\begin{array}{l}\text { FUERZA / } \\
\text { TAMAÑO }\end{array}$ & $\begin{array}{l}\text { Boult 1949, p.29 } \\
\text { Kahn 1975, p.9 }\end{array}$ \\
\hline Tensión del gesto & Tensión muscular & $\begin{array}{l}\text { Sonidos mas } \\
\text { fuertes necesitan } \\
\text { más esfuerzo }\end{array}$ & FUERZA & $\begin{array}{c}\text { Roe 1970, p.235 } \\
\text { Busch 1984, pp.73-4 }\end{array}$ \\
\hline \multirow[t]{3}{*}{ Velocidad del Gesto } & Velocidad del movimiento & $\begin{array}{l}\text { Más rápido es } \\
\text { más fuerte }\end{array}$ & VELOCIDAD & Green 1997, p.73 \\
\hline & $\begin{array}{c}\text { Peso del ictus = } \\
\text { aceleración al punto de } \\
\text { pulsación }\end{array}$ & $\begin{array}{c}\text { Objetos más } \\
\text { pesados emiten } \\
\text { sonidos más } \\
\text { fuertes }\end{array}$ & PESO & $\begin{array}{c}\text { Roe, } 1970, \text { p.235 } \\
\text { Woodgate 1944, p.27 }\end{array}$ \\
\hline & $\begin{array}{c}\text { Subir y bajar la mano } \\
\text { izquierda }\end{array}$ & Arriba es más & VERTICALIDAD & $\begin{array}{c}\text { Rudolph 1995, p.74 } \\
\text { Gordon, 1989, p.79 } \\
\text { Green 1997, p.93 } \\
\text { Kahn 1975, p.86 } \\
\text { Busch 1984, p.86 }\end{array}$ \\
\hline
\end{tabular}

Tabla 6.I: Congruencias entre modulación del gesto, metáforas y esquema imagen (Garnett,2009).

(b) Gambetta (2009) organiza un conjunto de afinidades entre los factores de movimiento Laban y los elementos de la expresión musical (Tabla 6.2), con el objetivo de ayudar a los directores a establecer conexiones básicas entre los modos de pensar el movimiento y la música y guiarlos a una genuina experiencia de equivalencia entre movimiento y música. 


\begin{tabular}{|c|c|c|c|c|c|}
\hline \multirow{2}{*}{\multicolumn{2}{|c|}{ Factor de Movimiento }} & \multicolumn{4}{|c|}{ Elementos de la expresión Musical } \\
\hline & & Tempo & Dinámica & Articulación & Fraseo \\
\hline \multirow{2}{*}{ Espacio } & flexible & neutral & neutral & largas & flexible \\
\hline & direccionado & neutral & neutral & cortas & estricto \\
\hline \multirow{2}{*}{ Tiempo } & sostenido & disminuye & neutral & desacentuada & estirado \\
\hline & acelerado & aumenta & neutral & acentuada & condensado \\
\hline \multirow{2}{*}{ Peso } & liviano & aumenta & disminuye & $\begin{array}{l}\text { disminuye } \\
\text { intensidad }\end{array}$ & neutral \\
\hline & pesado & disminuye & aumenta & $\begin{array}{c}\text { aumenta } \\
\text { intensidad }\end{array}$ & neutral \\
\hline \multirow{2}{*}{ Flujo } & libre & neutral & aumenta & neutral & fluído \\
\hline & contenido & neutral & disminuye & neutral & controlado \\
\hline
\end{tabular}

Tabla 6.2: Congruencias entre factores de movimiento Laban y elementos de la expresión musical (Gambetta, 2009).

Estas comparaciones manifiestan la necesidad de contar con puentes categoriales de base para referirnos a los vínculos entre significaciones entre dominios.

El diseño de este estudio se basa principalmente en la relación de tres de los marcos de referencia desarrollados, a saber: i) El concepto de gesto musical (Hatten, 2004, 2006) referido al modelado energético del sonido en el tiempo para ser significativamente interpretado en su rasgo de carácter cualitativo correspondiente al modo en que se modula la energía gestual (Capítulo 4); ii) El sistema de análisis de movimiento Laban para describir la expresión del movimiento, puntualmente en el componente los factores de movimiento de la eukinética, que formaliza las cualidades internas del movimiento en descripciones de "estado a estado" (Laban y Lawrence, 1947; Francoise, 2015; Truong et al., 2016) (Capítulo 5); y iii) el Alineamiento Expresivo en su segunda modalidad (Leman, 2016), referido a la correspondencia continua del flujo de patrones de movimiento y el flujo de patrones del discurso musical 
como base de un modelo de comunicación enactivo, cuyo impulso es la expresión, considerada elemento constructivo para la habilidad de comunicarse y clave para establecer interacciones.

En Luck et al. (2010) encontramos el principal antecedente para el abordaje del estudio de la expresión de los gestos de director utilizando técnicas de captura de movimiento. El objetivo del estudio fue investigar las relaciones entre las características cinemáticas de los gestos de director y la expresión de la energía emocional percibida. Se utilizaron categorías de movimiento de bajo-nivel; la correlación fue establecida con juicios continuos de energía percibida mediante las categorías expresión, valencia, actividad y potencia. Los resultados vincularon altos niveles de expresividad (en término de las categorías utilizadas) con las variables de movimiento que presentaron altos índices de amplitud, varianza y velocidad. En pos de controlar las variables, los juicios de puntuación fueron realizados a través de la observación de videos de trayectorias MoCap.

\subsection{Hipótesis}

i) La expresión musical expresada en términos de energía modulada, presentará correlaciones entre las categorías de análisis del dominio movimiento y el dominio música.

ii) Se observarán mayores correlaciones en la condición intersubjetiva, dado que la interacción intersubjetiva es el contexto ontológico de la expresión musical desde la perspectiva de segunda persona.

iii) Se observará mayor frecuencia de correlaciones en la mano izquierda, por su rol expresivo determinado por los métodos de enseñanza de la dirección orquestal/coral.

\subsection{Objetivos}

Configurar un mapa de correlaciones entre categorías de análisis expresivas de los dominio música y movimiento. 
Buscar evidencia que sustente las vinculaciones entre categorías musicales y de movimiento.

Verificar si las correlaciones de energía expresada dan cuenta de la diferencias entre un entorno intrasubjetivo y otro intersubjetivo

Describir el rol enactivo de la manos, en relación a la expresión musical, en términos de energía, mientras realizan los movimientos de dirección en una performance.

\subsection{Métodos}

Participantes. Rol director: hombre, 55 años, director de coro en actividad, con formación académica en dirección orquestal en la Universidad de La Plata, docente de Dirección Coral. Rol cantante: 2 mujeres, edades 37 y 25 años, con formación musical académica, experiencia como cantante de coro, y una de ellas estudiante de dirección coral.

Estímulo. Ave Verum K 618, de W.A. Mozart. Fragmento entre los compases 3 a 18. Únicamente la línea de soprano.
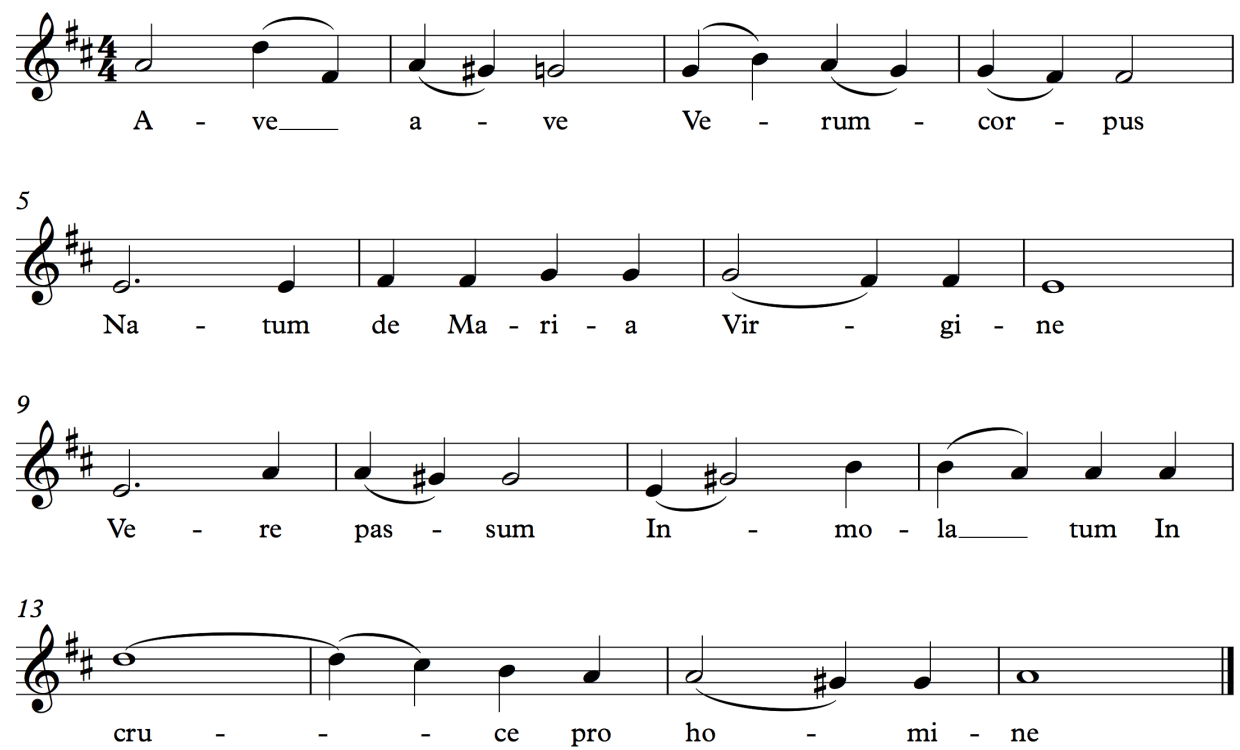

Figura 6.I: Ave Verum K 6/8, de W.A. Mozart. Compases 3 a 18. Línea de soprano. 
Aparatos. El movimiento del director se capturó y registró con un sistema de captura de movimiento, Optitrack, compuesto por 12 cámaras infrarrojas modelo flex 3 y el software Motive como sistema de control desde una computadora con entorno windows. Se utilizaron 37 marcadores reflectivos sobre un traje especialmente diseñado para configurar el cuerpo completo en base a protocolo Rizzoli para el director. En este estudio se utilizaron únicamente los datos obtenidos de los marcadores de las manos.

El pre-procesamiento de los datos MoCap comprendió la sincronización con las grabaciones de audio; la limpieza básica de posibles marcas perdidas; la normalización de la traslación del cuerpo y la aplicación de un filtro SavitzkyGolay para descartar el ruido de la señal. El audio de la performance se registró con la grabadora Zoom H4n en un canal mono a $44.1 \mathrm{khz}$. Se realizaron grabaciones en video con propósito de referencia.

\subsection{Procedimiento y diseño}

El estudio se organiza en dos condiciones desde la perspectiva del director: A) Monológica, intrasubjetiva: Auto-dirección mientras él mismo canta el estímulo. B) Dialógica, intersubjetiva: Performance dirigiendo a los cantantes. Previo a la condición $\mathrm{B}$, se realizó un ensayo de 15 min. para preparar la performance.

\subsection{Definición de la unidad de análisis}

El foco del estudio es la correlación de categorías de medio-nivel entre dominios. Este nivel se caracteriza por organizar sus unidades en patrones (Ver matriz de referencia conceptual $\underline{4.5}$ ).

Estar en un entorno sonoro nos embebe en una temporalidad definida por la música por lo tanto, para delimitar la unidades de análisis, será coherente realizar la segmentación temporal en base a criterios musicológicos: estructura métrica, frases, períodos, motivos. A su vez, es necesario que las unidades de análisis se puedan considerar como unidades de significado musical. Es decir 
que lo que sucede dentro de la unidad, en el devenir temporal entre su inicio y su final, tiene que poder constituir sentido expresivo. Así, se podrá sustentar la validez expresiva de las correlaciones entre las categorías que utilizaremos para describir la performance.

En base a una entrevista realizada con el director participante y a análisis musicológicos de la estructura formal, se delimitaron 8 unidades de análisis, correspondientes cada una a un segmento de dos compases. Priorizando el sentido musical, se respetaron las unidades que tienen comienzo anacrúsico; de modo que las unidades 1 a 5 y 7 son de ocho beats, la unidad 6 es de siete beats y la 8 de nueve beats. Las diferentes proporciones se tendrán en cuenta en el procesamiento de la variable que describe el timing expresivo. La ubicación temporal de los beats se obtuvo por la anotación en base a la señal de audio utilizando el entorno de trabajo del software Sonic Visualiser (Cannam et al., 2010).

Para los segmentos de movimiento la ventana de análisis se desplazó al beat anterior al utilizado en el análisis musicológico, dado que el movimiento del gesto de dirección anticipa y prepara la 'entrada' a cada unidad formal.

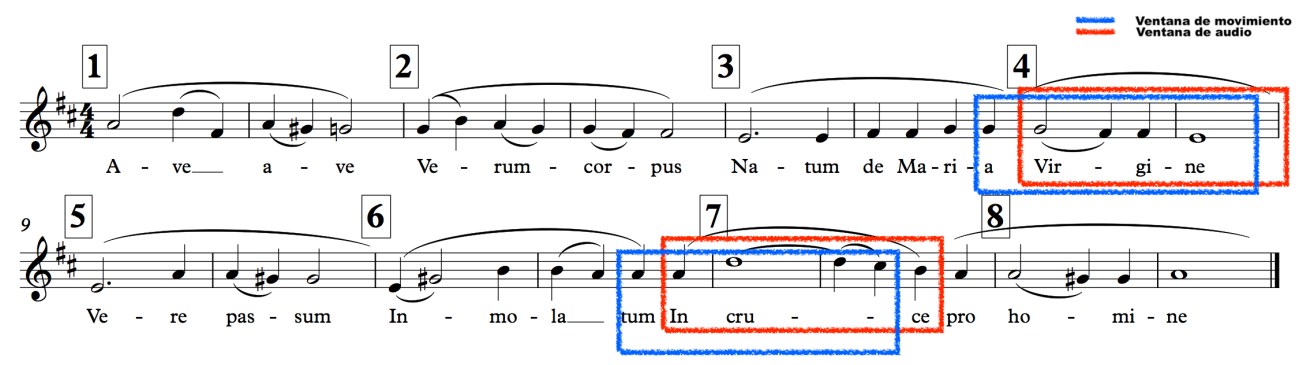

Figura 6.2: Unidades de análisis (Rojo: Ventana de audio / Azul:Ventana de movimiento).

\subsubsection{Laban: desde los descriptores de movimiento de bajo-nivel}

Para poder analizar cuantitativamente con las categorías de Laban, es necesario definir con qué fórmula se tratarán los datos de movimiento crudo, 
es decir los de la señal física de movimiento del bajo-nivel, para obtener una magnitud que dé cuenta de la descripción en el medio-nivel donde se organizan los patrones.

Hay varios estudios que prueban distintas alternativas correlacionadas con la evaluación de expertos entrenados en la metodología Laban (Fdili Alaoui, 2017). Los objetivos de estos trabajos son diversos. Giraud et al. (2016) estudian el impacto de condiciones de valencia expresiva en una tarea de fitness; Piana et al. (2013) estudian las configuraciones corporeizadas de la emoción en el movimiento libre; Van Dick et al. (2013, 2014) estudian las emociones que induce la música en el movimiento de la danza libre; Maes et al. (2014) estudian la correlación entre los descriptores Laban y descriptores lingüísticos para la conformación de significados musicales.

A partir de las propuestas de 'traducción' entre los datos de movimiento crudo y los descriptores Laban desarrollados en estos trabajos previos se elaboró la propuesta de este trabajo para aplicarlo al entorno de una performance de dirección musical. Todos los estudios que mencionamos analizan la configuración de las categorías Laban en el movimiento del cuerpo completo. Si bien nosotros también capturamos los datos del cuerpo completo, tomamos la decisión metodológica de hacer foco en el movimiento de las manos por separado. Esto constituye una diferencia importante al momento de diseñar los algoritmos para la medición.

\subsubsection{Selección de categorías de movimiento}

En el marco del análisis de movimiento Laban, elegimos tres factores de movimiento de la eukinética, es decir las descripciones de estado-a-estado que dan cuenta de la energía interna del movimiento: factor espacio, factor tiempo y factor peso. También incluimos una categoría de la Coréutica en las descripciones de lugar-a-lugar: el componente forma. Esta decisión es por dos motivos: primero porque estas últimas descripciones son más inmediatas, y segundo, porque como afirma Laban, están intrínsecamente vinculadas como 
dos perspectivas del mismo objeto de estudio. El criterio para definir las fórmulas que describirán cada categoría combina los aportes de los estudios previos, la adaptación para aplicarlas al movimiento de las manos en la tarea de dirección y propuestas propias para reemplazar fórmulas que no se adecuaban a este contexto de análisis.

\subsubsection{Expansividad}

El índice de expansividad está asociado al descriptor Laban componente forma. Este descriptor da cuenta de la cantidad (volumen) de espacio que recorre la mano en su trayectoria. En los estudios previos mencionados son descripciones de la expansión/apertura del cuerpo entero (Giraud et al., 2016; Piana et al., 2013). En nuestro estudio consideramos el volumen de la trayectoria de la mano desplegado en el espacio. Esta magnitud se expresa con un índice que relaciona el volumen total (de todo el estímulo) con el volumen de cada unidad analizada. La fórmula para obtener este índice, calcula el volumen a partir de la triangulación que representa los límites conformados alrededor de los puntos $(x, y, z)$, correspondientes a las tres dimensiones. Para realizar este cálculo se utilizó la función boundary, con un factor de contracción cero. Las figuras 6.3 y 6.4 comparan el diseño de la trayectoria (izquierda) con los límites del volumen del espacio involucrado en el recorrido de dicha trayectoria (derecha). A su vez se pueden comparar las unidades que reportan mayor volumen (Condición A / mano derecha / unidad 7 / índice 0.47) y menor volumen (Condición A / mano derecha / unidad 4 / índice 0.07).
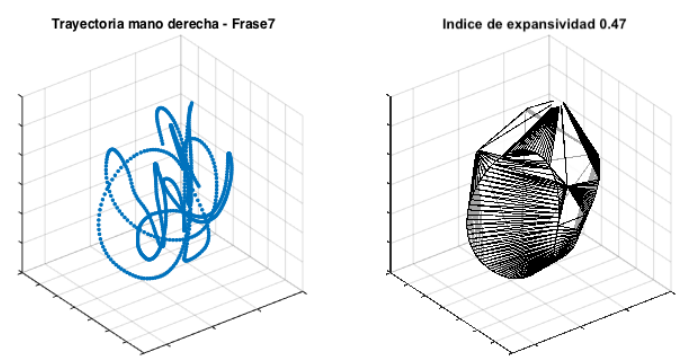

Figura 6.3: Trayectoria de la mano vs. Indice de expansividad (Frase 4). 

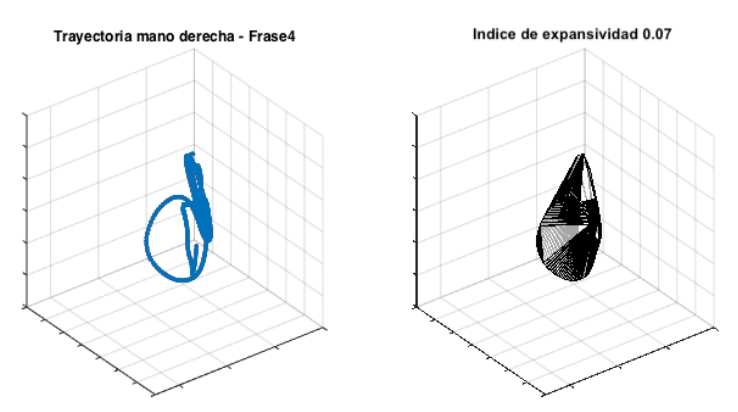

Figura 6.4: Trayectoria de la mano vs. Indice de expansividad (Frase 7).

\subsubsection{Direccionalidad}

El índice de direccionalidad se asocia al factor de movimiento espacio. Este descriptor da cuenta de si la trayectoria de la mano en su recorrido es más rectilínea, direccionada, focalizada, o por el contrario es más ondulada, desviada, no focalizada. Para este caso utilizamos la fórmula propuesta por Piana et al. (2013) que computa por la proporción entre la distancia euclidiana, calculada entre el punto de inicio y el punto final de la trayectoria, y la longitud total de la trayectoria. La fórmula correspondiente es: (1), donde $\mathrm{Xs}, \mathrm{Ys}$, Zs son las coordenadas del punto de inicio, XE,YE,ZE, son las coordenadas del punto final y $\mathrm{N}$ es el largo de la trayectoria; y k cada una de las instancias de muestreo -en este caso las capturas de movimiento son a 100 fps (cuadros/muestras por segundo)-.

$$
D I=\frac{\sqrt{\left(x_{E}-x_{S}\right)^{2}+\left(y_{E}-y_{S}\right)^{2}+\left(z_{E}-z_{S}\right)^{2}}}{\sum_{k=1}^{N-1} \sqrt{\left(x_{k+1}-x_{k}\right)^{2}+\left(y_{k+1}-y_{k}\right)^{2}+\left(z_{k+1}-z_{k}\right)^{2}}}
$$

Este índice lo expresamos calculando la media cuadrática, valor cuadrático medio o RMS (del inglés root mean square), que nos da una medida estadística de la magnitud de la cantidad variable de Índice de Direccionalidad por cada segmento analizado. Todos los cálculos fueron programados por el autor en entorno Matlab. 


\subsubsection{Impulsividad}

El índice de impulsividad se asocia a la categoría Laban factor de movimiento tiempo. Este descriptor da cuenta de las aceleraciones y desaceleraciones de la trayectoria de la mano. En este caso optamos por incluir dos mediciones: rango e intensidad.

6.5.3.3a Rango. Se consideró la fórmula utilizada en Van Dick et al. (2013) que computa el rango de amplitud de la velocidad euclidiana en relación a cada segmento. Para este cálculo se utilizó la función range de Matlab, que provee la diferencia entre el mínimo y el máximo de una muestra. La magnitud del rango de velocidad por segmento se expresa en $\mathrm{cm} / \mathrm{seg}$.

6.5.3.3b Intensidad. Esta una medida propuesta en un trabajo anterior (Naveda et al, 2016), el nivel de velocidad acumulada por segmento. En el primer estudio se utilizó para dar cuenta de la distribución del flujo de la velocidad de las manos en una tarea de movimiento libre, en este estudio, dará cuenta de la intensidad de la acumulación expresada a partir del cálculo de la media cuadrática (RMS) por segmento.

\subsubsection{4 Índice de Rotación}

En este caso buscamos describir el factor de movimiento peso. Éste daría cuenta del incremento o decremento de la presión y/o el esfuerzo al realizar la trayectoria; en el contexto de la dirección musical lo podríamos considerar como el presionar, forzar o torsionar una trayectoria para enactuar un esfuerzo expresivo.

No encontramos la posibilidad de transferir los métodos utilizados en otros estudios, dado que unos utilizan la masa corporal según tablas de modelos corporales (Giraud et al., 2016) o la aceleración (Maes et al., 2014; Van Dyck et al., 2013). El primero no podemos aplicarlo porque para calcular la masa corporal de la mano necesitaríamos los datos de los dedos que nuestro sistema no captura; y la segunda opción nos resulta poco representativa del descriptor 
Laban en cuestión. Fdili Alaoui (2017) utiliza datos de activación muscular, obtenidos con un sensor muscular electromiográfico (EMG); esta medición es la que consideramos más apropiada, pero no tuvimos acceso a dicho sensor.

En base a estas consideraciones, decidimos considerar las descripciones de la rotación de la mano. Para ello calculamos la rotación entre los puntos de unión metacarpo-falange del dedo índice y del dedo meñique en relación al punto de unión metacarpo-falange del bloque de dedos mayor-anular, en el plano frontal. El cálculo se realizó con una adaptación de la función mcrotate del MoCap toolbox (Burger y Toiviainen, 2013). Se expresa con la magnitud del rango de rotación.

\subsubsection{Selección de categorías en Música}

Palmer (1997) señala que tempo y dinámica son las dos modalidades principales con las que el performer comunica sus intenciones expresivas, mientras que timbre y articulación son consideradas secundarias. Cómo administrar las variaciones de estos parámetros es parte del proceso creativoexpresivo del performer.

La producción temporal de la performance se puede describir en variaciones de articulación, tempo y timing expresivo (Juslin, 2009). Articulación es el tiempo entre el final de un sonido y el inicio del siguiente. Tempo se entiende como la velocidad promedio que tiene lugar entre la ejecución de cada beat. Timing expresivo es la variación de los valores canónicos de las notas en relación a su notación en la partitura. La producción "espacial” (ver apartado 4.1) de la performance se puede describir en variaciones de dinámica (intensidad) y timbre.

Dada la unidad de análisis establecida para el presente trabajo, seleccionamos descriptores continuos del flujo del discurso musical. Por lo expuesto, utilizaremos tempo y dinámica como categorías de análisis para describir la energía musical expresada y correlacionar con las categorías de movimiento. 


\subsubsection{Dinámica (Intensidad)}

Para obtener la magnitud de intensidad de cada unidad se calculó la media cuadrática o RMS de la señal de de audio, previamente normalizada y filtrada. La decisión de utilizar únicamente la línea de soprano del Ave Verum, responde a facilitar el pre-procesamiento del audio y obtener una señal más limpia. Los cálculos de RMS se realizaron con la función mirrms del toolbox MIR (Lartillot et al., 2008) el cual se basa en la siguiente fórmula (2).

$$
x_{\mathrm{rms}}=\sqrt{\frac{1}{n} \sum_{i=1}^{n} x_{i}^{2}}=\sqrt{\frac{x_{1}^{2}+x_{2}^{2}+\cdots+x_{n}^{2}}{n}}
$$

\subsubsection{Tempo}

Para obtener el tempo de cada unidad de análisis se calcularon los beats por minuto (BPM) a partir de la unidad de medida temporal de cada muestra. La fórmula para calcular los BPM de las series de movimiento es (3), donde $\mathrm{N}$ corresponde a cada unidad de análisis. De este modo obtenemos un BPM promedio en relación a cada segmento.

$\mathrm{BPM}_{\mathrm{N}}=\left(\right.$ totaldesegunosd $\mathrm{N}_{\mathrm{N}} /$ Cantidaddebeats $) / 100$ frames $\left._{\mathrm{N}}\right) * 60$ segundos $(3)$

\subsubsection{Atracción Tonal}

Las alturas que organizan el contorno melódico constituyen una variable estructural, dado que en el contexto de la interpretación de una melodía coral de Mozart, el performer no va a cambiar la notas de la melodía con fines expresivos; otro sería el caso si consideramos las prácticas de los músicos de jazz, por ejemplo. 

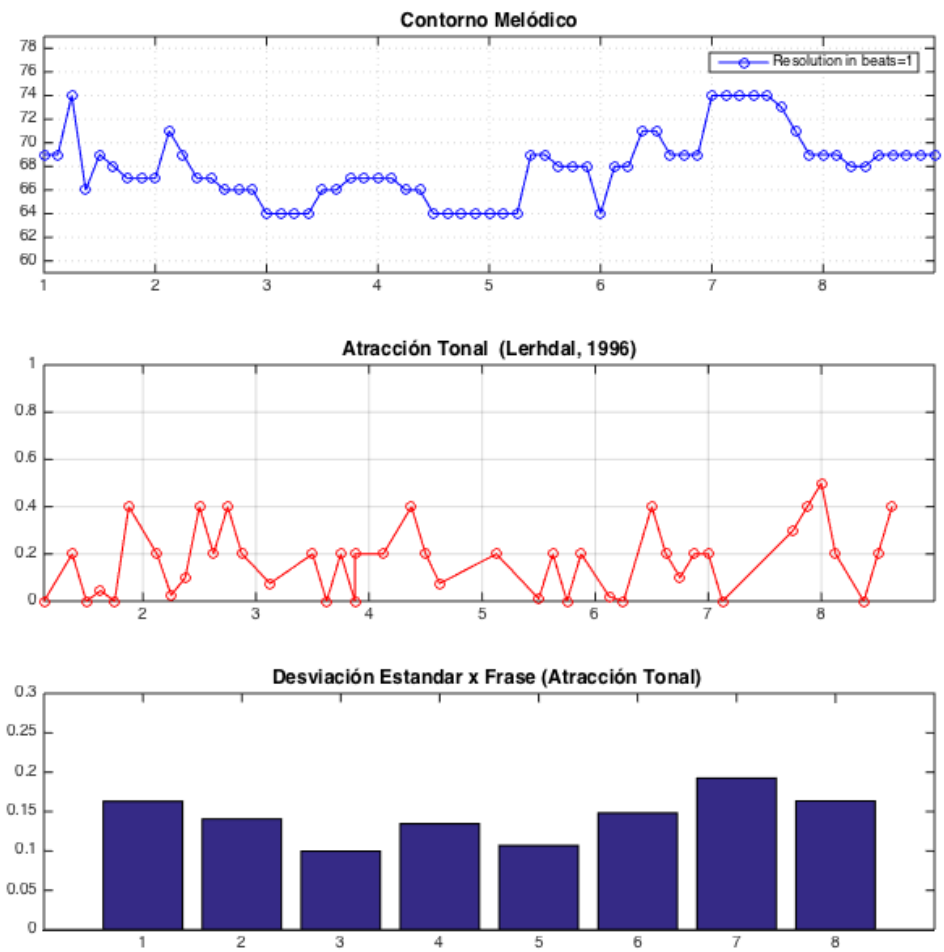

Figura 6.5: Transcripción MIDI de la partitura (caja superior). Magnitud de atracción tonal de cada altura(caja central). Desviación estándar por unidad de análisis (caja inferior).

Con el fin de observar si las variables expresivas de música y movimiento tienen correlato e interactúan con la estructura tonal de obra musical, incorporamos al mapa de correlaciones una medida de la energía implícita en la configuración tonal de la melodía. Lerdahl (1996) propone ponderar la magnitud de atracción tonal inherente a cada altura de una secuencia melódica a través de un algoritmo que considera los grados de tensión armónica y melódica en el espacio tonal, basada en el componente prolongacional de la teoría generativa de la música (Lerdahl y Jackendoff, 1983),

El flujo de trabajo para obtener esta categoría se ve en la figura 6.5. A partir de la transcripción MIDI de la partitura (caja superior), se calcula la magnitud de atracción tonal de cada altura con la función mellatracttion del MIDI toolbox 
(Toiviainen y Eerola, 2016) (caja central) y con esos datos se calcula la desviación estándar para cada una de las unidades de análisis (caja inferior).

La tabla 6.3 presenta un resumen de las categorías de análisis implementadas, su relación con Laban, las fórmulas de cálculo, la expresión para correr los estadísticos y la serie temporal de base sobre la que se realizaron los cálculos.

\subsection{Resultados}

Uno de los objetivos de este trabajo era diseñar un mapa de correlaciones entre las categorías de música y de movimiento. Con este fin preparamos los datos para calcular el coeficiente de correlación de Pearson. Elegimos este análisis estadístico porque está pensado para variables cuantitativas. Es un índice que mide el grado de covariación entre variables que tengan relación lineal. A diferencia de la covarianza, la correlación de Pearson es independiente de las escalas de medida de las variables.

Para poder calcular la correlación de Pearson, primero tuvimos que comprobar si las variables se ajustaban a una distribución normal de los datos. Para ello utilizamos la prueba de Kolmogorov-Smirnov, que determina la bondad de ajuste de dos distribuciones de probabilidad entre sí. A tal fin se creó una serie de datos con una distribución $t$ de Student, eficaz para estimar una distribución normal cuando el tamaño de la muestra es pequeño. 


\begin{tabular}{|c|c|c|c|c|c|}
\hline \multicolumn{6}{|c|}{ Movimiento } \\
\hline & $\begin{array}{l}\text { Categoría de } \\
\text { análisis }\end{array}$ & $\begin{array}{l}\text { Relación } \\
\text { Laban }\end{array}$ & Fórmula de cálculo & $\begin{array}{l}\text { Expresado } \\
\text { en: }\end{array}$ & $\begin{array}{l}\text { serie } \\
\text { tempora } \\
\text { de base }\end{array}$ \\
\hline 6.5.3.1 & $\begin{array}{c}\text { Índice de } \\
\text { expansividad }\end{array}$ & $\begin{array}{c}\text { Componente } \\
\text { Forma }\end{array}$ & $\begin{array}{l}\text { Volumen de la } \\
\text { trayectoria de la mano }\end{array}$ & $\begin{array}{l}\text { índice en } \\
\text { relación al } \\
\text { total }\end{array}$ & $\begin{array}{l}\text { posición } \\
\text { en eje } \\
\text { X/Y/Z }\end{array}$ \\
\hline 6.5.3.2 & $\begin{array}{c}\text { Índice de } \\
\text { direccionalidad }\end{array}$ & $\begin{array}{l}\text { factor de } \\
\text { movimiento } \\
\text { espacio }\end{array}$ & $\begin{array}{c}\text { proporción entre la } \\
\text { distancia euclidiana, } \\
\text { calculada entre el } \\
\text { punto de inicio y el } \\
\text { punto final de la } \\
\text { trayectoria, y la } \\
\text { longitud total de la } \\
\text { trayectoria }\end{array}$ & RMS del DI & $\begin{array}{l}\text { Velocidad } \\
\text { Euclidiana }\end{array}$ \\
\hline 6.5.3.3 & $\begin{array}{l}\text { Índice de } \\
\text { Impulsividad }\end{array}$ & $\begin{array}{l}\text { factor de } \\
\text { movimiento } \\
\text { tiempo }\end{array}$ & $\begin{array}{l}\text { a. Rango de velocidad } \\
\text { en el espacio } \\
\text { euclidiano } \\
\text { b RMS (intensidad) de } \\
\text { la Velocidad }\end{array}$ & $\begin{array}{l}\text { a. unidad } \\
\text { de } \\
\text { velocidad } \\
\text { b. RMS }\end{array}$ & $\begin{array}{l}\text { Velocidad } \\
\text { Euclidiana }\end{array}$ \\
\hline 6.5.3.4 & $\begin{array}{l}\text { Índice de } \\
\text { Rotación }\end{array}$ & $\begin{array}{l}\text { factor de } \\
\text { movimiento } \\
\text { peso }\end{array}$ & $\begin{array}{l}\text { Rotación de la mano en } \\
\text { el Plano frontal }\end{array}$ & $\begin{array}{l}\text { Diferencia } \\
\text { entre } \\
\text { máx. y mín. }\end{array}$ & $\begin{array}{l}\text { posición } \\
\text { en eje } \\
\text { X/Y }\end{array}$ \\
\hline \multicolumn{6}{|c|}{ Música } \\
\hline & $\begin{array}{l}\text { Unidad de } \\
\text { análisis }\end{array}$ & Tipo & Fórmula de cálculo & $\begin{array}{l}\text { Expresado } \\
\text { en: }\end{array}$ & \\
\hline 6.5.4.1 & Dinámica & Expresiva & $\begin{array}{l}\text { RMS de la señal de } \\
\text { audio }\end{array}$ & RMS & \\
\hline 6.5.4.2 & Tempo & Expresiva & $\begin{array}{c}\text { promedio de duración } \\
\text { de los beat de cada } \\
\text { unidad }\end{array}$ & BPM & \\
\hline 6.5.4.3 & Atracción Tonal & Estructural & $\begin{array}{l}\text { Atracción Tonal } \\
\text { Lerdahl, } 1996\end{array}$ & $\begin{array}{l}\text { Desviación } \\
\text { Estándar }\end{array}$ & \\
\hline
\end{tabular}

Tabla 6.3: Resumen de las categorías de análisis implementadas en el estudio 2. 

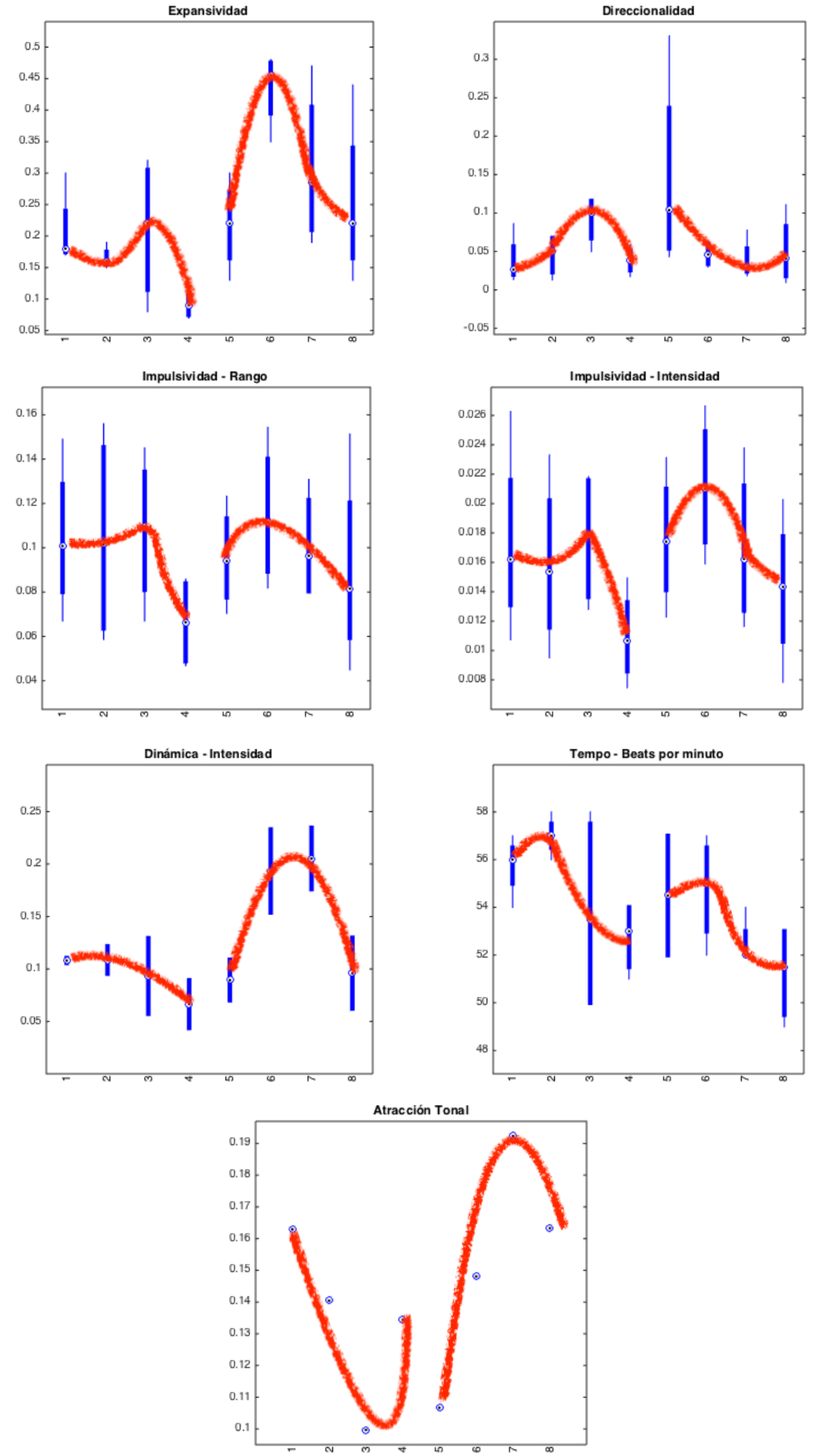

Figura 6.6: Distribución y varianza de los datos (categoría por unidad de análisis). 
La prueba de Kolmogorov-Smirnov nos informó que la única variable que no se ajustaba a una distribución normal es el índice de rotación (‥5.3.4), por lo tanto no la incluimos en las correlaciones.

La primer exploración de los datos la realizamos con diagramas de caja (boxplot) para visualizar la distribución y varianza de los datos (Figura 6.6). Desde la perspectiva propuesta en este estudio, podríamos leer estos gráficos como la distribución y varianza de la energía acumulada expresada en cada categoría analizada. A modo ensayo, se trazó una curva entre los puntos de las medianas para una posible visualización de los perfiles de energía, en este caso con un criterio de agrupamiento morfológico en periodos según criterios musicológicos. No realizaremos inferencias sobre estos gráficos; el objetivo de presentarlos es dar cuenta de esta meta para el futuro de nuestra investigación, consistente en diseñar visualizaciones del flujo expresivo del discurso musical en términos de energía, en sus distintos niveles de organización formal.

\subsection{Mapa de correlaciones}

Las figuras 6.7 y 6.8 presentan las correlaciones Pearson significativas entre el dominio del Movimiento y la Música.

Tanto para la condición Monológica, intrasubjetiva (Figura 6.7) y la condición Dialógica, intersubjetiva (Figura 6.8), mano izquierda y derecha se distribuyen a la izquierda y derecha del cuadro respectivamente. Analizaremos los datos partiendo de inferencias globales para ir avanzando hacia inferencias cada vez más puntuales.

En la condición intrasubjetiva se observan mayor cantidad de correlaciones altamente significativas (rojo, en fase y azul, en contrafase). Cuando la tarea consistió en auto-dirigirse o -descrita desde otra perspectiva- cuando el cantante tenía acceso directo a las intenciones del director porque era la misma persona, las correlaciones son más sólidas que en la condición en la que existe cierto tipo de negociación entre cantante y director. Este dato se podría 
interpretar en término de la complejidad del sistema. En la condición intersubjetiva la correlación es de menor intensidad, por el mayor número de personas que participan en la actividad del sistema, resultando en mayor complejidad a los fines de consolidar los alineamientos expresivos.

Desde el punto de vista de la frecuencia de correlaciones, si consideramos las dos manos como una unidad, la condición A tiene mayor frecuencia $(\mathrm{f}=14)$ que la condición $\mathrm{B}(\mathrm{f}=11)$ (Figura 6.9); pero si analizamos las manos por separado, la que tiene mayor frecuencia de correlación es la mano derecha. Esto nos lleva a cuestionar el rol expresivo de las manos, que en el capítulo 1 se describe bajo el paradigma de mano izquierda como equivalente a mano de uso expresivo. Estos resultados sugieren lo contrario, dado que la mano con mayor energía expresada es la mano derecha. En este sentido, y considerando que la condición $\mathrm{B}$ es intersubjetiva y que en ella la mano derecha presenta mayor frecuencia $(\mathrm{f}=9)$, podríamos sugerir que a más correlaciones activas corresponde una mayor comunicación intersubjetiva. Esta idea se refuerza en el marco de la expresión musical desde la perspectiva de segunda persona, caracterizada por la intención ostensible de comunicarse con el otro.

La categoría musical con mayor cantidad de correlaciones es la dinámica. Este resultado reafirma los resultados de Eitan (2013) en relación a que la intensidad es el componente con mayor uso en la transmodalidad espacial. La dinámica se vincula con expansividad e impulsividad del movimiento en la condición intrasubjetiva, pero también se vincula con direccionalidad cuando la condición es intersubjetiva. Esta correlación entre direccionalidad y dinámica es en contrafase, es decir que a mayor dinámica menos direccionado es el movimiento. Esto nos resulta difícil de explicar, ya que contradice nuestras primeras intuiciones: más direccionado $\Leftrightarrow$ más énfasis $\Leftrightarrow$ más fuerte. Habría que realizar un análisis puntual de ese segmento para tratar de encontrar claves visuales que nos orienten para explicar este correlato. Fdili Alaoui (2017) y Volpe (2003) reportan inconsistencias sobre el índice de direccionalidad, y proponen conjugarlo con información de velocidad y aceleración para mejorar este correlato. 


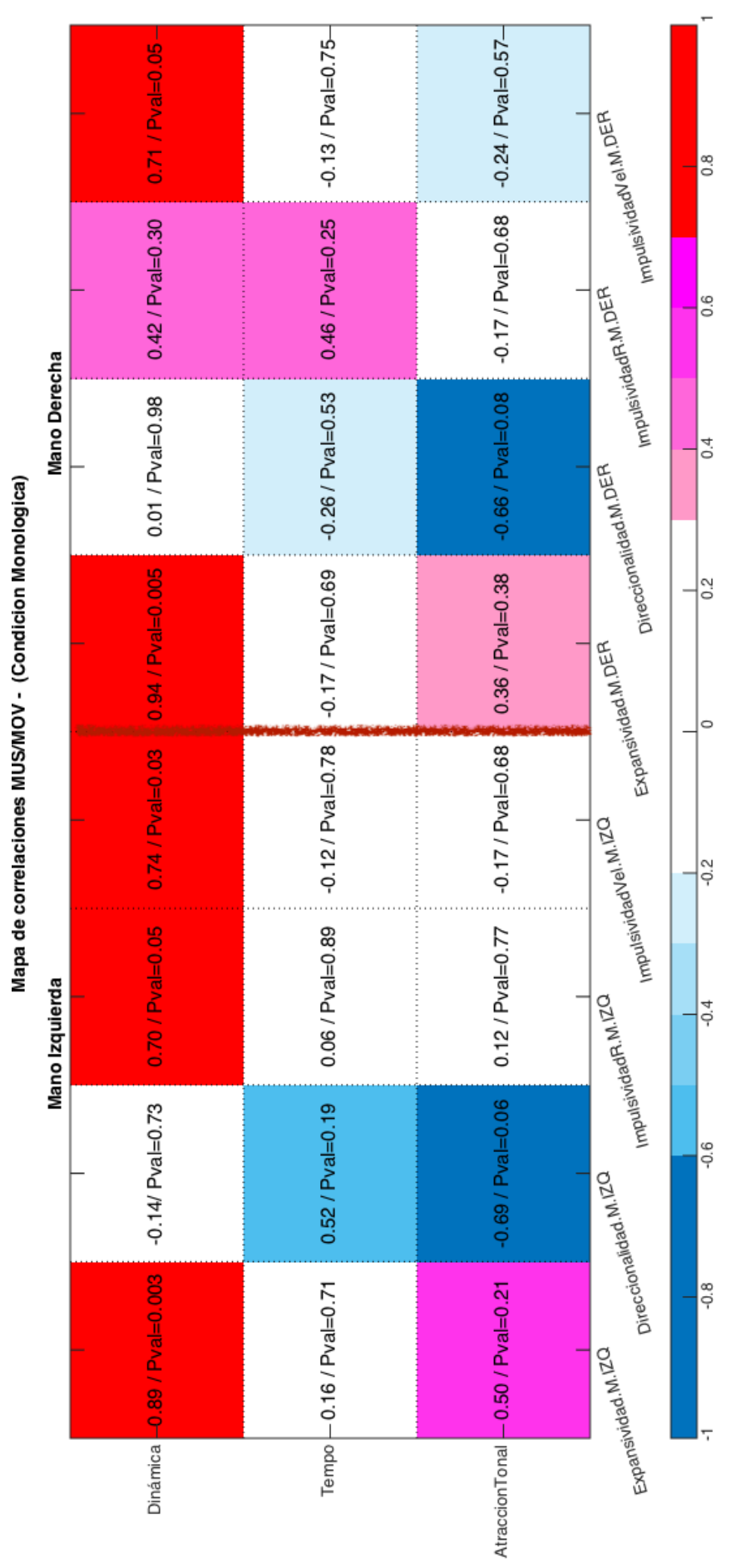

Figura 6.7: Mapa de correlaciones entre música y movimiento (Condición Monológica). 


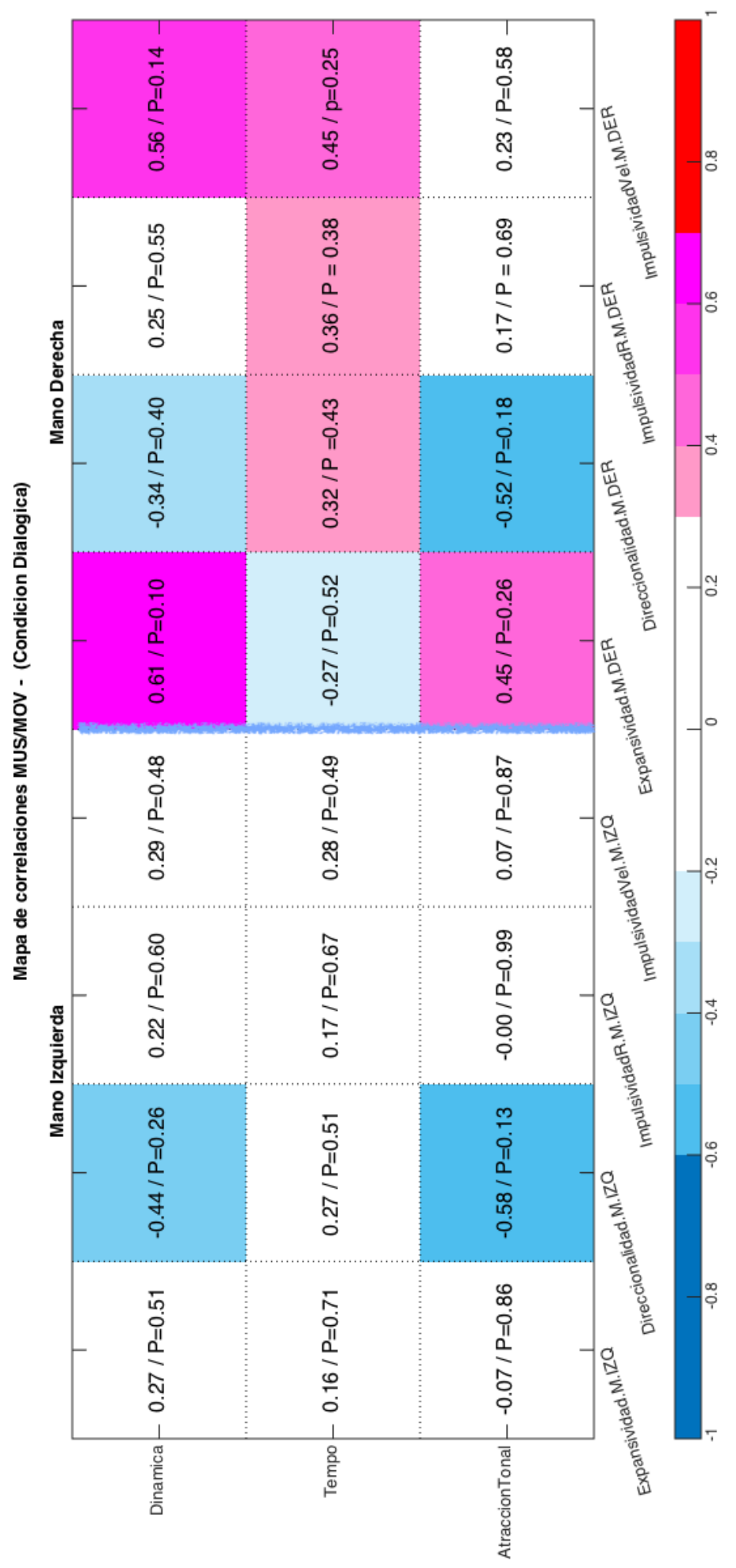

Figura 6.8: Mapa de correlaciones entre música y movimiento (Condición Dialógica). 


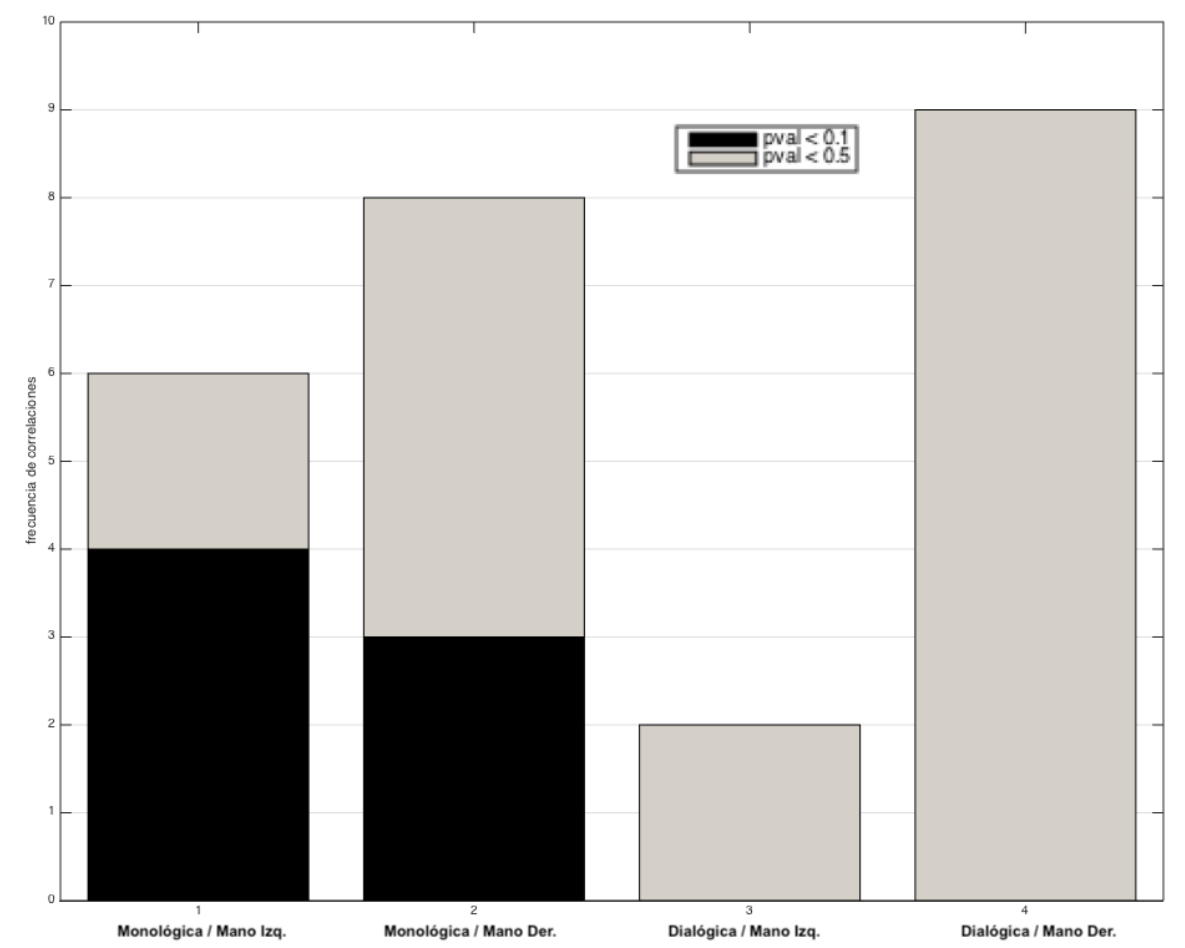

Figura 6.9: Frecuencia de correlaciones por mano por condiciones

\subsection{Discusión}

A partir de nuestra búsqueda de correlaciones entre las categorías de análisis de movimiento Laban y las categorías expresivo-musicales podemos afirmar que es válido utilizar las categorías de movimiento para describir la energía expresada en patrones musicales.

Las correlaciones entre dinámica, expansividad e impulsividad fueron significativas en ambas condiciones y se perfilan como las más robustas.

La descripción de la expansividad podría desdoblarse en sus afinidades con los factores de movimiento, a saber: abrir/cerrar, elevar/hundir, avanzar/retroceder (ver Tabla 4.4). Nuestro cálculo de expansividad no considera estas distinciones y podría correlacionar con cualquiera de la tres alternativas. Si tenemos en cuenta los resultados del estudio 1 (Capítulo 5) se podría especular 
que en su mayoría se trata de expansividad con afinidad al factor de movimiento tiempo, es decir que espacialmente la trayectoria avanza y retrocede.

Tener más categorías descriptivas de la Coréutica ayudaría a precisar el modo en que se gestionan las trayectorias en el espacio desde la perspectiva topokinética. Diseñar una visualización con coordenadas del 'cómo' y el 'dónde' nos daría un acceso más inmediato sobre los modos en que se expresa la energía musical.

Ampliar esta metodología a los cuatro factores de movimiento Laban permitiría vincular las correlaciones con algún grupo de categorías de altonivel de la matriz de referencia conceptual (Tabla 4.5), a saber: i) significados de las acciones básicas (BEA) del modelo Laban, ii) descripciones conceptuales organizadas en pares lógicos (Maes et al, 2014), y iii) descripciones de las formas vitales (Stern, 2010; Martínez y Pereira Ghiena, 2015). 


\section{7}

\section{Estudio 2 - Parte 2 Interacción como comunicación de energía musical expresada}

\section{I Introducción}

Desde la perspectiva de segunda persona, el gesto es considerado como la expresión de un acto comunicativo (Gomila, 2010; Leman, 2016), en este contexto se podría considerar que no puede existir música sin movimiento porque no existe comunicación sin cuerpo ni movimiento. El gesto, desde esta perspectiva, no es un mediador de significados, sino un impulso que activa nuestra propia experiencia corporal (Shifres, 2007). Asumimos un modelo de comunicación impulsado por la expresión, elemento constructivo de la habilidad de comunicarse, y clave para establecer interacciones.

La dimensión expresiva en la música emerge en patrones con los cuales es posible alinearse expresivamente, es decir establecer un proceso de alineamiento enactivo (Leman, 2016) entre un patrón de movimiento corporal $\mathrm{y}$ un patrón musical. Este alineamiento es enactivo porque se entiende como un bucle de acoplamiento sensoriomotor de acción-percepción con el mundo (Maiese, 2011) en el cual el organismo produce su propio dominio de significados (Schiavio et al., 2017).

El entorno de una performance que involucra el intercambio director-músicos es un contexto ideal para abordar el estudio de la interacción en relación a la comunicación de la energía musical expresada (analizada en la parte 1 del 
estudio). La interacción en el contexto de la performance musical se ha abordado anteriormente con distintos objetivos: medir la interacción social (Volpe et al., 2016); buscar insights sobre expresividad y cohesión (Glowinski et al., 2013); ponderar la cognición social de afiliación y control en la improvisación (Aucouturier y Canonne, 2017); buscar indicios de la construcción participativa del sentido (Martínez et al., 2017); describir la sincronización y el liderazgo (Timmers et al., 2014); evaluar la autoorganización en la improvisación (Walton et al., 2015); y describir la interacción interpersonal entre músicos y director (D’Ausilio et al., 2011; Luck y Toiviainen, 2006).

Se propone utilizar en el presente estudio la estimación estadística Densidad Causal, que es la medida de la cantidad total de interactividad que sostiene un sistema, basada en la Causalidad Granger que actualmente se utiliza en numerosos trabajos de investigación en interacción musical (D'Ausilio et al., 2011, 2012; Badino et al., 2014; Chang et al., 2017; Pachet et al., 2017; Aucouturier y Cannone, 2017; Martínez et al., 2017).

La densidad causal se estimará sobre series temporales del movimiento de la cabeza. Hay antecedentes de estudios que han puesto el foco en el movimiento de la cabeza (Camurri et al., 2013; Gnecco et al., 2009; Livingstone y Palmer, 2016). En el contexto de la performance musical los movimientos de la cabeza expresan el modo en que los músicos entienden el fraseo y las respiraciones de la música que ejecutan (Glowinski et al., 2013). En estudios de performance instrumental se considera que las manos tienen una relevancia funcional en la producción de sonido; mientras que los movimientos de la cabeza juegan un rol más importante en la expresividad (Walton et al., 2015; Castellano et al., 2008; Juchniewicz, 2008).

\subsection{Hipótesis}

i) El movimiento corporal en una performance coral evidencia componentes de interacción en términos de transferencia de información no proposicional. 
Por lo tanto, a mayores niveles de interacción se observarán mayor cantidad de correlaciones con las categorías de la energía musical expresada (Parte 1 del estudio).

\subsection{Objetivos}

Vincular la energía musical expresada, según el abordaje propuesto en el estudio 2, con la actividad de intercambios intersubjetivos que se pueden inferir de una variable de movimiento.

Buscar evidencia que sustente el abordaje de la expresión musical desde la perspectiva de segunda persona.

\subsection{Métodos}

Los apartados participantes, estímulo, aparatos, procedimiento y diseño de esta segunda parte del estudio son los mismos que en la primera parte (6.4).

\subsection{Causalidad Granger y Densidad Causal}

La Causalidad Granger es un concepto estadístico que se basa en la predicción. Se dice que una serie temporal $x$ puede "Granger causar" a otra serie temporal, si los valores del pasado de $x$ proveen información estadísticamente significativa para predecir el siguiente valor de $y$ (Granger, 1969). Si la Causalidad Granger es positiva, implica que cierta información de $x$ se transfirió al comportamiento de $y$.

A partir de las estimaciones de la Causalidad Granger se obtiene la Densidad Causal, que es la medida de la cantidad total de interactividad que sostiene una red o sistema. Valores altos de Causalidad Granger indican que los elementos que conforman el sistema están globalmente coordinados en su actividad (Seth, 2010). El nodo de una red de interacciones, que presenta Densidad Causal alta, se lo considera centro de actividad del sistema (Barnett y Seth, 2014). 
Para obtener la Causalidad Granger entre dos series temporales (figura 1), se calcula el índice en que el segmento de la serie temporal 1 (predictor 1) contribuye a predecir el estado actual de la serie temporal 2 (punto rojo), en relación a cuanto lo predice su propio pasado (predictor 2). Este cálculo se repite para todas las observaciones de la serie temporal. El tamaño de la ventana de predicción se determina por la computación del orden del modelo (Seth, 2010) que mejor se ajuste al diseño de la serie temporal.

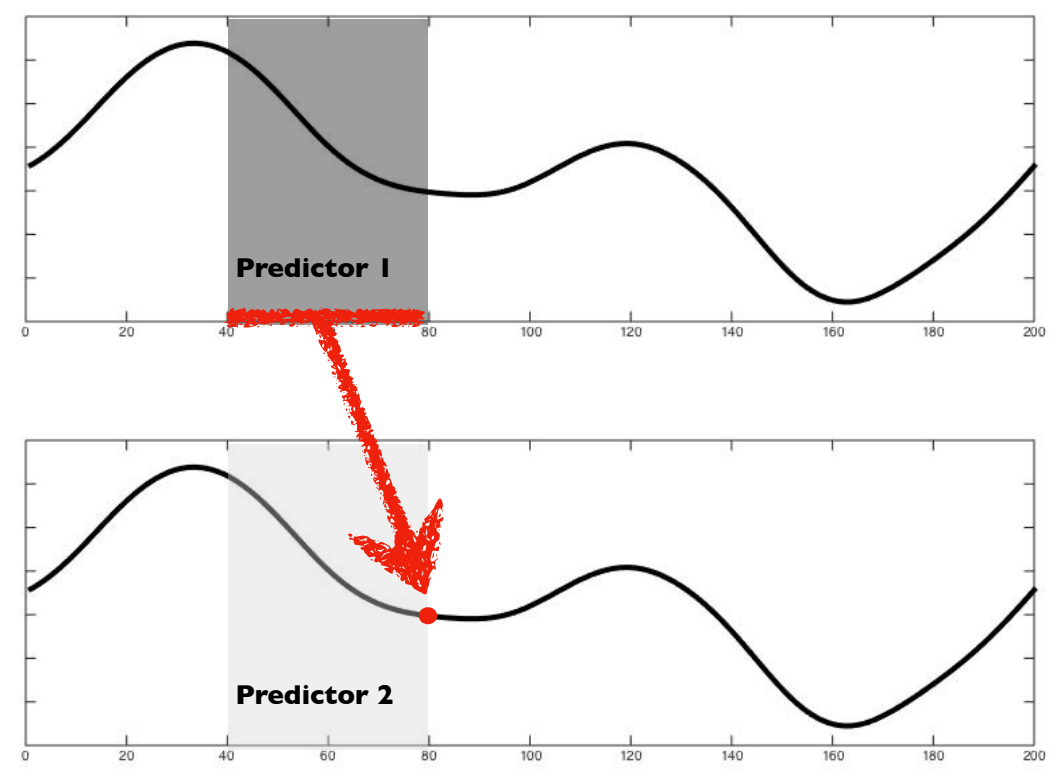

Figura 7.I: Esquema de cálculo de Causalidad Granger.

\subsubsection{Serie temporal}

El set de datos consistió en las series temporales de los cambios de posición en el espacio euclidiano de los marcadores de la cabeza del director y la de las cantantes, en relación a un centro de referencia espacial en medio de la tríada. La elección del movimiento de la cabeza como emergente de interacción en 
una performance musical tiene antecedentes con resultados positivos en estudios con cuartetos de cuerdas (D'Ausilio et al., 2012, Badino et al., 2014; Chang et al., 2017) y con dúos de saxos (Martínez et al., 2017).

El balanceo corporal es una medida global de las acciones individuales (Shockley et al., 2009); en estudios de performance instrumental, el estudio del balanceo corporal capturado desde el movimiento de la cabeza se ha utilizado como emergente de la comunicación interpersonal con metas estéticas y expresivas, como la coordinación de fraseos, dinámicas y timing (Chang et al., 2017; Badino et al., 2014) y como evidencia del sentido participativo (Martínez et al., 2017). Finalmente, también puede citarsela evidencia que surge del estudio 1, donde encontramos que la diferencia más significativa entre la condición intrasubjetiva y la intersubjetiva ocurre en el movimiento de la cabeza (Figura 5.2).

\subsubsection{Protocolo de pre-procesamiento}

Antes de realizar los cálculos de Causalidad Granger, se llevó adelante el protocolo de pre-procesamiento recomendado. Las variables se registraron en simultáneo de modo que $t=t_{n}$ en la serie temporal 1 se corresponde a $t=t_{n}$ en todas las otras series. El número de observaciones excede significativamente el número de variables. A las series temporales se les quitó la media (demean), yla tendencia (detrended), se normalizaron a z-scores, y se comprobó la covarianza estacionaria por cada unidad de análisis. Por último, se realizó una corrección de Bonferroni con un umbral de probabilidad de 0.05 para la significación estadística de las comparaciones.

\subsection{Resultados}

Todos los resultados se obtuvieron con la medida de la Densidad Causal de las series temporales del desplazamiento en el espacio euclidiano de las cabezas de los participantes en relación a un centro de referencia espacial. El estímulo 
fue segmentado en ocho unidades de análisis que se corresponden con las de la primera parte del estudio (ver capítulo 6, figura 6.2).

La red de interacciones de este estudio permite tres díadas: (i) Director $\Leftrightarrow$ Cantante 1, (ii) Director $\Leftrightarrow$ Cantante 2, y (iii) Cantante $1 \Leftrightarrow$ Cantante 2. Se encontraron niveles significativos de interacción en las tres díadas. Las de mayor interacción son (i) y (ii), ambas incluyen al director. La descripción está en acuerdo con el foco de intercambios que establece el rol de dirigir. También se infiere mayor interacción con el cantante 1 que con el 2; es decir que el flujo comunicacional con el cantante 1 fue más activo. Asimismo, nos permite afirmar que se establecieron algunas interacciones entre los cantantes, es decir, que hubo un acoplamiento entre los sujetos en rol de cantantes. Se podría afirmar en este caso que el modelo de comunicación activó todas las combinaciones de intercambio y se corresponde con el modelo triangular de sincronía interactiva (Ordás, 2012).

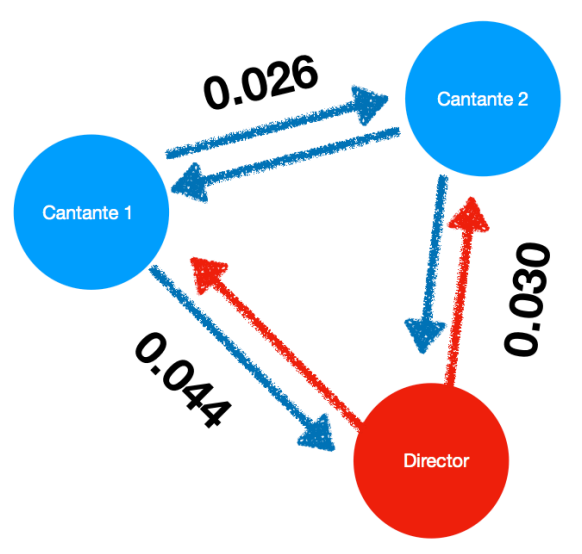

Figura 7.2: Densidad Causal global por díadas.

Las descripciones inferidas de los datos de la figura 7.2 nos aportan rasgos globales del modelo de intercambios intersubjetivos. Con el fin de analizar la distribución de estos intercambios en vinculación con la estructura formal y 
las unidades de análisis, se diseñó la figura 7.3.

La primer observación se focaliza en las unidades 1 y 8 que presentan la mayor interactividad. Es probable que esto se vincule a cuestiones que tienen que ver con iniciar y finalizar la tarea y la mayor demanda de coordinación que ello implica. El movimiento de la cabeza podría informar sobre la coordinación para entrada y salida a la tarea, sobre la transición entre las unidades formales (Demos, 2013), o sobre la enacción de patrones de energía musical expresada. La Densidad Causal no discrimina cuál o cuáles de ellas están conjugadas en cada momento. Esta visualización en una muestra más grande nos permitirá estimar momentos de mayor o menor cohesión a partir de la ponderación de la dispersión de los valores, de modo que se podría sugerir que la unidad 4 es la que presenta mayor cohesión entre las díadas, a pesar de ser la unidad con menor intercambio interactivo. Nuevamente la unidad 5, con mayor densidad causal que la anterior, corresponde al inicio del segundo periodo formal.

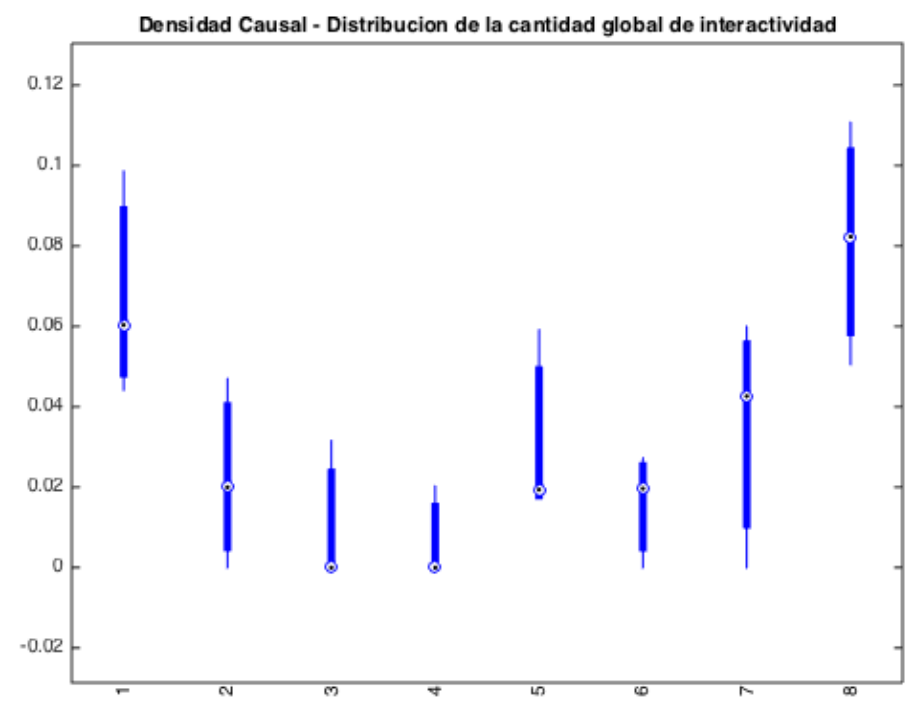

Figura 7.3: Distribución de la cantidad global de interactividad (densidad causal). 
Aunque no analizamos la distribución de la actividad díada por díada ya que excede el alcance del presente trabajo, la figura 7.4 aporta una posible visualización que sugiere que sería promisorio diseñar un futuro trabajo para estudiar la dinámica de interactividad y su distribución.

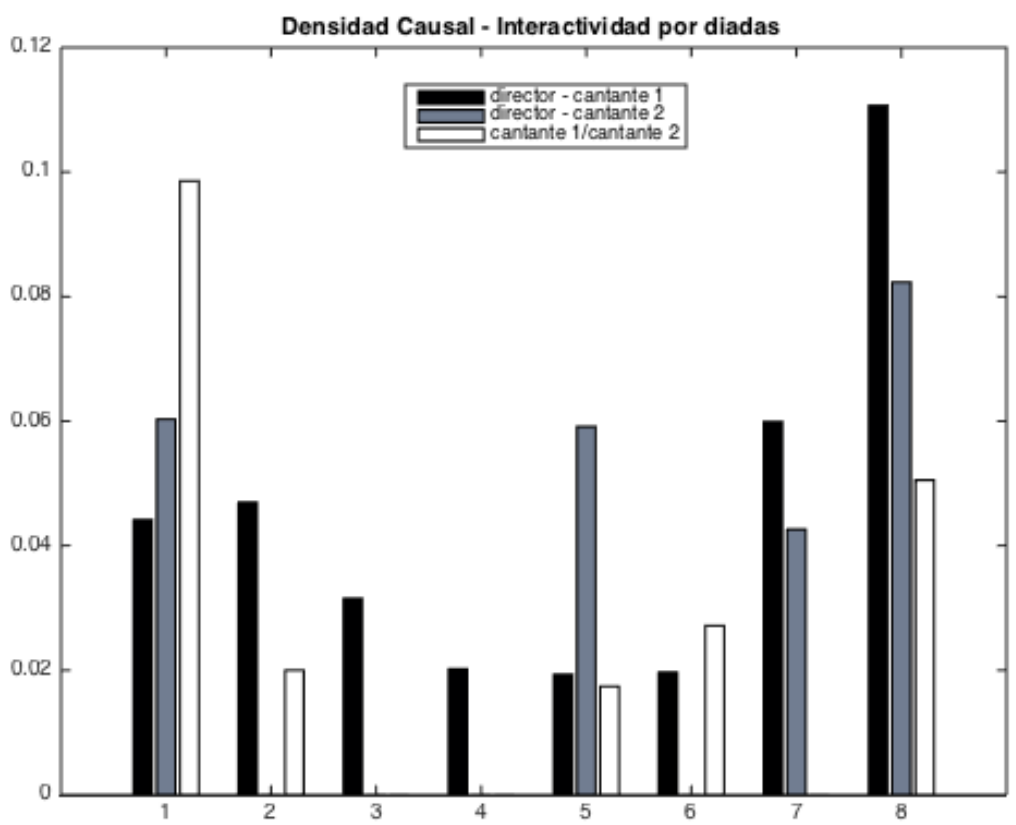

Figura 7.4: Densidad Causal - Distribución de la interactividad por díadas.

\subsection{Correlaciones Música / Interacción}

Al analizar los resultados de la figura 7.5 llama la atención la correlación entre la atracción tonal y la interactividad, si esto es así podemos deducir que la atracción tonal moviliza intercambios enactivos, que de algún modo darían cuenta de una interacción con la obra musical, ya que esta categoría no es expresiva; no se trata de una modulación de la energía expresada, sino que constituye un atributo inherente a la estructura tonal. 


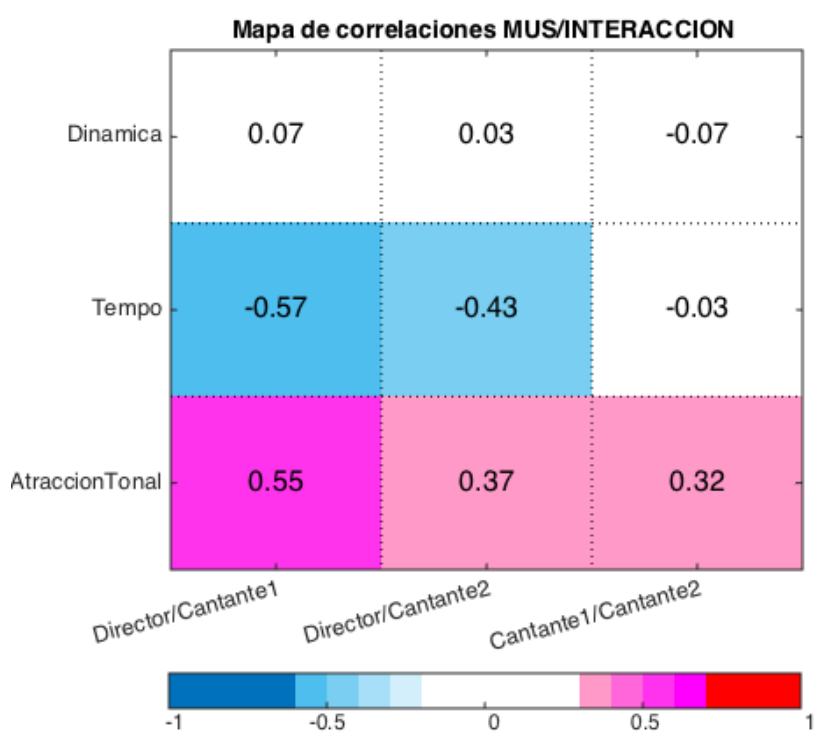

Figura 7.5: Mapa de Correlación entre categorías de Música y Densidad Causal por díada.

La segunda correlación importante es con el tempo; en este caso sucede en contra fase, es decir que a menor velocidad de tempo, mayor intercambio interactivo. Si observamos los perfiles de tempo en la figura $\underline{6.6}$ del capítulo 6 , las unidades de menor tempo son la 4 y la 8 , correspondientes a los finales de periodo. Esto se encuadraría en el grupo de interacción en relación a la estructura formal.

Notablemente no hay correlaciones con la dinámica, siendo esta una variable de la producción sonoro/expresiva conjunta de las cantantes, ni siquiera en los correlatos con la díada cantante-cantante resulta significativa.

\subsubsection{Correlaciones Movimiento / Interacción}

$\mathrm{Si}$ bien las series temporales de base de las categorías que estamos correlacionando (movimiento e interacción) son ambas de movimiento, las correlaciones corresponden a dos niveles de significación distintos. Las categorías Laban describen la energía expresada mientras que la densidad causal aporta una descripción de la interactividad, por lo tanto los correlatos que buscamos con este análisis son entre energía expresada e interactividad (Figura 7.6). 


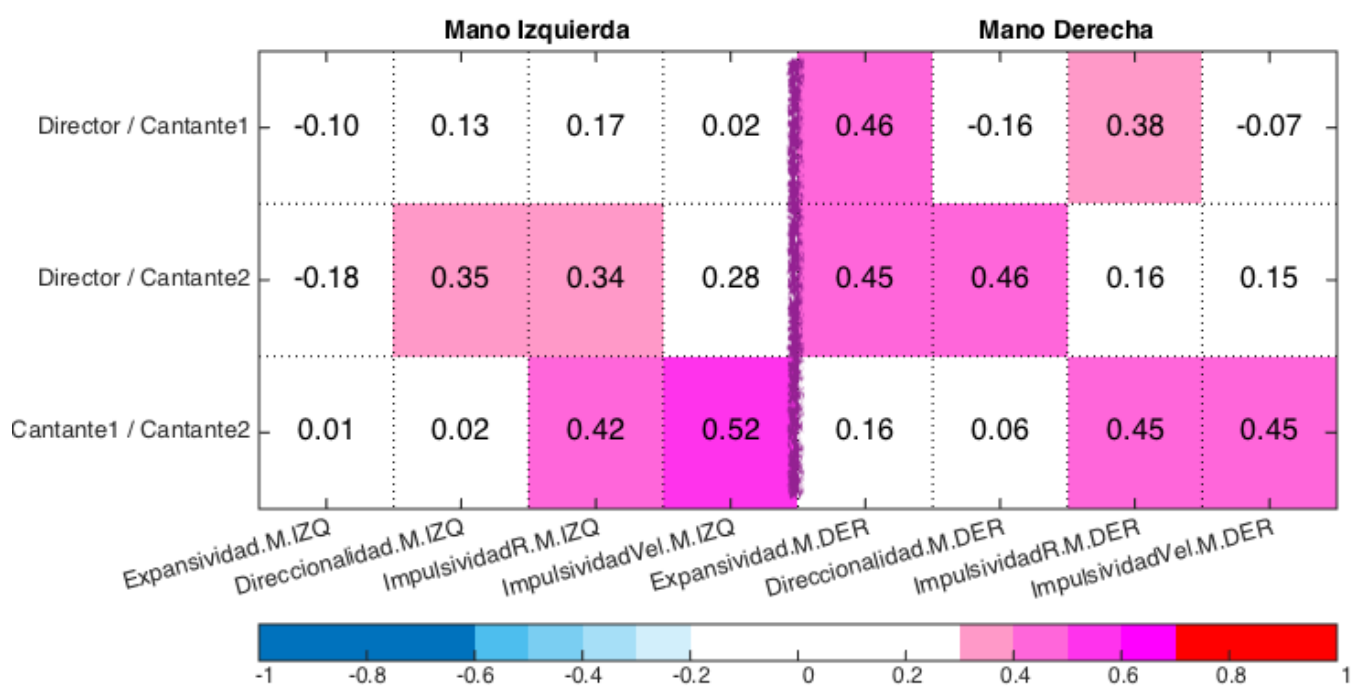

Figura 7.6: Mapa de Correlación entre categorías de Movimiento y Densidad Causal por díada.

Pero nuestra hipótesis apuntaba a triangular una correlación robusta entre el dominio de la música y el del movimiento como por ejemplo, la dinámica con momentos de alta interactividad. Dado que no se obtuvieron resultados de correlato, consideramos que ensayar un análisis de las correlaciones de la figura 7.6 no sería pertinente.

\subsection{Discusión}

Los rasgos globales del modelo de intercambios intersubjetivos inferidos a partir de la Causalidad Granger señalan niveles significativos de interacción en las tres díadas (Director $\Leftrightarrow$ Cantante 1; Director $\Leftrightarrow$ Cantante $2 \mathrm{y}$; Cantante $1 \Leftrightarrow$ Cantante 2). Los canales de mayor interacción son los que se vinculan al rol director, aunque también hay acoplamiento interactivo entre los sujetos en rol de cantantes. Estas descripción aporta nueva evidencia al modelo de interactividad en el coro propuesto por Ordás $(2012 ; 2016)$.

La distribución de estos intercambios en vinculación con la estructura formal y las unidades de análisis, presentó la mayor interactividad en las unidades de mayor transición formal. Este indicador a su vez permitiría estimar momentos 
de mayor o menor cohesión a partir de la ponderación de la dispersión de los valores. La correlación significativa en contrafase con la variable tempo se alinea con esta vinculación entre interacción y estructura formal.

La inclusión de una categoría de la estructura musical, como es el caso de atracción tonal, fue motivada para buscar pistas de interactividad con la obra musical en sí misma, es decir si la configuración constructiva, en término de energía tonal (en sintonía con la idea de las fuerzas musicales de Larson, impulsa los intercambios expresivos. La correlación significativa entre la categoría atracción tonal y los movimientos de la cabeza es una pista que podría confirmar esta perspectiva. 


\section{8}

\section{Conclusiones}

\section{I Resumen de los resultados}

Estudiar la modulación expresiva del movimiento de los gestos de dirección implica estudiar las variaciones sobre el movimiento de base que suponen los esquemas de marcación en el contexto del sistema dinámico directorcantantes, donde se alinean patrones de energía musical y de movimiento, impulsados por la expresión, que desde una perspectiva de segunda persona es elemental para comunicarse y establecer interacciones.

\section{I.I Estudio I}

Con el objetivo de focalizar las modulaciones expresivas, el estudio 1 indagó por un lado sobre la preferencia del uso del eje anteroposterior; y por otro, la relevancia de incorporar o integrar esta dimensión a los diseños experimentales, dado que en los estudios previos revisados se había despreciado esta dimensión adelante/atrás y nuestro sentido común informado en la práctica de la dirección la considera organizadora de estas modulaciones.

El estudio reporta que las diferencias entre las condiciones intra e intersubjetiva emergen en el eje anteroposterior. Este resultado alimenta el supuesto de que a mayor actividad cinética en este eje se corresponde con una 
mayor actividad o expresivo-comunicacional, o de interacciones de intercambio expresivo entre los participantes.

A su vez, la mano izquierda presenta más variaciones de este tipo en el eje anteroposterior. En contradicción con el postulado pedagógico que propone otorgarle a la mano izquierda el rol expresivo exclusivo a partir de la organización de sus movimientos en trayectorias sobre el eje vertical.

El balanceo corporal es una medida global de las acciones individuales. El balanceo observado a partir del movimiento de la cabeza se ha utilizado como emergente de la comunicación interpersonal con metas estéticas y expresivas. Los resultados son consistentes con esta afirmación: el indicador con mayor diferencia entre condiciones fue el movimiento de la cabeza en el eje anteroposterior (Figura 5.2).

En futuros estudios se podría corroborar a partir del análisis de principal componente, cuál es la significación estadística de esta hipótesis. Los resultados de este primer estudio sugieren una respuesta afirmativa.

\subsubsection{Estudio 2 -Parte I}

La búsqueda de correlaciones entre las categorías de análisis de movimiento Laban y las categorías expresivo-musicales desarrollada en el estudio 2 resultó positiva. La primera afirmación que surge es validar las categorías de movimiento para describir la energía expresada en patrones musicales. Dinámica es la categoría musical que obtuvo las correlaciones más robustas. Esto reafirma, desde un abordaje completamente distinto, las conclusiones de Eitan (2013) que señalan el parámetro intensidad como más ubicuo en vinculación al movimiento.

Asimismo, se observa que la condición intrasubjetiva, tiene mayor solidez en sus correlaciones en comparación con la condición intersubjetiva. Entendemos que cuantas más personas participan del sistema-coro, este se torna más complejo, proporcionalmente las correlaciones bajan. Un estudio que compare 
distintos sistemas coro, podría utilizar este indicador para evaluar su eficacia expresivo/comunicativa.

En consonancia con el estudio 1, la mano derecha tiene más actividad expresiva que que la izquierda. Los patrones de administración de la energía en las variables del movimiento de la mano derecha tienen mejores correspondencias con los patrones de energía de las unidades musicales.

\subsubsection{Estudio 2 -Parte 2}

Los rasgos globales del modelo de intercambios intersubjetivos inferidos a partir de la Causalidad Granger, señalan niveles significativos de interacción en las tres díadas (Director $\Leftrightarrow$ Cantante 1; Director $\Leftrightarrow$ Cantante $2 \mathrm{y}$; Cantante $1 \Leftrightarrow$ Cantante 2). Los canales de mayor interacción son los que se vinculan al rol director; pero a su vez hay acoplamiento interactivo entre los sujetos en rol de cantantes. Esta descripción aporta nueva evidencia al modelo de interactividad en el coro propuesto por Ordás (2012; 2016).

La distribución de estos intercambios en vinculación con la estructura formal y las unidades de análisis presentó la mayor interactividad en las unidades de mayor transición formal. Este indicador a su vez permitiría estimar momentos de mayor o menor cohesión a partir de la ponderación de la dispersión de los valores. La correlación significativa en contrafase con la variable tempo se alinea con esta vinculación entre interacción y estructura formal.

La inclusión de una categoría de la estructura musical, como es el caso de atracción tonal, fue incorporada para buscar pistas de interactividad con la obra musical en sí misma, es decir si la configuración constructiva, en término de energía tonal (en sintonía con la idea de las fuerzas musicales de Larson (2012), impulsa intercambios expresivos. La correlación significativa de la categoría atracción tonal con los movimientos de la cabeza es una pista que podría confirmar esta perspectiva. 


\subsection{Recomendaciones para la continuación de los estudios}

El principal eje de continuidad para estos estudios es la vinculación con significados y estructuras de alto-nivel, y verificar si este modelo permite inferencias en común entre las atribuciones de intención de las acciones básicas de la eukinética y las intenciones de expresión musical.

Si se incorporan los factores peso y flujo a los algoritmos de estimación de las categorías de análisis completando los cuatro factores de movimiento que configuran las acciones básicas, se podrían diseñar metodologías que conecten los correlatos música-movimiento con el diseño de la dínamosfera y la kinesfera, profundizando los análisis en vinculación con la inferencias que promueve el sistema Laban.

Replicar estos estudios con varios sistemas-coro, permitiría contar con una variedad de mapas de correlación y diseños de redes de interacción que aportarían descripciones más consistentes. A su vez hay que tener presente, los recortes que suponen en los mapas y redes, las variables sociales y culturales que representan los integrantes del sistema-coro y las obras musicales que se analicen.

Nuestro abordaje metodológico es fundamentalmente cuantitativo, por tal motivo se propone conjugarlo con investigaciones de corte cualitativo para enriquecer el alcance de las conclusiones.

\subsection{Respuesta a las preguntas germinales}

De las ontologías de gestos de dirección, descripta en el capitulo 1, emerge una disociación entre dos dimensiones: una temporal y otra expresiva. La primera es considerada de orden estructural y la segunda, en subordinación, le otorga contenidos a la primera. Esta descripción despierta paralelismos con la perspectiva de las metodologías tradicionales para el estudio de lo expresivo en música, considerado como el desvío de la norma canónica configurada por los rasgos temporales. 
Esta tesis propone una idea de gesto donde lo expresivo es inherente al mismo, y al ser un rasgo constitutivo de la comunicación, expresar es un tipo de acción mediante la cual se revela un estado mental, una intención. El movimiento como acción intencional posee rasgos energéticos que lo caracterizan. Las coincidencias entre los perfiles de energía de patrones movimiento y de patrones musicales cimientan las descripciones metafóricas interdominio y el uso de categorías puente para describir los correlatos.

Abordar la descripción de los gestos del director en términos de la expresión musical, implicó delimitar el marco de referencia conceptual en relación a qué categorías utilizar para describir la expresión musical corporeizada en los esquemas gestuales. Nos resultó adecuada la elección del medio-nivel conceptual, basado en la descripción del diseño de los patrones, como energía musical expresada. Es en este nivel conceptual donde se establece la posibilidad de hacer puentes categoriales entre música y movimiento, y el que abre la posibilidad de hablar de gestos musicales, porque ante la ausencia de categorías musicológicas para describir patrones de energía musical, utilizamos las categorías del movimiento para ello.

Las relaciones entre categorías del medio-nivel permite cierta generalización que el alto-nivel no tiene, dado que este último también conjuga en sus categorías descriptivas perspectivas culturales e individuales.

De todos modos, la red de correlaciones música-movimiento puede continuar con conexiones desde el medio-nivel hacia el alto-nivel, es decir desde la descripción de los patrones hacia la descripción de sus significados, para estudiar su vinculación con estados mentales, emociones, intenciones, o conceptos lingüísticos.

Si bien el medio-nivel facilita los puentes descriptivos entre los patrones de energía expresada en el movimiento y en la música, sus categorías no son las más inmediatas. En el transcurso de la investigación encontramos dos tendencias en nuestro pensamiento y en el de numerosos autores: la primera, 
corresponde a la tendencia de vincular los patrones musicales directamente con categorías de alto-nivel, es decir buscar vinculaciones directas con los significados, haciendo transparente el 'recorrido' que supone el mapa conceptual. La segunda, es la tendencia a ensayar explicaciones sobre los significados recurriendo a las descripciones de la señal física, las de bajonivel; en esto caso resultó transparente la conexión con el medio-nivel. Cuando logramos sintonizar nuestros ejercicios descriptivos con el medionivel, la tarea de correlacionar los patrones de energía musical ganó fluidez y coherencia.

El enfoque que supone la idea de energía musical expresada, nos permite describir atributos de los perfiles de flujo de la energía compartidos entre patrones de música y patrones de movimiento. Es energía acústica o cinética, expresada porque se configura con intención de comunicarla.

La preguntas en torno a la práctica expresiva de la dirección, en esta tesis no implican la creación de un diseño pedagógico ni metodológico sobre cómo enseñar a dirigir expresivamente. Sin embargo interpelan la ontología de coro y cómo se piensa la expresión musical en relación a los gestos de dirección. La performance coral tradicionalmente se considera como el resultado de un proceso unidireccional desde el director hacia la "masa" de cantantes; este modelo es aquí cuestionado por una ontología de coro intersubjetiva, multidireccional donde existe una construcción de sentido construido y compartido entre quienes participan de la práctica (Ordás, 2017; Ordás y Martínez, 2013).

La energía musical expresada emerge en patrones, lo cual posibilita establecer un proceso de alineamiento expresivo entre el flujo de los patrones de movimiento corporales y musicales. El alineamiento expresivo entre los roles que integran el sistema dinámico coro es la base de un modelo de comunicación enactivo. Comunicación que es impulsada por la expresión, clave para establecer interacciones y para construir sentidos compartidos. 


\subsection{Contribuciones y reflexión final}

Consideramos que esta tesis contribuye en: i) delinear un marco de referencia conceptual que permite correlacionar patrones expresivos de energía musical y energía cinética; ii) la adaptación y programación aplicada de algoritmos para computar las categorías de análisis Laban de la Eukinética en contextos de performance coral; y iii) brindar comprensión adicional sobre los modos en que se vincula la energía musical expresada en el interdominio sonoro-cinético desde la perspectiva interactiva y comunicacional dada en una performance coral.

Estas contribuciones son potencialmente aplicables a otros contextos de performance musical y danza de modalidad intersubjetiva que posibilitarían profundizar y avanzar en el conocimiento de las vinculaciones expresivas entre los dominios de la música y del movimiento. 


\section{9}

9. Referencias

Aucouturier, J.-J., y Canonne, C. (2017). Musical friends and foes: The social cognition of affiliation and control in improvised interactions. Cognition, 161(Supplement C), 94-108. https://doi.org/https://doi.org/10.1016/j.cognition. 2017.01.019

Badino, L., D’Ausilio, A., Glowinski, D., Camurri, A., y Fadiga, L. (2014). Sensorimotor communication in professional quartets. Neuropsychologia, 55(Supplement C), 98-104. https://doi.org/10.1016/j.neuropsychologia. 2013.11.012

Baily, J., y P. Howell, I. Cross, and R. West,. (1985). Music Structure and Human Movement. En Musical Structure and Cognition. (pp. 237-258). London: Academic Press.

Barba, E. (1994). The Paper Canoe: A Guide to Theatre Anthropology (Edición: 1). London; New York: Routledge.

Barnett, L., y Seth, A. K. (2014). The MVGC multivariate Granger causality toolbox: A new approach to Granger-causal inference. Journal of Neuroscience Methods, 223(Supplement C), 50-68. https://doi.org/10.1016/ j.jneumeth.2013.10.018 
Barresi, A. I. (1980). [Review of Review of The Development of a Theoretical Position on Conducting Using Principles of Body Movement as Explicated by Rudolf Laban, por N. K. Bartee]. Bulletin of the Council for Research in Music Education, (64), 83-85.

Bartee, N. K. (1977). The development of a theoretical position on conducting using principles of body movement as explicated by Rudolf Laban. (Doctoral). University of Illinois, Urbana, Champaign.

Berlioz, H. (1856). The Orchestral Conductor. Theory of His Art. The Musical Times and Singing Class Circular, 7(159), 227-230.

Bernstein, L. (1959). The Joy of Music Leonard Bernstein (Original 1959). Pompton Plains, NJ: Amadeus Press.

Bernstein, R., Shafir, T., Tsachor, R., Studd, K., y Schuster, A. (2015). Laban movement analysis using kinect. Int. J. Comput. Electr. Autom. Control Inform. Eng, 9, 1394-1398.

Billingham, L. A. (2009). The Complete Conductor's Guide to Laban Movement Theory. GIA Publications.

Burger, B., y Toiviainen, P. (2007). MoCap Toolbox - A Matlab toolbox for computational analysis of movement data (pp. 172-178). Presentado en 10th Sound and Music Computing Conference, (SMC), Royal Institute of Technology, Stockholm.

Burton, S. J., Samadani, A.-A., Gorbet, R., y Kulić, D. (2016). Laban Movement Analysis and Affective Movement Generation for Robots and Other Near-Living Creatures. En J.-P. Laumond y N. Abe (Eds.), Dance Notations and Robot Motion (pp. 25-48). Cham: Springer International Publishing. https://doi.org/10.1007/978-3-319-25739-6_2

Butler, D. (1996). [Review of Review of Shaping Time: Music, the Brain, and Performance, por D. Epstein]. Intégral, 10, 155-166. 
Cadoz, C., y Wanderley, M. M. (2000). Gesture - Music. En I.-C. P. Marcelo Wanderley et Marc Battier (Ed.), Trends in Gestural Control of Music. Recuperado a partir de https://hal.archives-ouvertes.fr/hal-01105543

Camurri, A., Dardard, F., Ghisio, S., Glowinski, D., Gnecco, G., y Sanguineti, M. (2014). Exploiting the Shapley Value in the Estimation of the Position of a Point of Interest for a Group of Individuals. Procedia - Social and Behavioral Sciences, 108(Supplement C), 249-259. https://doi.org/10.1016/j.sbspro. 2013.12.835

Camurri, A., De Poli, G., Leman, M., y Volpe, G. (2001). A Multi-layered Conceptual Framework for Expressive Gesture Applications.

Camurri, A., Lagerlöf, I., y Volpe, G. (2003). Recognizing emotion from dance movement: comparison of spectator recognition and automated techniques. International Journal of Human-Computer Studies, 59(1-2), 213-225. https:// doi.org/10.1016/S1071-5819(03)00050-8

Camurri, A., Varni, G., y Volpe, G. (2009). Towards Analysis of Expressive Gesture in Groups of Users: Computational Models of Expressive Social Interaction. En S. Kopp y I. Wachsmuth (Eds.), Gesture in Embodied Communication and Human-Computer Interaction (pp. 122-133). Springer Berlin Heidelberg. https://doi.org/10.1007/978-3-642-12553-9_11

Cannam, C., Landone, C., y Sandler, M. (2010). Sonic Visualiser: An Open Source Application for Viewing, Analysing, and Annotating Music Audio Files. En Proceedings of the 18th ACM International Conference on Multimedia (pp. 1467-1468). New York, NY, USA: ACM. https://doi.org/ $10.1145 / 1873951.1874248$

Castellano, G., Mortillaro, M., Camurri, A., Volpe, G., y Scherer, K. (2008). Automated Analysis of Body Movement in Emotionally Expressive Piano Performances. Music Perception: An Interdisciplinary Journal, 26(2), 103-119. https://doi.org/10.1525/mp.2008.26.2.103 
Chang, A., Livingstone, S. R., Bosnyak, D. J., y Trainor, L. J. (2017). Body sway reflects leadership in joint music performance. Proceedings of the National Academy of Sciences, 114(21), E4134-E4141. https://doi.org/ 10.1073/pnas. 1617657114

Chen, J.-F., Lin, W.-C., Tsai, K.-H., y Dai, S.-Y. (2011). Analysis and evaluation of human movement based on laban movement analysis. 淡江理工 學刊, 14(3), 255-264.

Clarke, E. (2005). Ways of Listening: An Ecological Approach to the Perception of Musical Meaning. Oxford University Press.

Colombetti, y Thompson. (2008). The feeling body: Towards an enactive approach to emotion, 45-68.

Cook, Nicholas, y Clayton, Martin. (2003). Music as Performance. En The cultural study of music : a critical introduction. New York: Routledge. Recuperado a partir de http://dro.dur.ac.uk/8771/

Damesón, J., y Martínez, I. C. (2015). Dirección en 3D: la dimensión oculta del significado. Presentado en XII Encuentro de Ciencias Cognitivas de la Música (Buenos Aires, 2015). Recuperado a partir de http://hdl.handle.net/ $10915 / 54685$

Darwin, C. (1872). On the Expression of the Emotions in Man and Animals. John Murray.

D’Ausilio, A., Badino, L., Li, Y., Tokay, S., Craighero, L., Canto, R., ... Fadiga, L. (2011). Communication in Orchestra Playing as Measured with Granger Causality. En Intelligent Technologies for Interactive Entertainment (pp. 273-275). Springer, Berlin, Heidelberg. https://doi.org/ 10.1007/978-3-642-30214-5_37 
D’Ausilio, A., Badino, L., Li, Y., Tokay, S., Craighero, L., Canto, R., ... Fadiga, L. (2012). Leadership in Orchestra Emerges from the Causal Relationships of Movement Kinematics. PLOS ONE, 7(5), e35757. https:// doi.org/10.1371/journal.pone.0035757

Davidson, J., y Malloch, S. (2008). Musical communication: the body movements of performance. En C. Trevarthen (Ed.), Communicative Musicality: Exploring the Basis of Human Companionship. Oxford University Press.

Davies, E. (2001). Beyond Dance: Laban's Legacy of Movement Analysis (1 edition). New York: Routledge.

Delalande, F. (1988). Le geste, outil d'analyse. Quelques enseignements d'une recherche sur la gestique de Glenn Gould. Analyse Musicale, 1, 43-46.

Delalande, F. (2013). Las conductas musicales. Ed. Universidad de Cantabria.

Demaree, R. W., y Moses, D. V. (1995). The complete conductor: A comprehensive resource for the professional conductor of the twenty-first century. Prentice Hall.

Demos, A. (2013, julio 10). The Perception of Movement through Musical Sound: Towards a Dynamical Systems Theory of Music Performance (Doctoral). University of Connecticut. Recuperado a partir de http:// digitalcommons.uconn.edu/dissertations/155

Di Paolo. (2015). Conectivismo en D. Pérez Chico y M. G. Bedia (eds.), Nueva ciencia cognitiva/ hacia una teoría integral de la mente, PUZ, 2015 - (Vol. Nueva ciencia cognitiva/ hacia una teoría integral de la mente). PUZ. Recuperado a partir de https://ezequieldipaolo.files.wordpress.com/2011/10/ enactivismo_e2.pdf 
Drake, R., Wayne, V., y Adam, M. (2015). Gray's Anatomy for Students: With Student Consult Online Access, 3e (Edición: 3). Philadelphia, PA: Churchill Livingstone.

Eitan, Z. (2013). How pitch and loudness shape musical space and motion. En S.-L. Tan, A. J. Cohen, S. D. Lipscomb, y R. A. Kendall (Eds.), The psychology of music in multimedia. OUP Oxford.

Epstein, D. (1995). Shaping time: Music, the brain, and performance. Wadsworth Publishing Company.

Español, S. (2007). La elaboración del movimiento entre el bebé y el adulto. Presentado en Sexta Reunión Anual de SACCoM., SACCoM (Sociedad Argentina para las Ciencias Cognitivas de la Música). Recuperado a partir de http://www.aacademica.org/silvia.espanol/9

Español, S. (2008). La entrada al mundo a través de las artes temporales. Estudios de Psicología, 29(1), 81-102.

Español, S. (2010). Performances en la infancia; cuando el habla parece música, danza y poesía. Epistemus, 1(1), 59-95.

Español, S., y Shifres, F. (2015). The Artistic nfant Directed Performance: A Mycroanalysis of the Adult's Movements and Sounds. Integrative Psychological and Behavioral Science, 49(3), 371-397. https://doi.org/ 10.1007/s12124-015-9308-4

Español, Silvia. (2014). La forma repetición-variación. Una estrategia para la reciprocidad. En Español, Silvia (Ed.), Psicologia De La Musica Y El Desarrollo (1er ed.). Buenos Aires: Paidos.

Farberman, H. (1999). The Art of Conducting Technique: A New Perspective. Alfred Music. 
Fdili Alaoui, S., Françoise, J., Schiphorst, T., Studd, K., y Bevilacqua, F. (2017). Seeing, Sensing and Recognizing Laban Movement Qualities. https:// doi.org/10.1145/3025453.3025530

Francoise, J. (2015). Motion-Sound mapping by demostrotion (Doctoral). UNIVERSITÉ PIERRE ET MARIE CURIE, Francia.

Gabrielsson, A. (1973). Adjective ratings and dimension analyses of auditory rhythm patterns. Scandinavian Journal of Psychology, 14(4), 244-260.

Gallagher, S. (2005). How the Body Shapes the Mind. Clarendon Press.

Gambetta, C. (2009). Laban Movement Analysis for Conductors: Revealing the Equivalence Between Movement and Music. Journal of Laban Movement Studies, Volume 1, Number 1. Recuperado a partir de https://

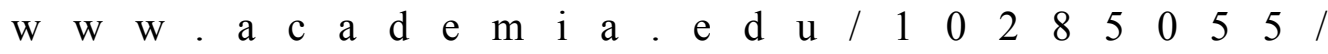
Laban_Movement_Analysis_for_Conductors_Revealing_the_Equivalence_Be tween_Movement_and_Music

Gambetta, C. L. (2005). Conducting outside the box: Creating a fresh approach to conducting gesture through the principles of Laban Movement Analysis (Doctoral). University of North Carolina at Greensboro. Recuperado a partir de http://www.uio.no/studier/emner/hf/imv/MUS2006/v14/litteratur/ Gambetta_2005.pdf

Garnett, L. (2009). Choral Conducting and the Construction of Meaning: Gesture, Voice, Identity. Ashgate Publishing, Ltd.

Gibbs, R. (1994). The Poetics of Mind: Figurative Thought, Language, and Understanding (First edition). Cambridge England ; New York, NY, USA: Cambridge University Press.

Gibbs, R. (2006). Embodiment and Cognitive Science (1 edition). Cambridge ; New York: Cambridge University Press. 
Gibbs, R. (2008). The Cambridge Handbook of Metaphor and Thought. (Gibbs, Raymond, Ed.). Cambridge University Press.

Gibson, J. J. (1979). The Ecological Approach to Visual Perception: Classic Edition. Psychology Press.

Giraud, T., Focone, F., Isableu, B., Martin, J.-C., y Demulier, V. (2016). Impact of elicited mood on movement expressivity during a fitness task. Human Movement Science, 49, 9-26. https://doi.org/10.1016/j.humov. 2016.05.009

Glowinski, D., Dael, N., Camurri, A., Volpe, G., Mortillaro, M., y Scherer, K. (2011). Toward a Minimal Representation of Affective Gestures. IEEE Transactions on Affective Computing, 2(2), 106-118. https://doi.org/10.1109/TAFFC.2011.7

Glowinski, D., Gnecco, G., Piana, S., y Camurri, A. (2013). Expressive Nonverbal Interaction in String Quartet. En 2013 Humaine Association Conference on Affective Computing and Intelligent Interaction (pp. 233-238). https:// doi.org/10.1109/ACII.2013.45

Gnecco, G., Glowinski, D., Camurri, A., y Sanguineti, M. (2009). On the Detection of the Level of Attention in an Orchestra Through Head Movements.

Gomila, Antoni. (2010). Música y emoción: El problema de la expresión y la perspectiva de segunda persona. En Significado, emoción y valor. Ensayos sobre filosofía de la música. Madrid: Antonio Machado Libros.

Granger, C. W. J. (1969). Investigating Causal Relations by Econometric Models and Cross-spectral Methods. Econometrica, 37(3), 424-438. https:// doi.org/10.2307/1912791

Green, E. A. H. (1961). On the Teaching of Conducting. Music Educators Journal, 47(6), 50-56. 
Green, E. A. H., Malko, 1883-1961. Conductor, Nicolai, y baton, his. (1997). The modern conductor : a college text on conducting based on the technical principles of Nicolai Malko as set forth in his The conductor and his baton (6th ed). Upper Saddle River, N.J. : Prentice Hall.

Green, M. S. (2007). Self-Expression. OUP Oxford.

Haas, P. M. (1992). Introduction: Epistemic Communities and International Policy Coordination. International Organization, 46(1), 1-35.

Hanna-Weir, S. A. (2013). Developing a Personal Pedagogy of Conducting (Doctoral). University o Maryland. Recuperado a partir de http:// drum.lib.umd.edu/handle/1903/14085

Hatten, R. (2006). A Theory of Musical Gesture and its Application to Beethoven and Schubert. En A. Gritten y E. King (Eds.), Music and Gesture (ASCI Art and Science, pp. 1-23).

Hatten, R. S. (2004). Interpreting Musical Gestures, Topics, and Tropes: Mozart, Beethoven, Schubert. Indiana University Press.

Henbing, L., y Leman, M. (2007). A Gesture-based Typology of Sliding-tones in Guqin Music. Journal of New Music Research, 36(2), 61-82. https://doi.org/ 10.1080/09298210701755073

Hurley, S. L. (1998). Consciousness in Action (1st edition). Cambridge, Mass.: Harvard University Press.

Jensenius, A., Wanderley, M., Godøy, R., y Leman, M. (2010). Musical Gestures: concepts and methods in research. https://doi.org/ $10.4324 / 9780203863411$

Johnson, M. (1987). The Body in the Mind: The Bodily Basis of Meaning, Imagination, and Reason. University of Chicago Press. 
Johnson, M. (2005). The philosophical significance of image schemas. En B. Hampe (Ed.), From Perception to MeaningImage Schemas in Cognitive Linguistics. Berlin, Boston: De Gruyter Mouton. https://doi.org/ 10.1515/9783110197532.1.15

Jordan, J. M. (1986). The effects of informal movement instruction derived from the theories of Rudolf Laban upon the rhythm performance and discrimination of high school students (Doctoral). Temple University, Philadelphia.

Jordan, J. M. (1996). Evoking sound: Fundamentals of choral conducting (2009.a ed.). Gia Publications.

Jordan, J. M., Wyers, G., y Andrews, M. (2011). The Conductor's Gesture: A Practical Application of Rudolf Von Laban's Movement Language.

Juchniewicz, J. (2008). The influence of physical movement on the perception of musical performance. Psychology of Music, 36(4), 417-427. https://doi.org/ 10.1177/0305735607086046

Juslin, P. N. (2009). Emotional Responses to Music. En S. Hallam y I. Cross (Eds.), Oxford Handbook of Music Psychology (1 ed.) (Oxford University Press.). Oxford. Recuperado a partir de http://www.oxfordhandbooks.com/ view/10.1093/oxfordhb/9780199298457.001.0001/oxfordhb-9780199298457e-012

Juslin, P. N. (2013). What does music express? Basic emotions and beyond. Frontiers in Psychology, 4. https://doi.org/10.3389/fpsyg.2013.00596

Kendon, A. (1980). Gesticulation and speech: Two aspects of the process of utterance. En M. R. Key (Ed.), The Relationship of Verbal and Nonverbal Communication (2nd printing 1981. Reprint 2011). Berlin, Boston: De Gruyter Mouton. https://doi.org/10.1515/9783110813098 
Kohn, D., y Eitan, Z. (2009). Musical Parameters and Children's Movement Responses. Recuperado a partir de https://jyx.jyu.fi/dspace/handle/ $123456789 / 20885$

Laban, R., y Lawrence, F. C. (1947). Effort (Edición: 2Rev e.). London: Macd.y E.

Laban, R. von. (1974). The language of movement;: A guidebook to choreutics,. Boston: Plays, inc.

Laban, R. von, y Ullmann, L. (1971). The mastery of movement. Boston: Plays.

Lakoff, G. (1987). Women, Fire and Dangerous Things: What Categories Reveal About the Mind (Edición: New edition). Chicago: University of Chicago Press.

Lakoff, G., y Johnson, M. (1980). Metaphors We Live By. University of Chicago Press.

Lakoff, G., y Johnson, M. (1999). Philosophy in the Flesh: The Embodied Mind and Its Challenge to Western Thought. Basic Books.

Lamb, W. (1965). Posture and gesture; an introduction to the study of physical behavior. London: Duckworth.

Lamb, W. (1978). Universal movement indicators of stress. American Journal of Dance Therapy, 2(1), 27-30. https://doi.org/10.1007/BF02579592

Larson, S. (2012). Musical Forces: Motion, Metaphor, and Meaning in Music. (F. by R. S. H. S. Larson, Ed.). Bloomington: Indiana University Press.

Lartillot, O., Toiviainen, P., y Eerola, T. (2008). A Matlab Toolbox for Music Information Retrieval. En Data Analysis, Machine Learning and Applications 
(pp. 261-268). Springer, Berlin, Heidelberg. https://doi.org/ 10.1007/978-3-540-78246-9_31

Leman, M. (2008). Embodied Music Cognition and Mediation Technology. MIT Press.

Leman, M. (2010). Music, gesture, and the formation of embodied meaning. En R. I. Godøy (Ed.), Musical Gestures: Sound, Movement, and Meaning (Edición: 1). New York: Routledge.

Leman, M. (2016). The Expressive Moment: How Interaction (with Music) Shapes Human Empowerment. MIT Press.

Lerdahl, F. (1996). Calculating Tonal Tension. Music Perception: An Interdisciplinary Journal, 13(3), 319-363. https://doi.org/10.2307/40286174

Lerdahl, F., y Jackendoff, R. S. (1983). A Generative Theory of Tonal Music (Revised edition). Cambridge, Mass.: The MIT Press.

Lesaffre, M. (2006). Music information retrieval: conceptuel framework, annotation and user behaviour (dissertation). Ghent University. Recuperado a partir de http://hdl.handle.net/1854/LU-3258568

Livingstone, S. R., y Palmer, C. (2016). Head movements encode emotions during speech and song. Emotion (Washington, D.C.), 16(3), 365-380. https:// doi.org/10.1037/emo0000106

López Cano, R. (2014). Música, mente y cuerpo De la semiótica de la representación a una semiótica de la performatividad. En M. Fornaro (Ed.), De cerca, de lejos... Miradas actuales en Musicología de/sobre América Latina (pp. 41-78). Montevideo: Universidad de la República: Comisión Sectorial de Educación Permanente / Escuela Universitaria de Música. Recuperado a partir de http://rlopezcano.blogspot.com.ar/2014/05/de-cerca-de-lejos-miradasactuales-en.html 
López Cano, R. L. (2013). El error de Descartes y las tres venganzas de René. Introducción al Dossier Cognición Musical Corporeizada. Epistemus. Revista de Estudios en Música, Cognición y Cultura, 2(1), 9-22. https://doi.org/ 10.21932/epistemus.2.2710.0

Luck, G., y Toiviainen, P. (2006). Ensemble Musicians' Synchronization With Conductors' Gestures: An Automated Feature-Extraction Analysis. Music Perception: An Interdisciplinary Journal, 24(2), 189-200. https://doi.org/ 10.1525/mp.2006.24.2.189

Luck, G., Toiviainen, P., y Thompson, M. R. (2010). Perception of Expression in Conductors' Gestures: A Continuous Response Study. Music Perception: An Interdisciplinary Journal, 28(1), 47-57. https://doi.org/10.1525/mp. 2010.28.1.47

Maes, P.-J., Van Dyck, E., Lesaffre, M., Leman, M., y Kroonenberg, P. (2014). The coupling of action and perception in musical meaning formation. MUSIC PERCEPTION, 32(1), 67-84. https://doi.org/http://dx.doi.org/10.1525/MP. 2014.32.1.67

Maiese, M. (2011). Embodiment, emotion, and cognition. Basingstoke, Hampshire: Palgrave Macmillan.

Maletic, V. (2005). Dance dynamics: effort y phrasing. Columbus, OH: Grade A Notes.

Malko, N. (1950). The conductor and his baton: fundamentals of the technic of conducting. Hansen.

Malloch, S., y Trevarthen, C. (Eds.). (2008). Communicative Musicality: Exploring the basis of human companionship. Oxford: OUP Oxford.

Marks, L. E. (Ed.). (1978). The Unity of the senses: Interrelations Among the Modalities. Academic Press. https://doi.org/10.1016/ B978-0-12-472960-5.50001-9 
Martínez, I. C., y Español, S. (2009). Image-schemas in parental performance. Recuperado a partir de https://jyx.jyu.fi/dspace/handle/123456789/20895

Martínez, I. C., y Pereira Ghiena, A. (2015). Formas de vitalidad y ejecución expresiva. Presentado en XII Encuentro de Ciencias Cognitivas de la Música (Buenos Aires, 2015). Recuperado a partir de http://hdl.handle.net/ $10915 / 54612$

Martinez, I., Dameson, J., Pereira Ghiena, A., y Herrera, R. (2015). Patrones de Movimiento y Forma Vital: Rasgos morfológicos, cinéticos y cinemáticos para su estudio. En Resúmenes de 12 o Encuentro de Ciencias Cognitivas de la Músi- ca : la experiencia musical: cuerpo, tiempo y sonido en el escenario de nuestra mente (pp. 109-111). San Juan: Sociedad Argentina para las Ciencias Cognitivas de la Música (SACCoM).

Martinez, Isabel. (2014). La Base corporeizada del significado musical. En Español, Silvia (Ed.), Psicologia De La Musica Y El Desarrollo (1er ed.). Buenos Aires: Paidos.

Martinez, Isabel, Dameson, Javier, Perez, Joaquin, Pereira Ghiena, Alejandro, Tanco, Matias, y Alimenti Bel, Demian. (2017). Participatory Sense Making in Jazz Performance: Agents' Expressive Alignment. En Proceedings of the 25th Anniversary Conference of the European Society for the Cognitive Sciences of Music. Ghent, Belgica: IPEM, Ghent University, Belgium.

Mathers, A. M. (2008). How theories of expressive movement and non-verbal communication can enhance expressive conducting at all levels of entering behaviour (thesis). Monash University. Faculty of Arts. School of Music Conservatorium. Recuperado a partir de http://arrow.monash.edu.au/vital/ access/manager/Repository/monash:32016

McElheran, B. (1964). Conducting Technique: For Beginners and Professionals. State University College, Crane Department of Music. 
McNeill, D. (1992). Hand and Mind: What Gestures Reveal About Thought (Edición: New ed.). Chicago: The University of Chicago Press.

McNeill, D. (2005). Gesture and Thought (Edición: 1). Chicago, Ill.: University of Chicago Press.

McNeill, D. (2012). How Language Began: Gesture and Speech in Human Evolution. Cambridge ; New York: Cambridge University Press.

McNeill, D., Duncan, S., y Quaeghebeur, L. (2009). IW - “The Man Who Lost His Body". En D. Schmicking y S. Gallagher (Eds.), Handbook of Phenomenology and Cognitive Science (Edición: 2010). Dordrecht: Springer.

Metois, E. (1996). Musical Sound Information Musical Gestures and Embedding Synthesis (Doctoral). Massachusetts Institute of Technology.

Meyer, L. B. (1989). Style and Music: Theory, History, and Ideology. University of Chicago Press.

Miranda, E. R., y Wanderley, M. (2006). New Digital Musical Instruments: Control And Interaction Beyond the Keyboard (1st edition). Middleton, Wis: A-R Editions, Inc.

Moore, C.-L. (2009). The harmonic structure of movement, music, and dance according to Rudolf Laban : an examination of his unpublished writings and drawings. Lewiston, N.Y. : Edwin Mellen Press. Recuperado a partir de https://trove.nla.gov.au/version/38719084

Moran, N. (2014). Social implications arise in embodied music cognition research which can counter musicological "individualism". Frontiers in Psychology, 5. https://doi.org/10.3389/fpsyg.2014.00676

Mudler, A. (1996). Hand Gestures for HCI. School of Kinesiology, Simon Fraser University,. Recuperado a partir de http://xspasm.com/x/sfu/vmi/HCIgestures.htm\#refs 
Nakra, T. M. (1999). Inside the Conductor's Jacket: Analysis, interpretation and musical synthesis of expressive gesture (Doctoral). Massachusetts Institute of Technology. Recuperado a partir de http://hd.media.mit.edu/tech-reports/ TR-518.pdf

Nattiez, J.-J. (1987). Music and Discourse. Toward a Semiology of Music. (Musicologie générale et sémiologie. Trans.: Carolyn Abbate). New Jersey: Princeton University Press.

Naveda, L. (2011). Gesture in Samba A cross-modal analysis of dance and music from the Afro-Brazilian culture (Doctoral). Ghent University Faculty of Arts and Philosophy Department of Musicology, Belgica. Recuperado a partir de http://www.ipem.ugent.be/samba/SambaProject/Thesis_files/ Naveda2011_GestureInSamba_PhDthesis.pdf

Naveda, L. (2015). SambaLib - A set Matlab tools for cross-modal analysis of music and movement. Recuperado 9 de diciembre de 2017, a partir de http:// luiznaveda.weebly.com/sambalib.html

Naveda, L., Martínez, I. C., Damesón, J., Pereira Ghiena, A., Herrera, R., y Ordás, M. A. (2016). Musical Meter, Rhythm and the Moving Body: Designing Methods for the Analysis of Unconstrained Body Movements. En R. Kronland-Martinet, M. Aramaki, y S. Ystad (Eds.), Music, Mind, and Embodiment (Vol. 9617, pp. 42-57). Cham: Springer International Publishing. Recuperado a partir de http://link.springer.com/10.1007/978-3-319-46282-0_3

Ness, S. A. (2008). Migrations of Gesture. Minneapolis: University of Minnesota Press.

Newlove, J., y Dalby, J. (2004). Laban for All. Nick Hern.

Ordás, M. A. (2012). Temporalidad intersubjetiva en la ejecución en coro: aportes para el desarrollo de un modelo prototípico de interacción de las claves comunicativas en la dirección coral. A contratiempo. Revista de Música 
en la Cultura, 20, serie 3. Recuperado a partir de http://hdl.handle.net/ $\underline{10915 / 40573}$

Ordás, A. (2017). La Comunicación Intersubjetiva en la Práctica del Coro. Claves multimodales e interacción entre los coreutas y el director (Doctoral). Universidad Nacional de La Plata, Facultad de Bellas Artes.

Otranto, C. M. P. C. (1993). A conductor's guide for Beethoven's Symphony no. 4: communicating music through expressive gestures (Doctoral). Arizona State University.

Pachet, F., Roy, P., y Foulon, R. (2017). Do Jazz Improvisers Really Interact? Routledge Handbooks Online. https://doi.org/10.4324/9781315621364.ch18

Palmer, C. (1997). Music performance. Annual Review of Psychology, 48, 115-138. https://doi.org/10.1146/annurev.psych.48.1.115

Palmer, C., Koopmans, E., Carter, C., Loehr, J., y Wanderley, M. (2009). Synchronization of motion and timing in clarinet performance.

Palmquist, J. (1998, winter). Dalcroze Instruction: It's Not Just for General Music Teachers. American String Teacher, 48(1).

Piana, S., Mancini, M., Camurri, A., Varni, G., y Volpe, G. (2013). Automated Analysis of Non-Verbal Expressive Gesture. https://doi.org/ 10.2991/978-94-6239-018-8_3

Piana, S., Stagliano, A., Camurri, A., y Odone, F. (2013). A set of full-body movement features for emotion recognition to help children affected by autism spectrum condition. En IDGEI International Workshop.

Poch, G. (1982). Conducting: Movement analogues through effort shape. Choral Journal, 23(3), 21. 
Ramstein, C. (1991, diciembre 18). Analyse, représentation et traitement $d u$ geste instrumental : application aux instruments à clavier (phdthesis). Institut National Polytechnique de Grenoble - INPG. Recuperado a partir de https:// tel.archives-ouvertes.fr/tel-00340367/document

Robinson, Jenefer. (2005). Deeper than Reason: Emotion and its Role in Literature, Music, and Art. Oxford, New York: Oxford University Press.

Samadani, A.-A., Burton, S., Gorbet, R., y Kulic, D. (2013). Laban effort and shape analysis of affective hand and arm movements. En Affective Computing and Intelligent Interaction (ACII), 2013 Humaine Association Conference on (pp. 343-348). IEEE.

Sandene, B. (1994). Awakening Students to the Art of Conducting. Music Educators Journal, 81(3), 38-40. https://doi.org/10.2307/3398763

Schiavio, A., Schyff, D. van der, Cespedes-Guevara, J., y Reybrouck, M. (2017). Enacting musical emotions. sense-making, dynamic systems, and the embodied mind. Phenomenology and the Cognitive Sciences, 16(5), 785-809. https://doi.org/10.1007/s11097-016-9477-8

Schuller, G. (1986). Musings: The Musical Worlds of Gunther Schuller. Oxford University Press.

Seth, A. K. (2010). A MATLAB toolbox for Granger causal connectivity analysis. Journal of Neuroscience Methods, 186(2), 262-273. https://doi.org/ 10.1016/j.jneumeth.2009.11.020

Shifres, F. (2007). Poniéndole el cuerpo a la música. Presentado en III Jornadas de Investigación en Disciplinas Artísticas y Proyectuales (La Plata, 2007). Recuperado a partir de http://hdl.handle.net/10915/39368

Shifres, F. (2009). Movement and the Practice of Meaning in Song. Recuperado a partir de https://jyx.jyu.fi/dspace/bitstream/handle/ 123456789/20920/urn_nbn_fi_jyu-2009411321.pdf?sequence=1 
Shifres, F. (2014). Algo más sobre el enlace entre la infancia temprana y música: El poder expresivo del rubato. En Español, Silvia (Ed.), Psicologia De La Musica Y El Desarrollo (1er ed.). Buenos Aires: Paidos.

Shockley, K., Richardson, D. C., y Dale, R. (2009). Conversation and Coordinative Structures. Topics in Cognitive Science, 1(2), 305-319. https:// doi.org/10.1111/j.1756-8765.2009.01021.x

Shove, P., y Repp, B. H. (1995). Musical motion and performance: theoretical and empirical perspectives. En J. Rink (Ed.), The Practice of Performance: Studies in Musical Interpretation (pp. 55-83). Cambridge: Cambridge University Press. https://doi.org/10.1017/CBO9780511552366.004

Sievers, B., Polansky, L., Casey, M., y Wheatley, T. (2013). Music and movement share a dynamic structure that supports universal expressions of emotion. Proceedings of the National Academy of Sciences of the United States of America, 110(1), 70-75. https://doi.org/10.1073/pnas.1209023110

Sklar, D. (1991). On Dance Ethnography. Dance Research Journal, 23(1), 6-10. https://doi.org/10.2307/1478692

Stern, D. N. (2010). Forms of Vitality: Exploring Dynamic Experience in Psychology and the Arts (1 edition). Oxford ; New York: Oxford University Press.

Stewart, J., Stewart, J. R., Gapenne, O., y Paolo, E. A. D. (2010). Enaction: Toward a New Paradigm for Cognitive Science. MIT Press.

Thompson, E. (2007). Mind in Life: Biology, Phenomenology, and the Sciences of Mind. Harvard University Press.

Thompson, M. R., y Luck, G. (2012). Exploring relationships between pianists' body movements, their expressive intentions, and structural elements of the music. Musicae Scientiae, 16(1), 19-40. https://doi.org/ $10.1177 / 1029864911423457$ 
Timmers, R., Endo, S., Bradbury, A., y Wing, A. M. (2014). Synchronization and leadership in string quartet performance: a case study of auditory and visual cues. Frontiers in Psychology, 5. https://doi.org/10.3389/fpsyg. 2014.00645

Todd, N. P. (1992). The dynamics of dynamics: A model of musical expression. The Journal of the Acoustical Society of America, 91(6), 3540-3550. https://doi.org/10.1121/1.402843

Todd, N. P. M. (1995). The kinematics of musical expression. The Journal of the Acoustical Society of America, 97(3), 1940-1949. https://doi.org/ $10.1121 / 1.412067$

Todd, N. P. M. (1999). Motion in Music: A Neurobiological Perspective. Music Perception: An Interdisciplinary Journal, 17(1), 115-126. https:// doi.org/10.2307/40285814

Toiviainen, P., y Eerola, T. (2016). MIDI toolbox: MATLAB tools for music research. University of Jyväskylä: Kopijyvä, Jyväskylä, Finland. Recuperado a partir de https://github.com/miditoolbox/1.1

Truong, A., Boujut, H., y Zaharia, T. (2016). Laban descriptors for gesture recognition and emotional analysis. The Visual Computer, 32(1), 83-98. https://doi.org/10.1007/s00371-014-1057-8

Truong, A., y Zaharia, T. (2017). Laban movement analysis and hidden Markov models for dynamic 3D gesture recognition. EURASIP Journal on Image and Video Processing, 2017, 52. https://doi.org/10.1186/ s13640-017-0202-5

Van Dyck, E., Maes, P.-J., Hargreaves, J., Lesaffre, M., y Leman, M. (2013). Expressing Induced Emotions Through Free Dance Movement. Journal of Nonverbal Behavior, 37(3), 175-190. https://doi.org/10.1007/ s10919-013-0153-1 
Van Dyck, E., Vansteenkiste, P., Lenoir, M., Lesaffre, M., y Leman, M. (2014). Recognizing Induced Emotions of Happiness and Sadness from Dance Movement. PLOS ONE, 9(2), e89773. https://doi.org/10.1371/journal.pone. 0089773

Varela, F. J., Rosch, E., y Thompson, E. (1992). The Embodied Mind: Cognitive Science and Human Experience. MIT Press.

Volpe, G. (2003). Computational models of expressive gesture in multimedia systems (Doctoral). UNIVERSITY OF GENOVA Faculty of Engineering, Italia.

Volpe, G., D’Ausilio, A., Badino, L., Camurri, A., y Fadiga, L. (2016). Measuring social interaction in music ensembles. Phil. Trans. R. Soc. B, 371(1693), 20150377. https://doi.org/10.1098/rstb.2015.0377

Wagner, R. (1897). On Conducting:(Ueber Das Dirigiren): A Treatise on Style in the Execution of Classical Music. W. Reeves. Recuperado a partir de https:// archive.org/details/onconductinguebe00wagn

Walton, A. E., Richardson, M. J., Langland-Hassan, P., y Chemero, A. (2015). Improvisation and the self-organization of multiple musical bodies. Frontiers in Psychology, 6. https://doi.org/10.3389/fpsyg.2015.00313

Wanderley, M. M. (2001). Quantitative Analysis of Non-obvious Performer Gestures. En Gesture and Sign Language in Human-Computer Interaction (pp. 241-253). Springer, Berlin, Heidelberg. https://doi.org/ 10.1007/3-540-47873-6_26

Watson, C. N. (2012). Gesture as Communication: The Art of Carlos Kleiber. University of Sydney, Australia. Recuperado a partir de https:// ses.library.usyd.edu.au/bitstream/2123/8797/1/CN-Watson-2012-PhD.pdf 
Watt, R. J., y Ash, R. L. (1998). A Psychological Investigation of Meaning in Music. Musicae Scientiae, 2(1), 33-53. https://doi.org/ 10.1177/102986499800200103

Wis, R. M. (1993). Gesture and body movement as physical metaphor to facilitate learning and to enhance musical experience in the choral rehearsal. Northwestern University, Ann Arbor, Mich.

Yeston, M. (1976). The stratification of musical rhythm. New Haven,: Yale University Press,. 